\title{
STREAM2 for Aqueous Release Emergency Response
}

by

K. F. Chen

Westinghouse Savannah River Company

Savannah River Site

Aiken, South Carolina 29808

This paper was prepared in connection with work done under the above contract number with the U.S. Department of Energy. By acceptance of this paper, the publisher and/or recipient acknowledges the U. S. Government's right to retain a nonexclusive, royalty-free license in and to any copyright covering this paper, along with the right to reproduce and to authorize others to reproduce all or part of the copyrighted paper. 


\title{
STREAM2 for SRS Aqueous Release Emergency Response (U)
}

\author{
Kuo-Fu Chen \\ Savannah River Technology Center
}

Publication Date: June 1998

DOES NOT CONTAIN

UNCLASSIFIED CONTROLLED

NUCLEAR INFORMATION

ADC \&

Reviewing Official:

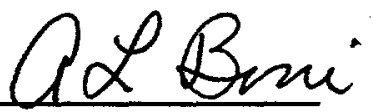

Date:

$7-21-98$

\section{Westinghouse Savannah River Company Savannah River Site \\ Aiken, SC 29808}

This document was prepared in connection with work done under Contract No. DE-AC09-96SR18500 with the U. S. Department of Energy 


\section{DISCLAIMER}

This report was prepared as an account of work sponsored by an agency of the United States Government. Neither the United States Government nor any agency thereof, nor any of their employees, makes any warranty, express or implied, or assumes any legal liability or responsibility for the accuracy, completeness, or usefulness of any information, apparatus, product, or process disclosed, or represents that its use would not infringe privately owned rights. Reference herein to any specific commercial product, process, or service by trade name, trademark, manufacturer, or otherwise does not necessarily constitute or imply its endorsement, recommendation, or favoring by the United States Government or any agency thereof. The views and opinions of authors expressed herein do not necessarily state or reflect those of the United States Government or any agency thereof.

This report has been reproduced directly from the best available copy.

Available to DOE and DOE contractors from the Office of Scientific and Technical Information, P.O. Box 62, Oak Ridge, TN 37831; prices available from (615) 576-8401.

Available to the public from the National Technical Information Service, U.S. Department of Commerce; 5285 Port Royal Road, Springfield, VA 22161. 


\section{DISCLAIMER}

Portions of this document may be illegible in electronic image products. Images are produced from the best available original document. 
WSRC-TR-98-00234

June 1998

DOCUMENT:

TITLE:

TASK:
WSRC-TR-98-00234

STREAM2 for SRS Aqueous Release Emergency Response (U)

TECHNICAL REVIEW

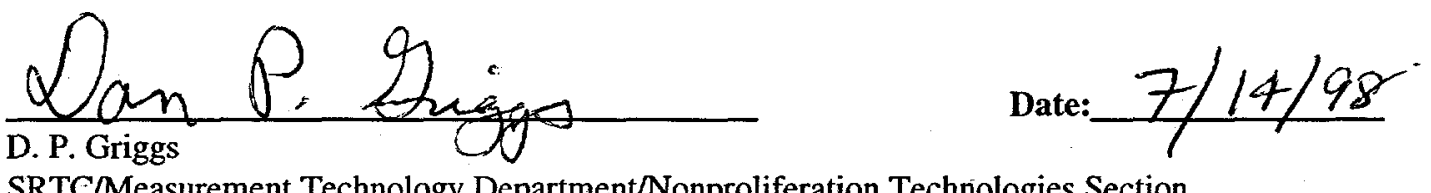

SRTC/Measurement Technology Department/Nonproliferation Technologies Section

APPROVALS

Robert Adds

Date: $7 / 20 / 98$

R. P. Addis, Manager, ATG

SRTC/Measurement Technology Department/Nonproliferation Technologies Section

Apron

Date: $7-21-98$

A. L. Beni, Manager, NTS

SRTC/Measurement Technology Department/Nonproliferation Technologies Section

iii 
WSRC-TR-98-00234

Jume 1998

(Blank Page) 


\section{ABSTRACT}

This report documents the STREAM2 code and its input models developed for the WIND System. STREAM2 is a modification of the STREAM code, which is the transport and diffusion module of the WIND System aqueous emergency response program. STREAM predicts downstream pollutant concentrations for releases from the Savannah River Site to the Savannah River. The STREAM calculation module uses an algebraic equation to approximate the solution of the differential one-dimensional advective transport equation. The advantage of this simplified approach is that the time required to obtain a solution is shortened to a matter of minutes. However, this approach generates spurious oscillations in the concentration profile when modeling long duration releases. To improve the capability of the STREAM code to model long-term releases, its calculation module was replaced by the transport module of the WASP5 code. WASP5 is a US EPA water quality analysis program that simulates pollutant transport and fate through surface water. The revised STREAM code is named STREAM2. 


\section{TABLE OF CONTENTS}

1. Introduction

2. STREAM2 Code Structure

2.1 Pre-processor Module

2.2 Calculation Module

2.2.1 The Pollutant Transport Equation

2.2.2 Finite Difference Approximation

2.3 Post-Processor Module

3. Input Files for Surface Stream Characterization

3.1 Savannah River

3.2 Upper Three Runs Creek

3.3 Beaver Dam Creek

3.4 Fourmile Branch

3.5 Pen Branch

3.6 Steel Creek

3.7 Lower Three Runs Creek

3.8 Input Flows

4. Output Files

5. References 


\section{LIST OF TABLES}

Table 1 Potential Release Locations

Table 2 File Name Convention 


\section{LIST OF FIGURES}

Figure 1. STREAM2 Flow Chart 14

Figure 2. Finite Difference Scheme 15

Figure 3. WASP5V Flow Chart 16

Figure 4. SRS Onsite Streams, Facilities, and USGS Gauge Stations $\quad 17$

Figure 5. Upper Three Runs Creek 18

Figure 6. Model Schematics for Upper Three Runs Creek (not to scale) 19

Figure 7. Beaver Dam Creek 20

Figure 8. Model Schematics for Beaver Dam Creek (not to scale) 21

Figure 9. Fourmile Branch 22

Figure 10. Model Schematics for Fourmile Branch (not to scale) - 23

Figure 11. Pen Branch 24

Figure 12. Model Schematics for Pen Branch (not to scale) 25

Figüre 13. Model Schematics for Steel Creek (not to scale) 26

Figure 14. Model Schematics for Lower Three Runs Creek (not to scale) 27 


\section{Introduction}

The STREAM2 code is the aqueous transport and diffusion module of the WIND System emergency response program. STREAM2 predicts downstream pollutant concentrations for releases from the SRS area to the Savannah River. The code consists of pre-processor, calculation, and post-processor modules. The pre-processor module provides a user interface. To run STREAM2, the user inputs through the pre-processor the time and date of release, the type of release, the location of release, the amount and duration of release, and the calculation units. The pre-processor passes the user-specified data to the calculation module, which calculates the pollutant concentrations and transport times at downstream locations. The calculated downstream pollutant concentrations and travel times are passed to the post-processor, which displays the calculated results (pollutant concentrations and travel times) on the computer screen in graphical and tabular forms.

STREAM2 is a replacement for the STREAM code [1], which for many years was the aqueous emergency response module in WIND system. The STREAM calculation module uses an algebraic equation to approximate the solution of the one-dimensional advective transport equation. The advantage of this simplified approach is that the time required to obtain a solution is shortened to a matter of minutes. However, this approach generates spurious oscillations in the concentration profile when modeling long duration releases.

To improve the capability of the STREAM code to model long-term releases, its calculation module was replaced by the transport module of the WASP5 code [2]. WASP5 is a US EPA water quality analysis program that simulates pollutant transport and fate through surface water. The revised STREAM code is named STREAM2.

STREAM2 calculations for aqueous releases to surface waters require two types of input. One is the user-specified input to STREAM2, described previously. The other consists of input files that describe the geometry and flow conditions of the stream and river systems.

This report documents the STREAM2 code. It contains descriptions of the code structure, user input requirements, the advective transport model, geometric input for Savannah River Site streams and rivers, and the code output.

\section{STREAM2 Code Structure}

The STREAM2 code consists of pre-processor, calculation, and post-processor modules, as shown in Figure 1. The pre-processor module provides user interface. The user inputs through the pre-processor the time and date of release, type of release, location of release, amount and duration of release, and the calculation units. The pre-processor passes the user-specified data to the calculation module that calculates the pollutant concentrations and transport times at downstream locations. The calculated downstream pollutant concentrations and travel times are 
passed to the post-processor, which displays the calculated results (pollutant concentrations and travel times) on the computer screen in graphical and tabular forms.

Additional input files that describe the geometry of the pollutant pathway from the release point to the coastal area and the stream/river flow conditions are required for STREAM2 simulation. Those additional input files are presented in Section 3.

\subsection{Pre-processor Module}

There are eight parameters that the user must input interactively. The eight input parameters are the time and date of release, the output units (in English or Metric units), the unit of released material (gallon, pound or curie), the location of the release, the amount released, and the duration of the release. Based on the release location, the subroutine Talk_virtual finds the input file names corresponding to the release location and passes these file names to the calculation module. The subroutine TRACE calculates release rates as a function of time based on user input values for the amount released and the release duration and passes a time series of release rates to the calculation module. If the release duration is equal to or less than three time steps, TRACE assumes the release is instantaneous. The time step is limited by numerical stability and varies from 5 to 10 minutes depending on the segment size. A discussion of the validity of this assumption follows.

For equal discharge amounts, the calculated downstream concentration increases as the discharge duration decreases. However, when the discharge duration becomes short relative to the transport time from the release point to downstream locations, the effect of discharge duration on downstream peak concentration is reduced by the dispersion process. Therefore, the discharge can be approximated as an instantaneous release when the release duration is short.

\subsection{Calculation Module}

The transport model of the WASP5 code is used by STREAM2 to perform pollutant transport calculations. WASP5 is a US EPA water quality analysis program that simulates pollutant transport and fate through surface water. The detailed descriptions of the WASP5 mathematical model, numerical approximation, program implementation and input manual are presented in Reference 2. A description of the transport model used by STREAM2 follows.

\subsubsection{Pollutant Transport Equation}

The pollutant transport equation is based on conservation of mass. In this equation, the rate change of the pollutant mass in a control volume equals the advective and dispersion transport; pollutant direct and diffusive loading; and rates of physical, chemical, and biological transformation. The advective transport equation is expressed as: 


$$
\begin{aligned}
\frac{\partial C}{\partial t}=- & \frac{\partial\left(U_{x} C\right)}{\partial x}-\frac{\partial\left(U_{y} C\right)}{\partial y}-\frac{\partial\left(U_{z} C\right)}{\partial z} \\
& +\frac{\partial}{\partial x}\left(E_{x} \frac{\partial C}{\partial x}\right)+\frac{\partial}{\partial y}\left(E_{y} \frac{\partial C}{\partial y}\right)+\frac{\partial}{\partial z}\left(E_{z} \frac{\partial C}{\partial z}\right) \\
& +S_{L}+S_{B}+S_{k}
\end{aligned}
$$

where:

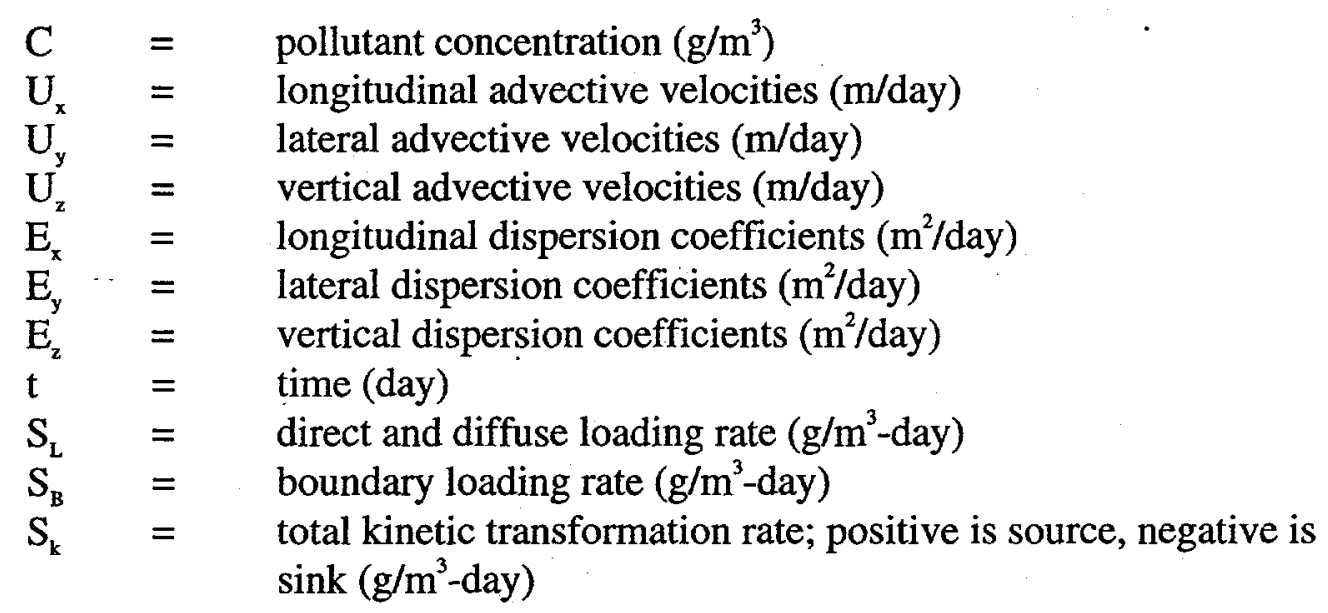

\subsubsection{Finite Difference Approximation}

For brevity and clarity, the derivation of the finite difference form of the transport equation will be for a one-dimensional reach. Assuming vertical and lateral homogeneity, Equation 1 can be integrated over the $y$ and $z$ directions to obtain

$$
\frac{\partial}{\partial t}(A C)=-\frac{\partial}{\partial x}\left(U_{x} A C\right)+\frac{\partial}{\partial x}\left(E_{x} A \frac{\partial C}{\partial x}\right)+A\left(S_{L}+S_{B}\right)+A S_{k}
$$

where:

A $=$ cross-sectional area $\left(\mathrm{m}^{2}\right)$

Using a Taylor series expansion, the concentration at $x_{0} \pm \Delta x$ can be expressed respectively as:

$$
\mathrm{C}\left(\mathrm{x}_{\mathrm{o}}+\Delta \mathrm{x}\right)=\mathrm{C}\left(\mathrm{x}_{\mathrm{o}}\right)+\left.\frac{\partial \mathrm{C}}{\partial \mathrm{x}}\right|_{\mathrm{x}_{0}} \Delta \mathrm{x}+\left.\frac{1}{2 !} \frac{\partial^{2} \mathrm{C}}{\partial \mathrm{x}^{2}}\right|_{\mathrm{x}_{0}} \Delta \mathrm{x}^{2}+\left.\frac{1}{3 !} \frac{\partial^{3} \mathrm{C}}{\partial \mathrm{x}^{3}}\right|_{\mathrm{x}_{\mathrm{o}}} \Delta \mathrm{x}^{3}+\cdots
$$

and 
$C\left(x_{0}-\Delta x\right)=C\left(x_{0}\right)-\left.\frac{\partial C}{\partial x}\right|_{x_{0}} \Delta x+\left.\frac{1}{2 !} \frac{\partial^{2} C}{\partial x^{2}}\right|_{x_{0}} \Delta x^{2}-\left.\frac{1}{3 !} \frac{\partial^{3} C}{\partial x^{3}}\right|_{x_{0}} \Delta x^{3}+\cdots$

By subtracting Equation 4 from Equation 3 and neglecting the higher order of $\Delta x$, the central difference approximation of the concentration derivative is obtained as:

$$
\left.\frac{\partial \mathrm{C}}{\partial \mathrm{x}}\right|_{\mathrm{x}_{\mathrm{o}}}=\frac{\mathrm{C}\left(\mathrm{x}_{\mathrm{o}}+\Delta \mathrm{x}\right)-\mathrm{C}\left(\mathrm{x}_{\mathrm{o}}-\Delta \mathrm{x}\right)}{2 \Delta \mathrm{x}}=\frac{\left.C\right|_{\mathrm{x}_{0}+\Delta \mathrm{x}}-\left.C\right|_{\mathrm{x}_{0}-\Delta \mathrm{x}}}{2 \Delta \mathrm{x}}
$$

The finite difference approximation of the dispersion term is expressed as:

$$
\frac{\partial}{\partial x}\left(E_{x} A \frac{\partial C}{\partial x}\right)=\frac{\left(E_{x} A \frac{\partial C}{\partial x}\right)_{\left(x_{0}+\Delta x\right)}-\left(E_{x} A \frac{\partial C}{\partial x}\right)_{\left(x_{0}-\Delta x\right)}}{2 \Delta x}
$$

Substituting Equation 5 into Equation 6 gives:

$$
\frac{\partial}{\partial x}\left(E_{x} A \frac{\partial C}{\partial x}\right)=\frac{\left(E_{x} A\right)_{\left(x_{0}+\Delta x\right)} \frac{C\left(x_{0}+2 \Delta x\right)-C\left(x_{0}\right)}{2 \Delta x}-\left(E_{x} A\right)_{\left(x_{0}-\Delta x\right)} \frac{C\left(x_{0}\right)-C\left(x_{0}-2 \Delta x\right)}{2 \Delta x}}{2 \Delta x}
$$

When applying the difference approximation to segment " $\mathrm{j}$ " in a network as in Figure 2, $\mathrm{x}_{\mathrm{o}}$ corresponds to the center of element $j, x_{0}+\Delta x$ to the interface between elements $j$ and $j+1, x_{0}-\Delta x$ to the interface between elements $j-1$ and $j, x-2 \Delta x$ to the center of element $j-1$, and $x_{0}+2 \Delta x$ to the center of element $j+1$. The pollutant transport equation for element $j$ can be written:

$$
\begin{aligned}
\frac{\partial}{\partial t}(A C)_{j}= & -\frac{(Q C)_{j, j+1}}{L_{j}}+\frac{(Q C)_{j-1, j}}{L_{j}} \\
& +\frac{\left(E_{x} A\right)_{j, j+1}}{L_{j, j+1} L_{j}}\left(C_{j+1}-C_{j}\right)-\frac{\left(E_{x} A\right)_{j-1, j}}{L_{j-1, j} L_{j}}\left(C_{j}-C_{j-1}\right) \\
& +A_{j} S_{j}^{T}
\end{aligned}
$$

where

$$
\begin{aligned}
& \mathrm{Q}=\mathrm{AU}, \text { volumetric flow rate }\left(\mathrm{m}^{3} / \text { day }\right) \\
& \mathrm{S}^{\mathrm{T}}=\mathrm{S}_{\mathrm{L}}+\mathrm{S}_{\mathrm{b}}+\mathrm{S}_{\mathrm{L}} \text {, total source and sink rates }\left(\mathrm{g} / \mathrm{m}^{3}\right. \text {-day) } \\
& \mathrm{L}=\quad \text { characteristic length shown in Figure } 2(\mathrm{~m})
\end{aligned}
$$


Multiplying both side of Equation 8 with $\mathrm{L}_{\mathrm{j}}$ gives:

$$
\begin{aligned}
\frac{\partial}{\partial t}(\mathrm{VC})_{j}= & -(Q C)_{j, j+1}+(Q C)_{j-1, j} \\
& +R_{j, j+1}\left(C_{j+1}-C_{j}\right)-R_{j-1, j}\left(C_{j}-C_{j-1}\right) \\
& +V_{j} S_{j}^{T}
\end{aligned}
$$

where

$\mathrm{V}=$ segment volume $\left(\mathrm{m}^{3}\right)$

$\mathrm{R}=\mathrm{EA} / \mathrm{L}$, dispersive flow $\left(\mathrm{m}^{3} /\right.$ day $)$

The concentrations at the interface of two segments are defined by WASP5 in terms of the segment concentrations as:

$$
\begin{aligned}
& \mathrm{C}_{\mathrm{j}, \mathrm{j}+1}=\alpha \mathrm{C}_{\mathrm{j}+1}+(1-\alpha) \mathrm{C}_{\mathrm{j}} \\
& \mathrm{C}_{\mathrm{j}-1, \mathrm{j}}=\alpha \mathrm{C}_{\mathrm{j}}+(1-\alpha) \mathrm{C}_{\mathrm{j} 1}
\end{aligned}
$$

where

$\alpha=$ numerical weighting factor (advection factor) between 0 and 1

When $\alpha$ is zero, a backward difference approximation for the advective term results. When $\alpha$ is 0.5 , a central difference approximation for the advective term is obtained.

WASP5 extends Equation 9 to the multi-dimensional form by including all segments (i's) adjoining segment $\mathrm{j}$. Interfaces are denoted as "i,j". The general equation used by WASP5 is expressed as:

$$
\frac{\partial}{\partial t}(\mathrm{VC})_{j}=-\sum_{i}(Q C)_{i, j}+\sum_{i} R_{i, j}\left(C_{i}-C_{j}\right)+V_{j} S_{j}^{T}
$$

where $Q$ is volumetric flow. $Q$ is positive when flow leaves segment $j$ and is negative when flow enters segment $j$. The pollutant mass of the segment $j$ is:

$$
M_{j}=(\mathrm{VC})_{j}
$$


Substituting Equation 13 into Equation 12, the general equation becomes:

$$
\frac{\partial}{\partial t}(M)_{j}=-\sum_{i}(Q C)_{i, j}+\sum_{i} R_{i, j}\left(C_{i}-C_{j}\right)+V_{j} S_{j}^{T}
$$

WASP5 uses Equation 14 to evaluate the mass derivatives for every segment $(j)$ during each time step between initial time $t_{o}$ and final $t_{\mathrm{r}}$. Given concentrations and volumes at time $t$, WASP5 calculates new masses at $t+\Delta t$ using the one-step Euler scheme:

$$
\left(M_{j}\right)_{t+\Delta t}=\left(M_{j}\right)_{t}+\frac{\partial}{\partial t}\left(M_{j}\right)_{t} \Delta t
$$

where $\Delta \mathrm{t}$ is the time step.

Given new mass at time $t+\Delta t$, WASP 5 calculates the new concentrations by dividing the masses with the volumes:

$$
\left(C_{j}\right)_{t+\Delta t}=\frac{\left(M_{j}\right)_{t+\Delta t}}{\left(V_{j}\right)_{t+\Delta t}}
$$

The segment volumes are input values in STREAM2.

Figure 3 shows that the calculation module, WASP5V, attaches the proper input files and reads input data from the input files. WASP5V calls subroutine EULER to perform transport simulations. EULER is the heart of the simulation, stepping through time performing a first-order Euler integration. At the start of a transport simulation, counters and time functions are initialized using subroutine TINIT. Initial mass derivatives are computed with a call to subroutine DERIV. For each time step, EULER loops through each segment, computing the new mass as shown in Equation 15. Each new concentration is obtained by dividing the new mass with a new volume (Equation 16). Next, EULER increments the time and adjusts the new day counter if necessary. If it is the proper time, EULER calls WASPB to store the intermediate results in the file with a file extension of "SMP". New mass derivatives are obtained with a call to DERIV. The final task for each time step is to check for a new time step and for the end of the simulation. New time steps are periodically set by subroutine WAS14. When the final time for the simulation is detected, EULER triggers a final call to WASPB to store the results and returns the control to the main program, STREAM2. Reference 2 contains a detailed description of WASP5.

\subsection{Post-Processor Module}

Calculated concentrations as functions of time for downstream locations are stored in an ASCII file with a file extension of "SMP". This ASCII file is passed to the subroutine SORT. Subroutine 
SORT finds the peak concentrations at downstream locations and the peak concentration travel times from the discharge point to the downstream locations. Subroutine SORT passes this information to the subroutines WINDOW_VIRTUAL and PLOTCON_VIRTUAL, which display the results in tabular and graphical forms, as shown in Figure 1.

\section{Input Files for Surface Stream Characterization}

Significant efforts were devoted to develop input files for each discharge location. There are fifteen pre-determined potential release points (listed in Table 1) in SRS. Figure 4 shows the onsite streams, facilities, and the USGS gauge stations. Table 2 shows the input file name conventions. The input files should be in the subdirectory INP and the subdirectory INP should be in the same directory of the STREAM2 executable file. The input manual modified from Reference 2 is presented in Appendix 1.

The pathway of the material released from the SRS facilities to the surface water includes onsite streams and the Savannah River. Therefore, the input model includes onsite streams and the Savannah River.

\subsection{Savannah River}

The development of the Savannah River model is described in Reference 3. Reference 3 also presents the benchmark of the model results with the dye tracer study results conducted by the US Environmental Protection Agency (EPA) in 1990 and 1991.

\subsection{Upper Three Runs Creek}

To model releases to Upper Three Runs Creek, the river system model includes both Upper Three Runs and the Savannah River. Figure 5 depicts this system. The reach from Point 1 to Point 2 in Figure 5 was divided into 19 segments, each with a cross-sectional area of $11.04 \mathrm{~m}^{2}$. The reach from Point 2 to Point 3 was divided into 42 segments, each with a cross-sectional area of 30.00 $\mathrm{m}^{2}$. The Savannah River from $30.5 \mathrm{~km}$ downstream from the New Savannah Bluff Lock and Dam to $14.5 \mathrm{~km}$ upstream from Fort Pulaski was divided into 489 segments, each with a cross-sectional area of $278 \mathrm{~m}^{2}$. All model segments are $500 \mathrm{~m}$ in length. The cross-sectional areas of Upper Three Runs Creek were estimated from USGS measurements. The cross-sectional area for the Savannah River was obtained from previous 1990 and 1991 EPA dye studies [3]. Figure 6 depicts the schematic for the finite difference model. Reference 4 presents Upper Three Runs Creek model development and the benchmarking of the model results with data obtained by the dye tracer studies conducted in 1995 and 1996. 


\subsection{Beaver Dam Creek}

To model the release to the Beaver Dam Creek, the river system modeled includes both Beaver Dam Creek and the Savannah River. Beaver Dam Creek, shown in Figure 7, was modeled for a distance of $5.54 \mathrm{~km}$, starting above the D-Area outfall and extending to the Savannah River. Beaver Dam Creek was divided into 11 segments with a segment length of $500 \mathrm{~m}$. An average cross section of $5.94 \mathrm{~m}^{2}$ was used. The Savannah River model was obtained from Reference 3. Figure 8 presents the finite difference scheme for the Beaver Dam Creek. There are no dye tracer study data available for Beaver Dam Creek. However, the Beaver Dam Creek model was benchmarked indirectly with the measured tritium concentrations in the Savannah River at the Highway 301 bridge, as described in Reference 5.

\subsection{Fourmile Branch}

To model the release to the Fourmile Branch, the river system modeled includes both Fourmile Branch and Savannah River. The original Fourmile Branch model was developed based on the 1995 dye tracer study, as presented in Reference 6. However, the computation time on an IBM $300 \mathrm{MHz}$ Pentium II personal computer is about forty minutes that is too long for emergency response application. Therefore, the segment size of the Formile Branch and the time step in Reference 6 were optimized to reduce the computation time. The computation time for the new model to simulate the pollutant transport from H-Area outfall to the city of Savannah, Georgia is less than fifteen minutes. As Figure 9 shows, Fourmile Branch was divided into 158 segments, each of which is $150 \mathrm{~m}$ long. The reach from Point 1 to Point 2 was divided into 137 segments, each with a cross-sectional area of $4.5 \mathrm{~m}^{2}$. The reach in the swamp area, from Point 2 to the mouth, was divided into 21 segments, each with a cross-sectional area of $5.0 \mathrm{~m}^{2}$. The Savannah River from the New Savannah Bluff Lock and Dam to $14.5 \mathrm{~km}$ upstream from Fort Pulaski was divided into 550 segments, each with a segment length of $500 \mathrm{~m}$ [3]. The cross-sectional areas of Fourmile Branch were adjusted so that the predicted dye plume traveling times matched the measured times from 1995 dye tracer study. The cross-sectional area of $278 \mathrm{~m}^{2}$ for the Savannah River was obtained from previous 1990 and 1991 EPA dye studies [3]. The segment length for the Fourmile Branch was shortened from $500 \mathrm{~m}$ to $150 \mathrm{~m}$. The reason for shortening the segment length follows.

The inherent numerical diffusion coefficient, $\left(\frac{U_{x} \Delta x}{2}\left(1-\frac{U_{x} \Delta t}{\Delta x}\right)\right)$, for the backward finite difference method, is proportional to the segment size. Numerical diffusion became too large when a segment length of $500 \mathrm{~m}$ was used for Fourmile Branch, and the predicted dye plume became too wide relative to the 1995 dye tracer measurements. Therefore, the segment length was shortened to $150 \mathrm{~m}$. The drawback to using this shorter segment length is that the number of segments increased and time step decreased due to numerical stability, causing the computing time to go up significantly. Figure 10 presents the finite difference scheme for the Fourmile Branch. 


\subsection{Pen Branch}

The development of Pen Branch model is presented in Reference 7. The river system model includes Indian Grave Branch, part of Pen Branch, part of Steel Creek, and the Savannah River, as shown in Figure 11. The K-Area outfalls discharge to Indian Grave Branch, which flows into Pen Branch about five miles upstream from the swamp. Pen Branch enters the swamp about three miles from the Savannah River, flows directly toward the Savannah River for about 1.5 miles, and then turns and runs parallel to the Savannah River for about five miles before discharging into Steel Creek about 0.5 miles from where Steel Creek empties into the Savannah River. The reach from Point 1 to Point 2 in Figure 11 was divided into 38 segments, each with a segment length of $500 \mathrm{~m}$ and a cross section area of $11.33 \mathrm{~m}^{2}$. The reach from Point 2 to Point 3 is in the swamp area and was divided into 22 segments, each with a segment length of $500 \mathrm{~m}$ and a cross section area of $197.14 \mathrm{~m}^{2}$. The Savannah River from the point $30.5 \mathrm{~km}$ downstream from the New Savannah Bluff Lock and Dam to the point $14.5 \mathrm{~km}$ upstream from Fort Pulaski was divided into 489 segments, each with a segment length of $500 \mathrm{~m}$ and a cross section area of $278 \mathrm{~m}^{2}$ [3]. Figure 12 presents the finite difference scheme for the Pen Branch. Reference 7 shows the comparison of the model results with the measured tritium concentrations from the 1991 K-Reactor tritiated aqueous release incident.

\subsection{Steel Creek}

The river system model includes both Steel Creek and the Savannah River. The reach from L lake Dam to the Steel Creek mouth was divided into 16 segments, each with a cross-sectional area of $10.498 \mathrm{~m}^{2}$. The Savannah River from $30.5 \mathrm{~km}$ downstream from the New Savannah Bluff Lock and Dam to $14.5 \mathrm{~km}$ upstream from Fort Pulaski was divided into 489 segments, each with a crosssectional area of $278 \mathrm{~m}^{2}$. All model segments are $500 \mathrm{~m}$ in length. The cross-sectional areas for Steel Creek were estimated from USGS discharge measurements at Road A [8]. The crosssectional area for the Savannah River was obtained from previous 1990 and 1991 EPA dye studies [3]. Figure 13 depicts the schematic for the finite difference model. No dye study data are available to benchmark the model. Therefore, it is suggested that a dye study be conducted for Steel Creek.

\subsection{Lower Three Runs Creek}

The river system model includes both Lower Three Runs Creek and the Savannah River. The reach from PAR Pond Dam to the Lower Three Runs Creek mouth in was divided into 32 segments, each with a cross-sectional area of $17.28 \mathrm{~m}^{2}$. The Savannah River from $30.5 \mathrm{~km}$ downstream from the New Savannah Bluff Lock and Dam to $14.5 \mathrm{~km}$ upstream from Fort Pulaski was divided into 489 segments, each with a cross-sectional area of $278 \mathrm{~m}^{2}$. All model segments are $500 \mathrm{~m}$ in length. The cross-sectional areas for Lower Three Runs were estimated from USGS discharge measurements at Station 02197400 [9]. The cross-sectional area for the Savannah River was obtained from previous 1990 and 1991 EPA dye studies [3]. Figure 14 depicts the schematic 
for the finite difference model. No dye study data are available to benchmark this model. Consequently, it is suggested that a dye study be conducted for Lower Three Runs Creek.

\subsection{Input Flows}

For the current version of STREAM2 code, the USGS measured historical flows are used in the calculation. When the USGS instantaneous measured flows become available, the user will have the option to chose the instantaneous measured stream flows for input. The current version of STREAM2 input flows are derived from USGS measured flow records. The input flow for the Savannah River is derived by averaging the measured daily mean flow by month from January 1 , 1975 to December 31, 1995. The same method is used to derive input flows for the onsite streams except that the averaging period for the onsite streams are shorter to exclude the influence of reactor discharge flows. The averaging period for onsite streams is from January $1,-1990$ to December 31, 1995.

Appendix 2 lists the input files for releases from H-Area to Fourmile Branch.

\section{Output Files}

STREAM2 simulations produce several files that may be examined by the user. Those files are in the Subdirectory OUT. Subdirectory OUT is in the subdirectory in which the executable file STREAM2 resides. These files use the file name of the input data set with a unique extension. Files created by a STREAM2 simulation include XX.OUT, XX.DMP, XX.MSS, XX.DAT, and XX.SMP (where ' $X X$ ' is the name of the input data set), as shown in Table 2. The .OUT file contains a record of the input data plus any simulation error messages that may have been generated.

The .DMP file contains calculated results for each segment at each print interval throughout the simulation.

The .MSS file contains a mass balance record for one designated system in the model network as a whole (in $\mathrm{kg}$ ). For each print interval, this file records the accumulated mass in from advection, dispersion, and loading; the accumulated mass out through advection, dispersion, burial (or volatilization), and kinetic transformation; the total resident mass; and the residual (unaccounted for) mass.

The .SMP file contains calculated results for selected segments at each print interval throughout the simulation. The selected segments correspond to the downstream locations of interest for displaying the results on the computer monitor in tabular and graphical forms.

The .DAT file contains a table that lists the peak concentration at selected downstream locations and the traveling time from the release point to the selected downstream locations. 
5 References

1. Hayes, D. W. and Buckner, M. R., 'Aqueous Emergency Response Program at SRL,' DPST-74420 , July 16,1974 .

2. Ambrose, Robert B., Wool, Tim A. and Martin, James L., "The Water Quality Analysis Simulation Program, WASP5, Part A: Model Documentation; Part B: Input Dataset," Environmental Research Laboratory, Office of Research and Development, U.S. Environmental Protection Agency, Athens, Georgia, September 20, 1993.

3. Chen, Kuo-Fu, "Revised STREAM Code and WASP5 Benchmark (U)," WSRC-RP-95-598, May 1995.

4. Chen, Kuo-Fu, "1995 and 1996 Upper Three Runs Dye Study Data Analyses (U)" WSRC-TR98-00225, June 1998.

5. Chen, Kuo-Fu, "Surface Water Modeling Using an EPA Computer Code for Tritiated Water Discharge from the Heavy Water Facility (U)," WSRC-TR-98-00230, June 1998.

6. Kuo-Fu Chen, "1995 Four Mile Creek Dye Studies Data Analyses (U)," WSRC-TR-98-00224, June 1998.

7. Kuo-Fu Chen, "Revised STREAM Code Benchmarking with 1991 K-Reactor Tritiated Aqueous Release Incident (U)," WSRC-RP-96-80, March, 1996.

8. Burton, J. M., "U.S. Geological Survey, Water Resources Division, Station No. 021973565 Discharge Measurement Notes," Message No. 84, April 22, 1998.

9. Smith, C. A., "U.S. Geological Survey, Water Resources Division, Station No. 02197400 Discharge Measurement Notes," Message No. 222, May 12, 1998. 
Table 1 Potential Release Locations

Release Location

D-Area Outfall to Beaver Dam

Highway 278 to Upper Three Runs

Road C to Upper Three Runs

Road A to Upper Three Runs

H-Area to Fourmile Branch

F-Area to Fourmile Branch

K-Area Outfall to Pen Branch Creek

Road A to Fourmile Branch

Road A to Steel Creek

Par Pond Dam to Lower Three Runs

Mouth of Lower Three Runs

Mouth of Steel-Pen Branch

Mouth of Fourmile Branch

Mouth of Beaver Dam

Mouth of Upper Three Runs
File Name Prefix

DD

H8

FS

UA

$\mathrm{HH}$

FF

KK

A4

AS

PD

ML

MS

M4

MB

MR 


\section{Table 2 File Name Conventions}

File Name Description

Input Files:

$\begin{array}{ll}\text { XX.INP } & \text { Input file } \\ \text { XX.NPS } & \text { Input file }\end{array}$

Output Files:

XX.OUT This file contains input data and error messages.

XX.DMP This file contains all the WASP5 simulation calculations.

XX.MSS This file contains mass balance table.

XX.SMP This file contains calculated concentrations as a function of time at sampling locations and is passed to the post-processor subroutines for displaying on the computer monitor.

XX.DAT This file contains the peak concentrations at sampling locations and the peak concentration transport time from the release point to the sampling location.

XX: Corresponding to the release location, as described in Table 1. 
Figure 1 STREAM2 Flow Chart

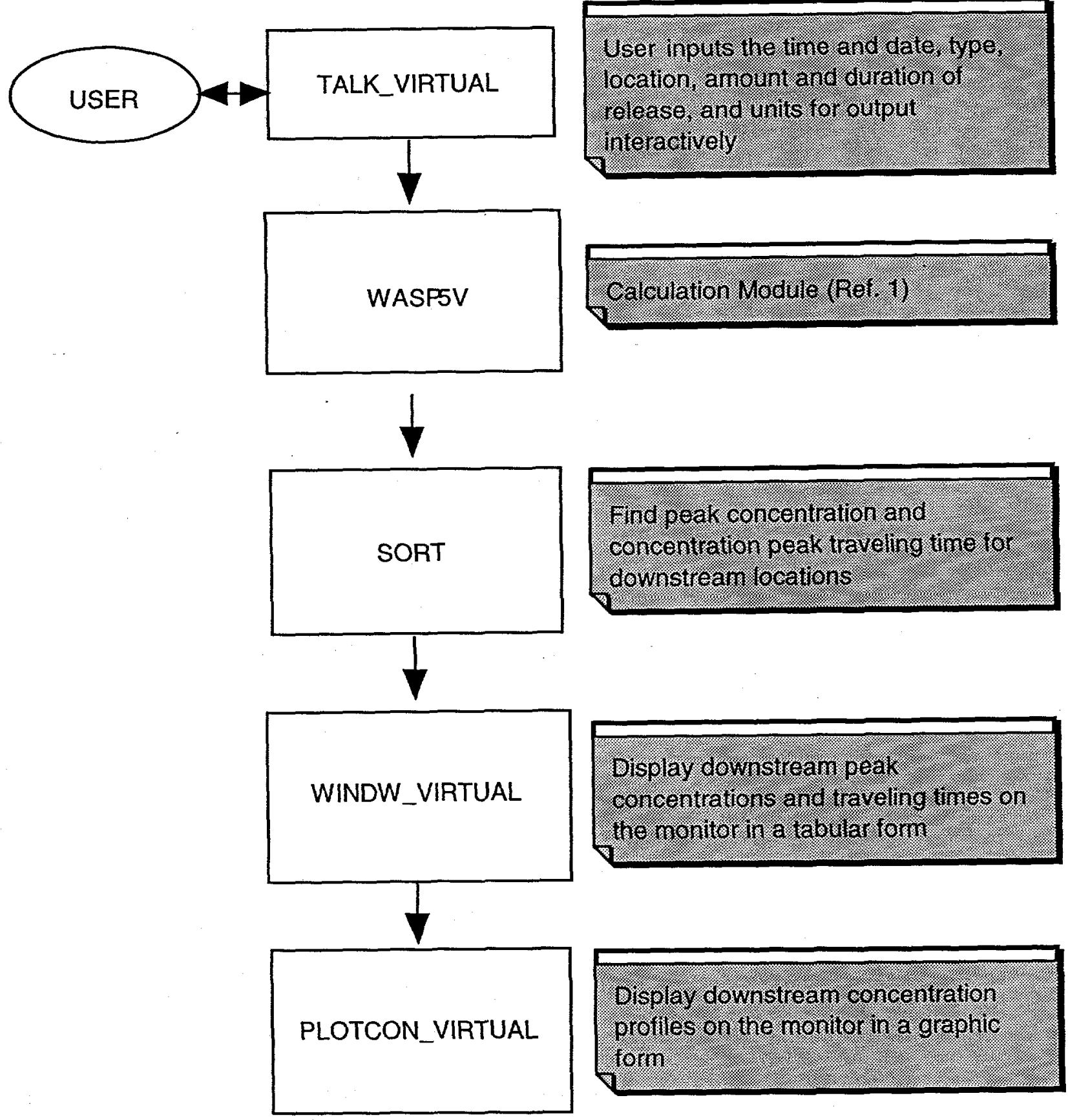


Figure 2 Finite Difference Scheme

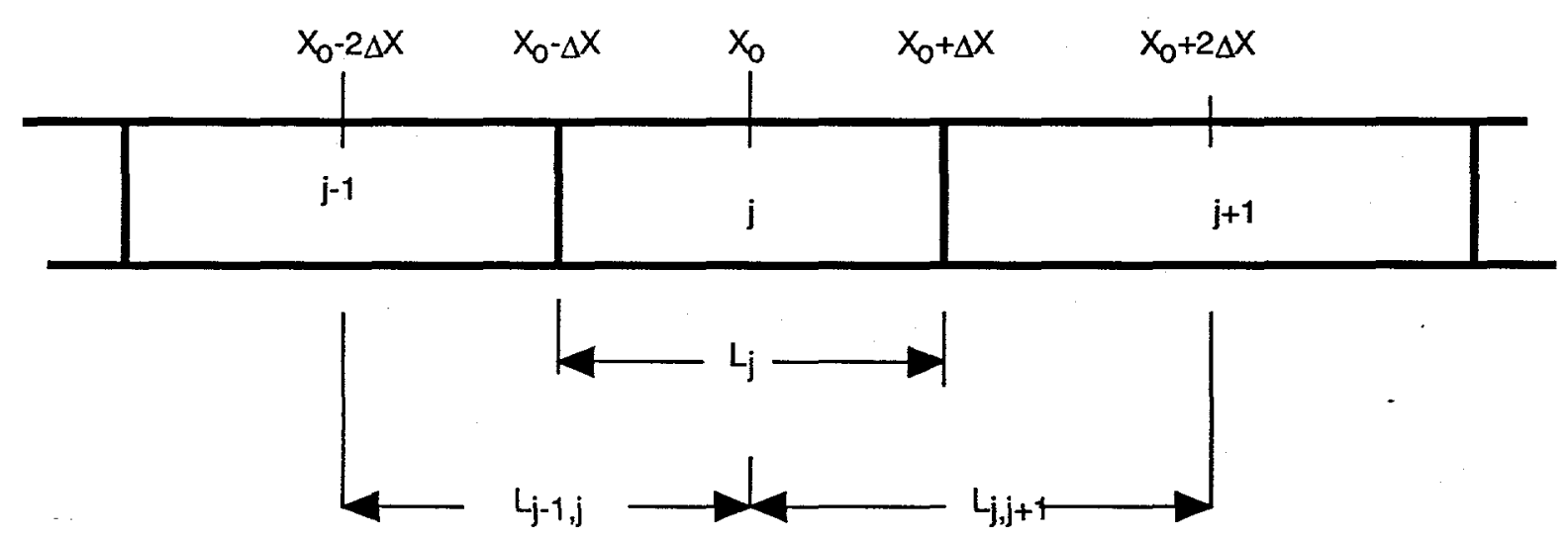


Figure 3 WASP5V Flow Chart
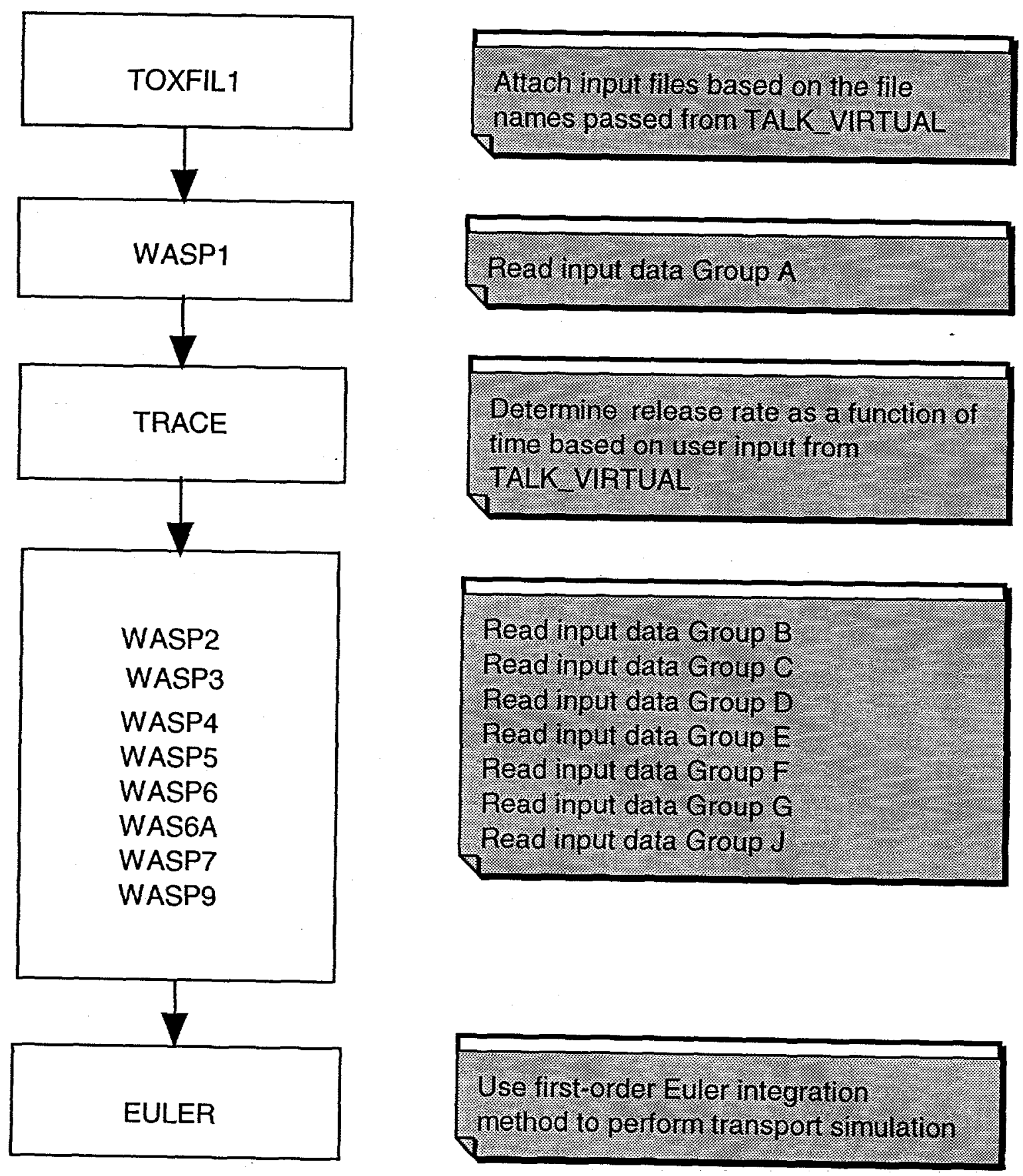
Figure 4 SRS Onsite streams, facilities, and the USGS gauge stations





Figure 5 Upper Three Runs Creek

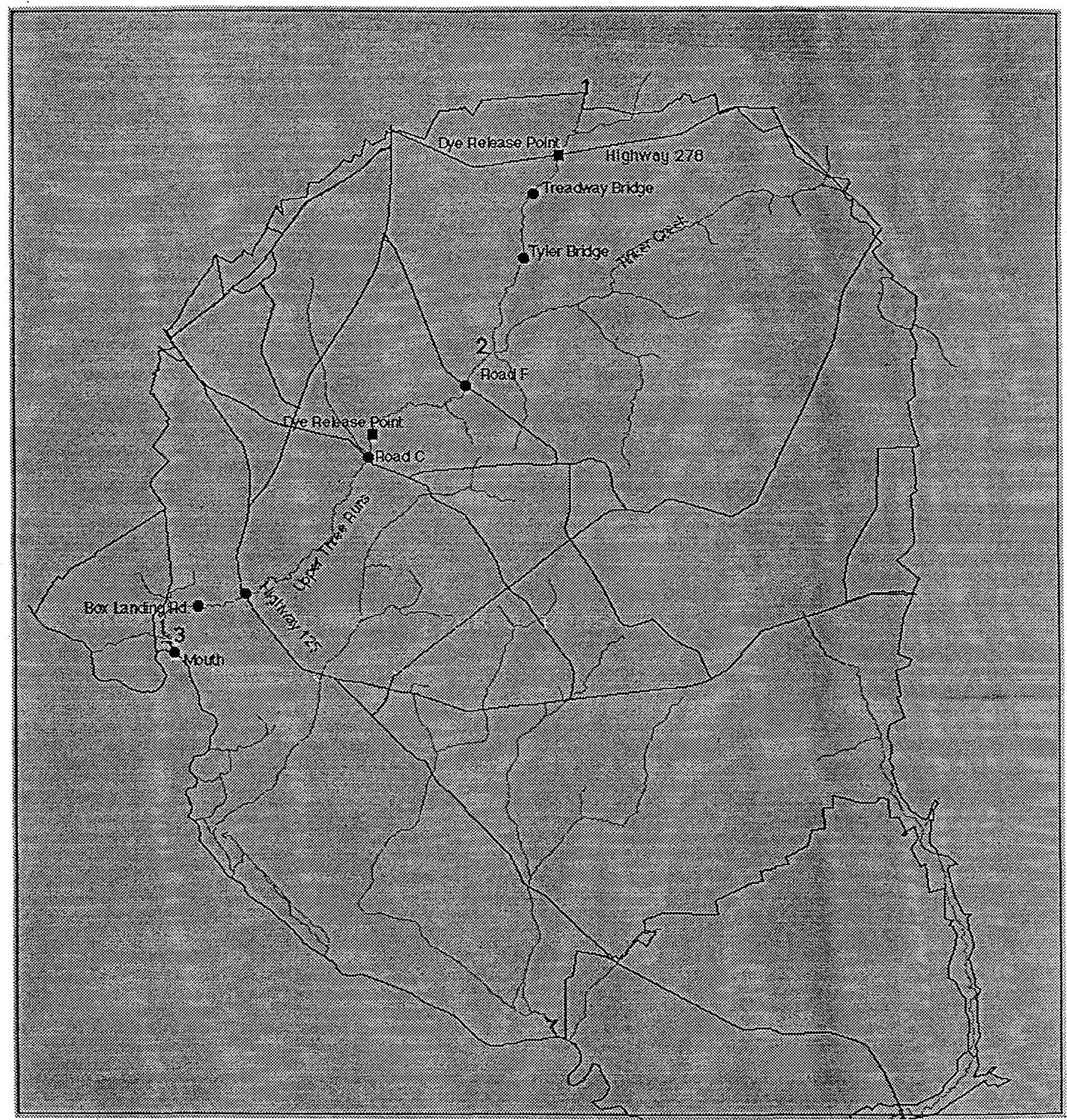


Figure 6 Model Schematics for Upper Three Runs Creek (not to scale)

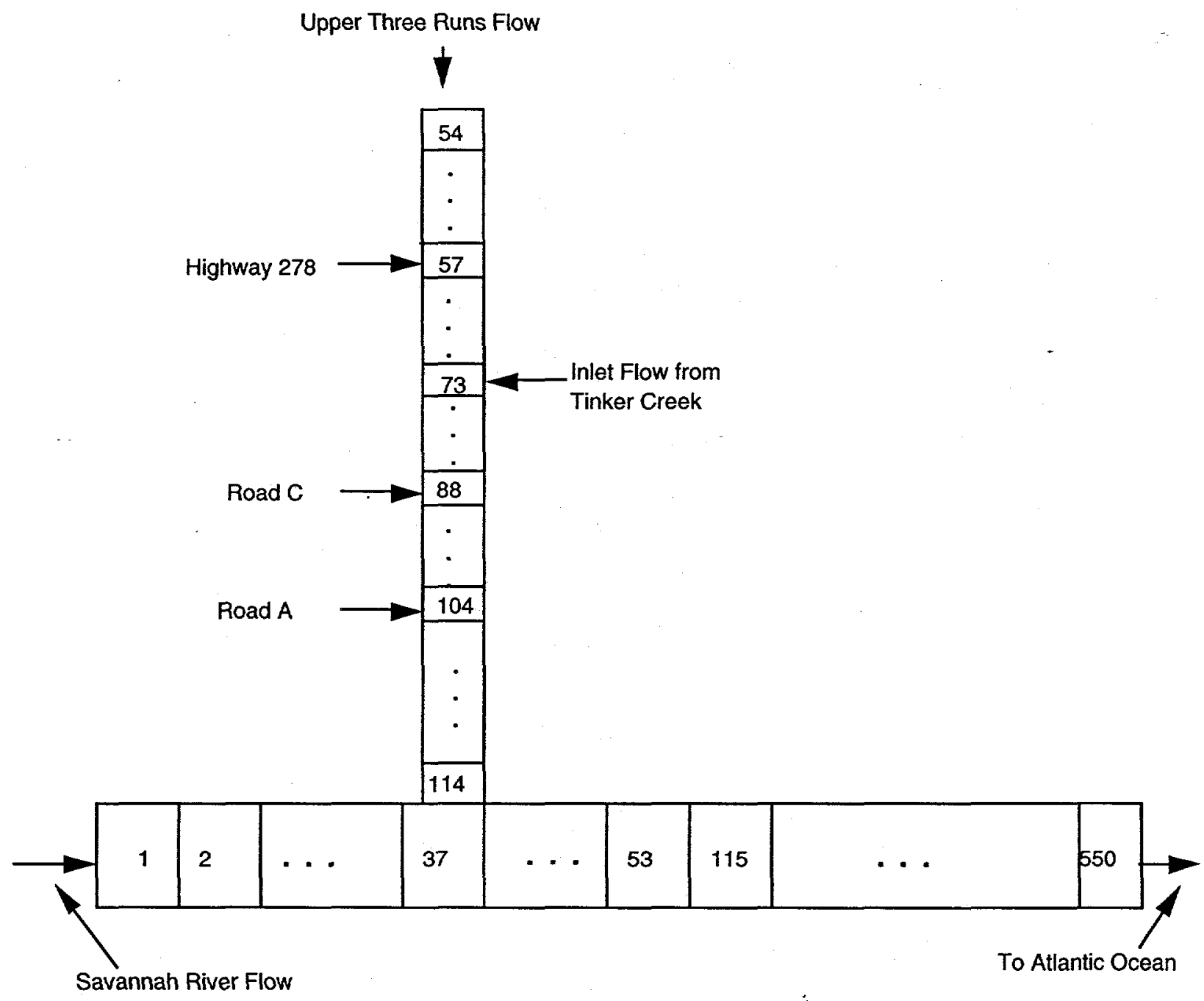


Figure 7 Beaver Dam Creek

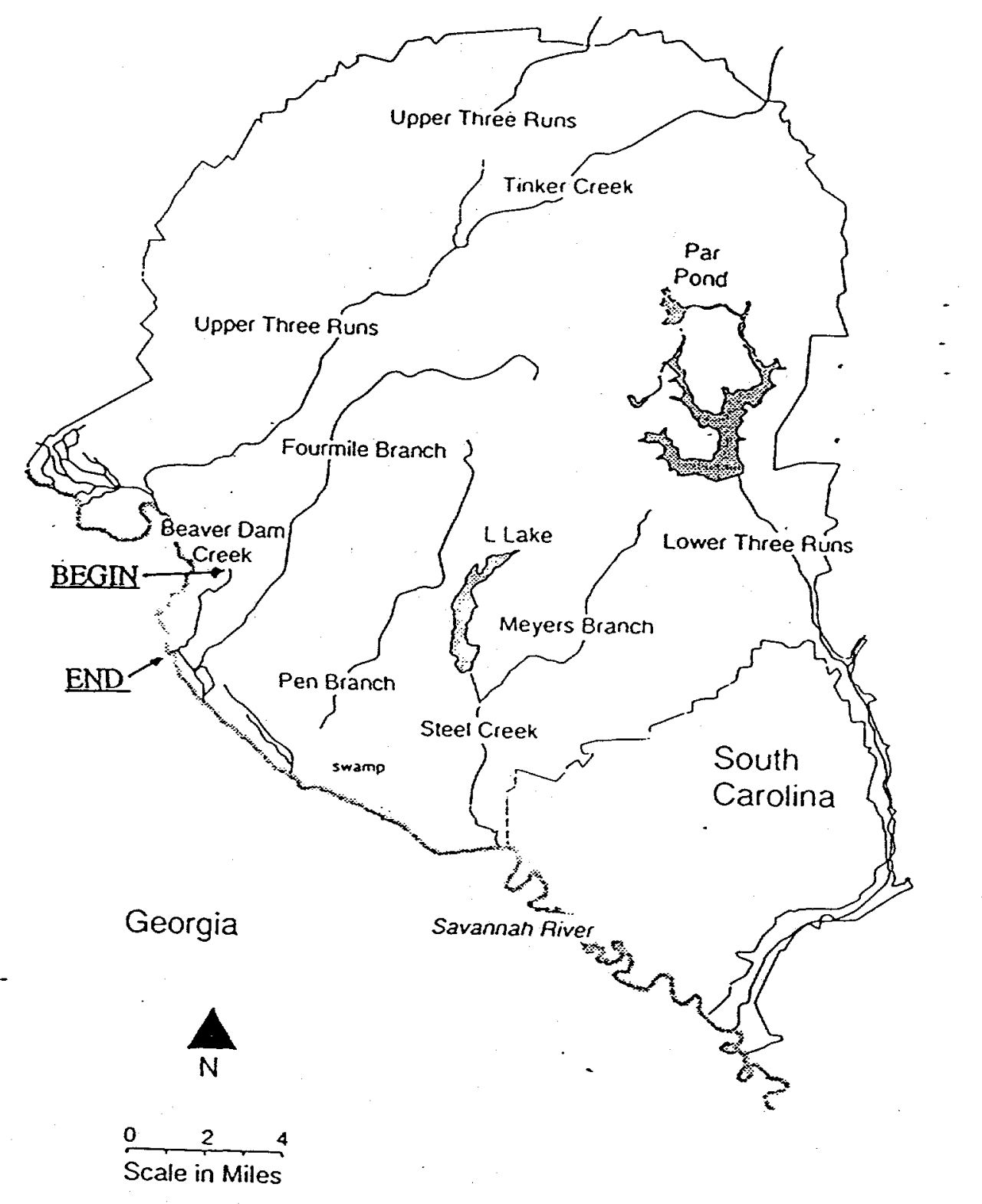

\begin{tabular}{lll}
$0 \quad 2 \quad 4$ & \\
\hline
\end{tabular}

Scale in Kilometers 
Figure 8 Model Schematics for Beaver Dam Creek (not to scale)

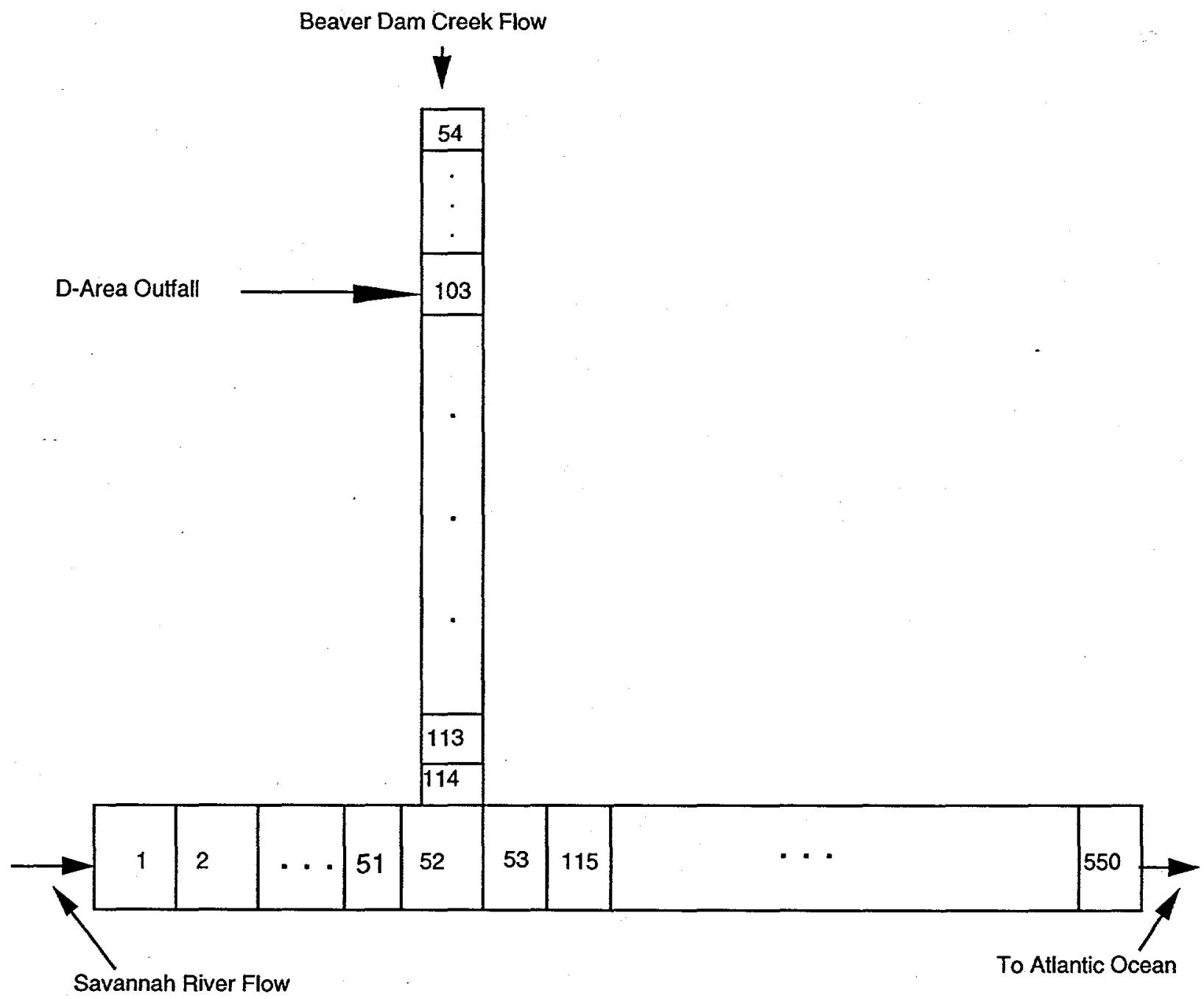


Figure 9 Fourmile Branch

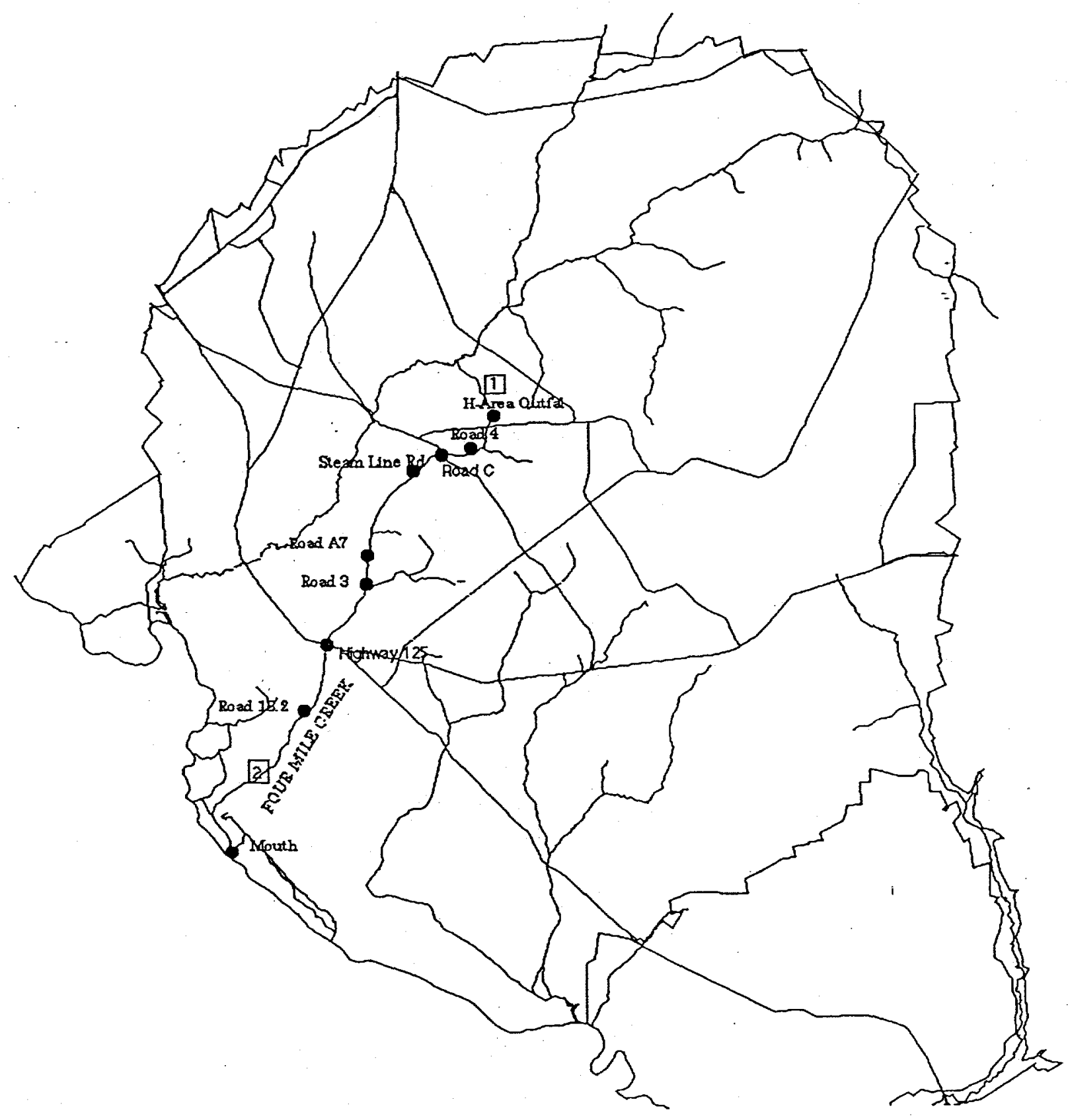


Figure 10 Model Schematics for Fourmile Branch (not to scale)

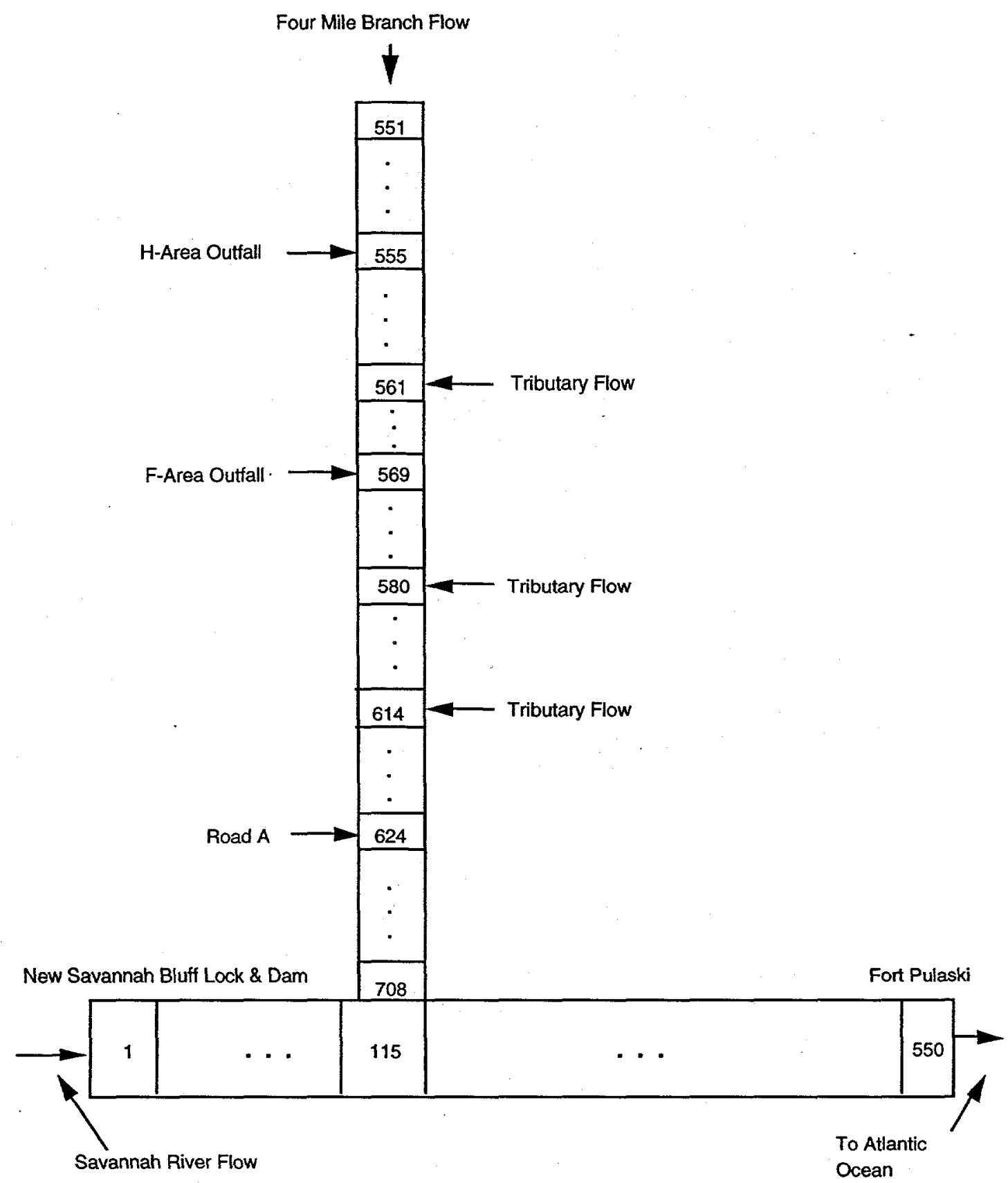


Figure 11 Pen Branch

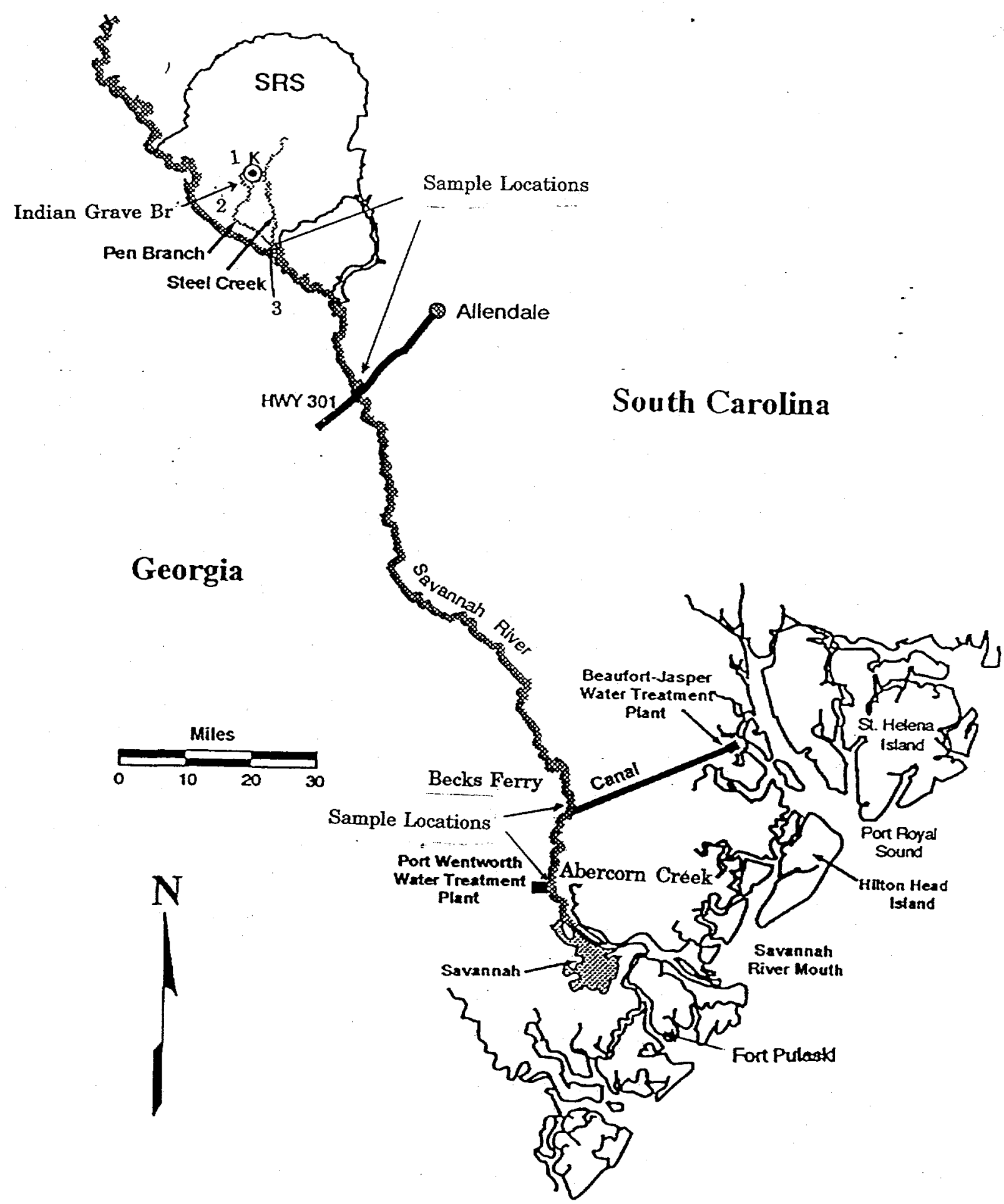


Figure 12 Model Schematics for Pen Branch (not to scale)

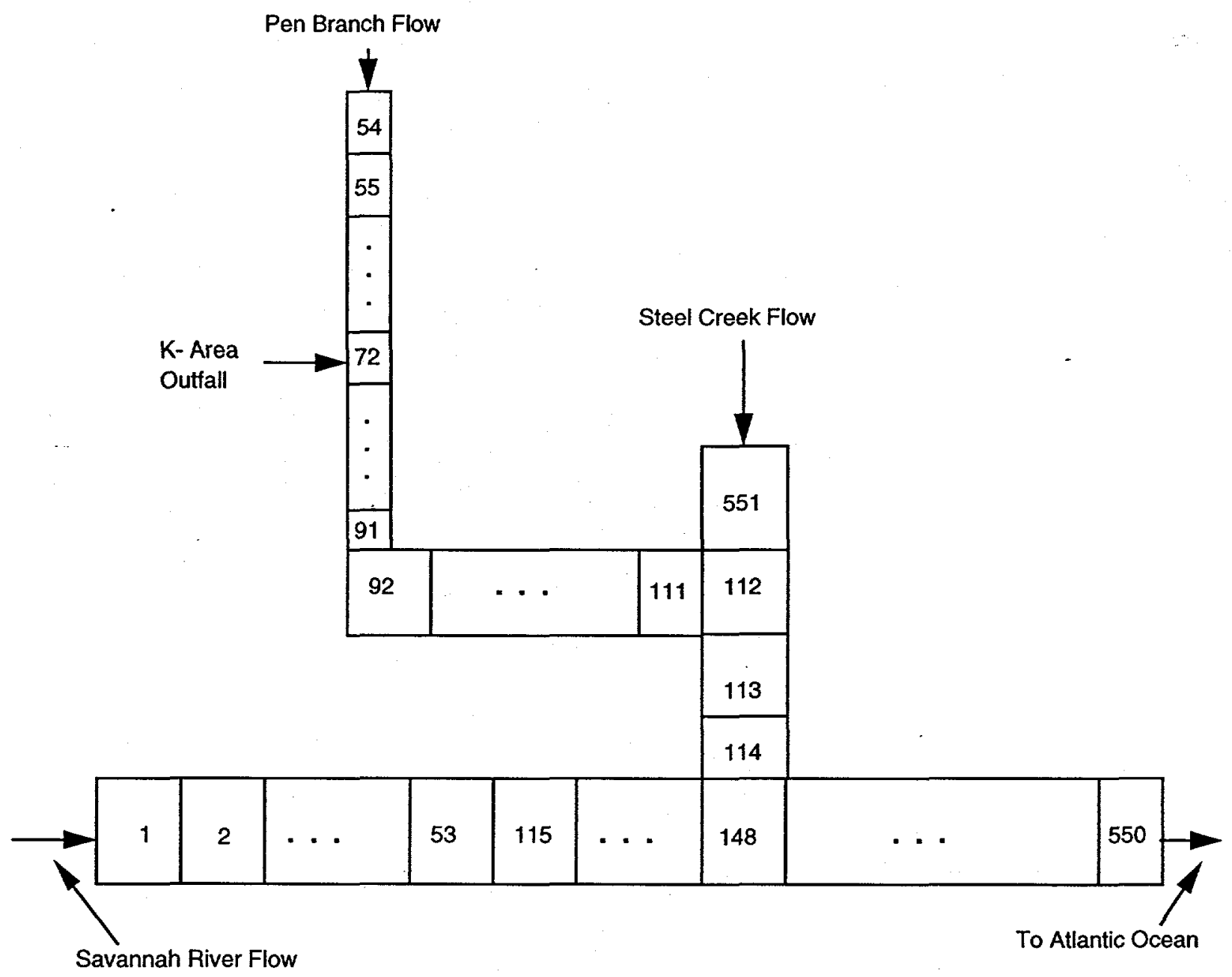


Figure 13 Model Schematics for Steel Creek (not to scale)

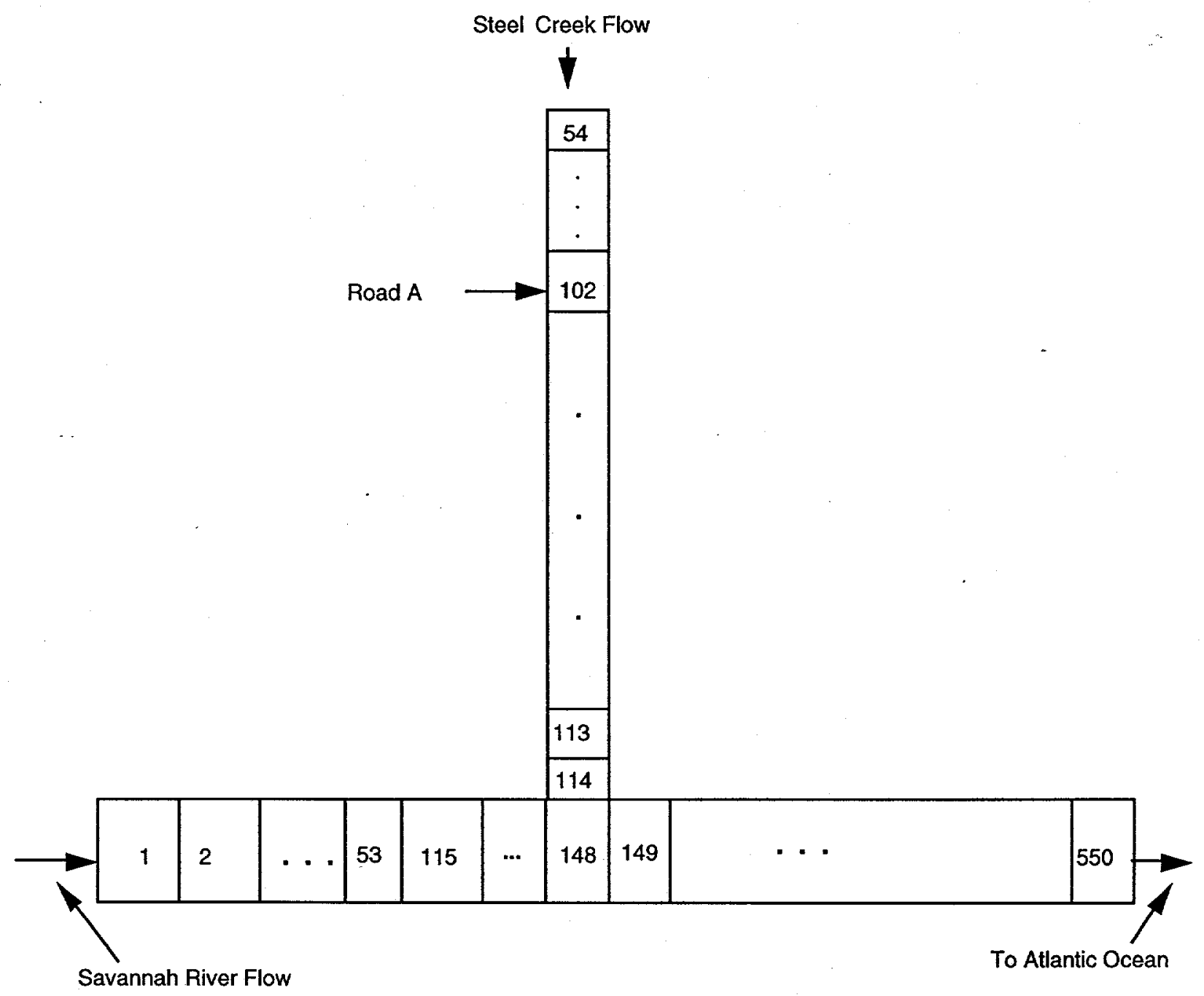


Figure 14 Model Schematics for Lower Three Runs Creek (not to scale)

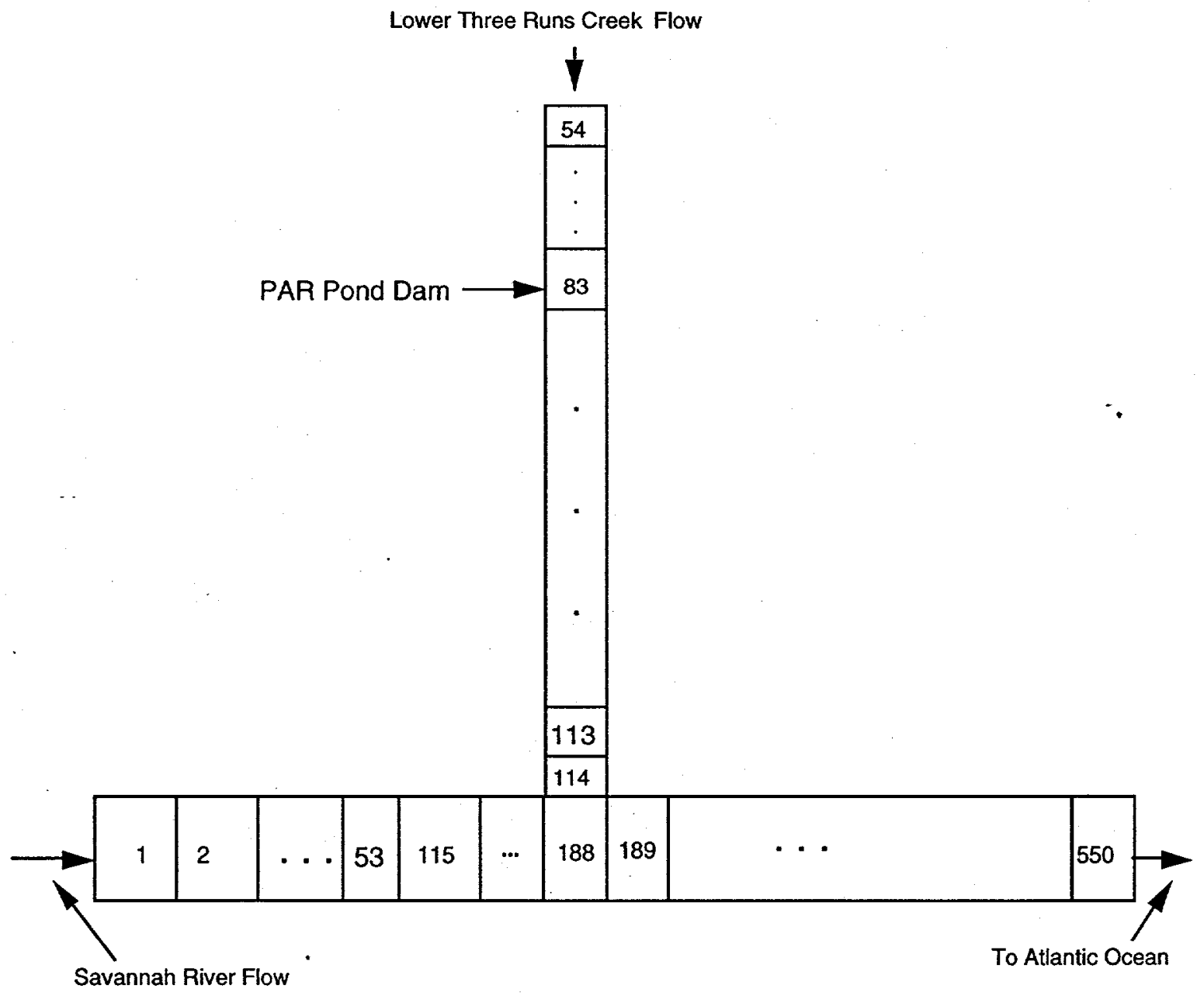


WSRC-TR-98-00234

June 1998

(Blank Page) 
Appendix 1 STREAM2 Input Manual

Input Manual for Model Development

The WASP5 input manual is modified for the STREAM2 model. WASP5 is a versatile water quality analysis simulation program, while the STREAM2 code is a pollutant transport model for SRS emergency response purpose. Therefore, specific values are assigned to some of the input variables, and the input flow (Data Group D) and the input source loading (Data Group F) sections are completely modified.

\section{DATA GROUP A: MODEL IDENTIFICATION AND SIMULATION CONTROL}

Basic simulation information is provided in Data Group A, beginning with titles and descriptions in Records 1 and 2. The number of systems (state variables) and segments are specifjed in Record 4. Calculation time steps are provided in Records 6 and 7, and print intervals in Records 8 and 9. System bypass options are set in Record 10.

\subsection{RECORD FORMATS}

$\underline{\text { Record 1--Title of Simulation (A80) }}$

TITLE1 = descriptive title of simulation. (A80)

Record 2--Description of Simulation (A80)

TITLE2 = description of simulation. (A80)

Record 3--Record 4 Names (A80)

HEADER = names of Record 4 variables, positioned properly; for user convenience only. (A80)

Record 4--Simulation Control Parameters (7I5, 2F5.0, F3.0, F2.0)

NOSEG = number of segments in model network. (I5)

NOSYS* $=2($ I5)

ICFL* $\quad=\quad$ flag controlling use of restart file; $0=$ neither read from nor write to restart file (initial conditions located in input file)

MFLAG $\quad=\quad$ flag controlling messages printed in XX.dmp file; $0=$ yes 


\begin{tabular}{|c|c|c|}
\hline & & messages printed; $1=$ no. $(15)$ \\
\hline JMASS & $=$ & $\begin{array}{l}0=\text { no mass balance table generated; or } \\
2=\text { generate mass balance table. (I5) }\end{array}$ \\
\hline NEGSLN & $=$ & $\begin{array}{l}\text { negative solution option; } 0=\text { prevents negative solutions; } 1= \\
\text { allows negative solutions. (I5) }\end{array}$ \\
\hline INTYP & $=$ & $\begin{array}{l}\text { time step option; } 0=\text { user inputs time step history; } 1=\text { model } \\
\text { calculates time step. (I5) }\end{array}$ \\
\hline ADFAC & $=$ & $\begin{array}{l}\text { advection factor; } 0=\text { backward difference; } 0.5=\text { central difference; } \\
0-0.4 \text { recommended. }(\text { F5.0) }\end{array}$ \\
\hline ZDAY & $=$ & day at beginning of simulation; 1 is first day. (F5.0) \\
\hline ZHR & $=$ & hour at the beginning of simulation. (F3.0) \\
\hline $\mathrm{ZMIN}$ & $=$ & minute at the beginning of simulation. (F2.0) \\
\hline TFLG & $=$ & $\begin{array}{l}\text { switch controlling generation of transport file; } 0=\text { generate file; } 1 \\
=\text { do not generate file. (I5) }\end{array}$ \\
\hline
\end{tabular}

Record 5-- Print Segments (615)

ISEGOUT $=$ six segment numbers for which the calculated peak concentration will be displayed on the screen. (I5)

Record 6--Number of Time Intervals (I5)

NOBRK $=$ number of intervals into which the total simulation time is divided. time step size used in calculation over each time interval is defined in Record 7. (I5)

Record 7--Time Steps (4(F10.0, F10.0))

DTS $(\mathrm{I})=$ maximum time step to be used until time $\mathrm{T}(\mathrm{I})$, days. $(\mathrm{F} 10.0)$

$\mathrm{T}(\mathrm{I})=\quad$ time up to when time step DTS(I) will be used, days. (F10.0)

Record 8--Number of Print Intervals (I5)

NPRINT $=$ number of print intervals. (I5) 
Record 9--Print Intervals (4(F10.0, F10.0))

PRINT(I) $\quad=\quad$ print interval to be used until time TPRINT(I), days. $(\mathrm{F} 10.0)$

TPRINT(I) $=$ time up to when print interval PRINT(I) will be used, days. (F10.0)

Record 10--System Bypass Options (1615)

$\operatorname{SYSBY}(\mathrm{K})^{*}=\quad \operatorname{SYSBY}(1)$ is 1 and $\operatorname{SYSBY}(2)$ is 0. (I5)

* A specific value is assigned to the variable. 


\section{DATA GROUP B: EXCHANGE COEFFICIENTS}

Exchange coefficients for surface water are computed from input dispersion coefficients, cross-sectional areas, and characteristic lengths. Dispersion coefficients may vary in time according to piecewise-linear time functions, with groups of segment pairs having the same dispersion time function.

\subsection{RECORD FORMATS}

$\underline{\text { Record 1--Number of Exchange Fields (I5, 75X) }}$

$\begin{array}{lll}\text { NRFLD* } & = & \text { number of exchange fields. NRFLD }=1 .(\text { I5) } \\ \text { TITLE } & = & \text { name of data group. }(75 \mathrm{X})\end{array}$

Record 2--Exchange Time Functions for Surface Water Field (I5, 2F10.0)

$\begin{array}{lll}\text { NTEX }(1)= & \text { number of exchange time functions for field 1. (I5) } \\ \text { SCALR } & =\quad \begin{array}{l}\text { scale factor for exchange coefficients. All exchange coefficients } \\ \text { for field } 1 \text { will be multiplied by this factor. (F10.0) }\end{array} \\ \text { CONVR } & =\quad \text { conversion factor for exchanges in field 1. (F10.0) }\end{array}$

Records 3-6 are input as a group NTEX(1) times:

Record 3--Exchange Data (I5)

$\operatorname{NORS}(1, \mathrm{NT}) \quad=\quad$ number of exchanges for field 1 , time function NT. (I5)

Record 4--Areas, Characteristic Lengths (2F10.0, 215)

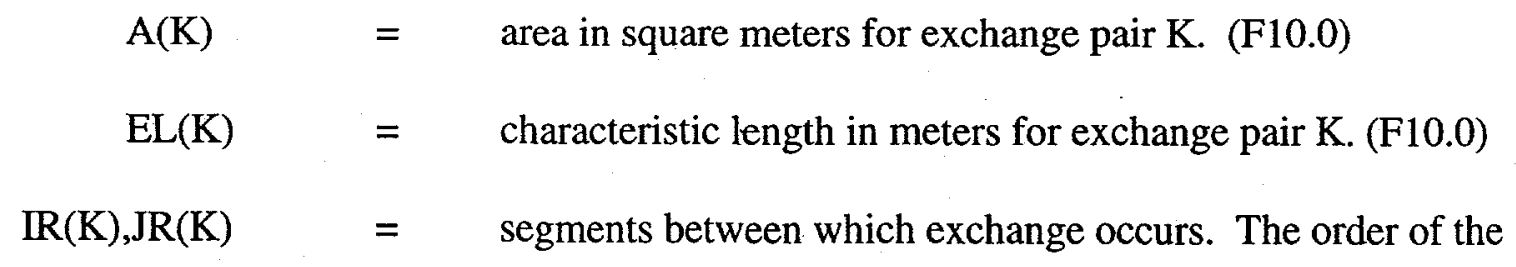


WSRC-TR-98-00234

June 1998

segments is unimportant. (2I5)

Record 4 is repeated NORS $(1, N T)$ times.

Record 5--Number of Breaks in Time Function (I5)

$\operatorname{NBRKR}(1, N T)=$ number of values and times used to describe dispersion coefficient piecewise-linear time function. (I5)

Record 6--Piecewise Linear Dispersion Time Function (4(F10.0, F10.0))

$\mathrm{RT}(\mathrm{K})=\quad$ value of dispersion coefficient in $\mathrm{m}^{2} / \mathrm{sec}$ at time $\mathrm{TR}(\mathrm{K}) .(\mathrm{F} 10.0)$

$\mathrm{TR}(\mathrm{K})=$ time in days. $(\mathrm{F} 10.0)$

Record 6 is repeated $N B R K R(1, N T) / 4$ times.

Record 7--Exchange Bypass Options (1615)

$\operatorname{RBY}(\mathrm{K})^{*} \quad=\quad \operatorname{RBY}(1)=1$ and $\mathrm{RBY}(2)=0$. (I5)

Record 1 is entered once for Data Group B. Records 2 through 6 are input for the surface water exchange field, with Records 3, 4, 5, and 6 being repeated for each time function in this exchange field. Record 4 uses as many lines as necessary to input NORS sets of $A(K), E L(K)$, $\mathrm{IR}(\mathrm{K})$, and $\mathrm{JR}(\mathrm{K})$, with 1 set on each line. Record 6 uses as many lines as needed to input NBRKR pairs of $R T(K)$ and $T R(K)$, with 4 pairs occupying each line.

After data for all exchange fields are entered, Record 7 is input on the following line with NOSYS entries. For STREAM2, NOSYS is 2. 


\section{DATA GROUP C: VOLUMES}

Initial segment volumes are provided in Data Group C. In addition, segment type and underlying segment numbers are specified.

\subsection{RECORD FORMATS}

Record 1--Preliminary Data (2I5, F10.0,60X)

$\begin{array}{lll}\text { IVOPT } & = & \begin{array}{l}\text { water column volume option }-1=\text { constant water column } \\ \text { volumes; } 2,3=\text { volumes adjusted to maintain flow continuity. (I5) }\end{array} \\ \text { IBEDV* } & =\quad \begin{array}{l}\text { benthic volume option }-0=\text { constant bed volumes. (I5) } \\ \text { TDINTS }\end{array} \quad \begin{array}{l}\text { benthic time step in days for recomputing porosity (if IBEDV =0) } \\ \text { or for sediment bed compaction (if IBEDV }=1) .(\text { F10.0) }\end{array} \\ \text { TITLE } & =\quad \text { name of data group. }(60 \mathrm{X})\end{array}$

Record 2--Scale Factors (2F10.0)

SCALV = scale factor for volumes. All volumes will be multiplied by this factor. (F10.0)

CONVV $=$ conversion factor for volumes. $(\mathrm{F} 10.0)$

Record 3 is repeated NOSEG times:

Record 3--Segment Types and Volumes $(3 \mathrm{I1} 0,5 \mathrm{~F} 10.0)$

ISEG = segment number.

IBOTSG = segment immediately below ISEG. (I10)

ITYPE(ISEG)* = segment types: $1=$ surface water segment. (I10)

BVOL(ISEG) = volume of segment ISEG in cubic meters. (F10.0) 
WSRC-TR-98-00234

June 1998

VMULT(ISEG) = hydraulic coefficient "a" for velocity in ISEG as a function of flow:

$$
\mathrm{v}=\mathrm{a} \mathrm{Q}^{\mathrm{b}}
$$

If $b=0$, VMULT is a constant velocity in $\mathrm{m} / \mathrm{sec}$. (F10.0)

VEXP(ISEG) = hydraulic exponent " $b$ " for velocity in ISEG as a function of flow $(0-1)$. A value of 0.4 represents rectangular channels. (F10.0)

DMULT(ISEG) = hydraulic coefficient "c" for depth of ISEG as a function of flow:

$$
\mathrm{d}=\quad \mathrm{CQ}^{\mathrm{d}}
$$

If $d=0$, DMULT is a constant depth in $\mathrm{m} .(\mathrm{F} 10.0)$

DXP(ISEG) = $\quad=\quad$ hydraulic exponent " $\mathrm{d}$ " for depth of ISEG as a function of flow (0-1). A value of 0.6 represents rectangular channels. (F10.0)

Note that the four hydraulic geometry parameters are used to calculate segment velocity and depth, which are not used by WASP5 in transport calculations. These are used to calculate reaeration or volatilization from segments.

Records 1 and 2 are entered once for Data Group C. Record 3 is repeated NOSEG times. 


\section{DATA GROUP D: FLOWS}

\subsection{RECORD FORMATS}

Data Group D provides for the advective transport flows that are used in the model. The input format for Data Group D is rewritten for the STREAM2 code. A constant flow as a function of the month in which the release is taking place is used for the transport calculation in STREAM2.

Record 1--Data Input Options: Number of Flow Fields (2I5, A12)

$\begin{array}{lll}\text { IQOPT* }^{*} & =1 \\ \text { NFIELD* } & =1(\mathrm{I5}) \\ \text { HYDFIL } & =\quad \begin{array}{l}\text { name of hydrodynamic file to be read by WASP5 during the } \\ \text { simulation (for example, RIVER1.HYD). (A12) }\end{array}\end{array}$

DATA BLOCK D1: Direct Input of Field One Flows

Record 2--Number of Flow Time Functions (15, 2F10.0)

$$
\begin{array}{lll}
\text { NINQ(1) }= & \text { number of time functions. (I5) } \\
\text { SCALQ }= & \begin{array}{l}
\text { scaling factor. All flows in Field one are multiplied by SCALQ. } \\
\text { (F10.0) }
\end{array} \\
\text { CONVQ }= & \text { units conversion factor. (F10.0) }
\end{array}
$$

Records $3-6$ are input as a group NINQ(1) times:

Record 3--Number of Flows (I5)

$\operatorname{NOQS}(1, \mathrm{NI}) \quad=\quad$ number of unit flow responses in field one, time function NI; each 
unit flow is defined for a single segment pair. (I5)

Record 4--Flow Routing for Field One (4(F10.0, 2I15))

$\begin{array}{lll}\mathrm{BQ}(1, \mathrm{NI}, \mathrm{K}) & = & \begin{array}{l}\text { portion of flow for field one, time function NI that flows between } \\ \text { segment pair } \mathrm{K} .(\mathrm{F} 10.0)\end{array} \\ \mathrm{JQ}(1, \mathrm{NI}, \mathrm{K}) & = & \text { upstream segment. (I5) } \\ \mathrm{IQ}(1, \mathrm{NI}, \mathrm{K}) & = & \text { downstream segment. (I5) }\end{array}$

Record 4 is repeated NOQS $(1, N I) / 4$ times.

Record 5-Flows from January to December (4F10.0))

QFLW $(\mathrm{l}) \quad=\quad$ advective flow in $\mathrm{m}^{3} / \mathrm{s}$. (F10.0)

Record 5, I =1 to 12, four entries per line.

Record 2 is input once for Data Block D1. Records 3, 4, and 5 are input once for each flow time function. Record 4 uses as many lines as needed to input NOQS sets of BQ, JQ, and IQ, with four sets per line. Record 5 uses three lines with four entries on each line.

\section{END OF DATA BLOCKS FOR D}

Record 6--Flow Bypass Options (1615)

QBY(ISYS) = flow bypass option $-0=$ flow transport occurs in system ISYS; $1=$ flow transport is bypassed for system ISYS. (I5)

ISYS $=1$, NOSYS. For STREAM2, NOSYS is 2.

The flow bypass option allows flow transport to be set to zero in one or more systems. The bypass option applies to all transport fields. The input values for STREAM2 are 1 and 0 . 


\section{DATA GROUP E: BOUNDARY CONCENTRATIONS}

Data Group E supplies concentrations for each system at the model network boundaries. Model boundaries consist of those segments that import, export, or exchange water with locations outside the network, as specified in Data Groups B and D. All system concentrations from 1 to NOSEG must be supplied for each boundary. Boundary concentrations vary with time following a piecewise linear time function specified by the user in Records 3 and 4 .

\subsection{RECORD FORMATS}

Data Group E is repeated, in its entirety, NOSYS times.

Record 1--Data Input Option--Number of Boundary Conditions (I10, 70X)

$\operatorname{NOBC}(\mathrm{K})=$ number of boundary conditions used for system $\mathrm{K}$. (I10)

TITLE $=$ name of data group. $(70 \mathrm{X})$

If no boundary conditions are to be input for system $\mathrm{K}$, set $\mathrm{NOBC}(\mathrm{K})$ equal to zero and either continue with the next system or go to Data Group $F$ if $\mathrm{K}$ is the last system.

Record 2--Scale Factor for Boundary Conditions ( 2 F10.0)

SCALB = scale factor for boundary conditions. All boundary conditions will be multiplied by this factor. (F10.0)

CONVB $=$ unit conversion factor for boundary conditions. Boundary conditions are expected to be in $\mathrm{mg} / \mathrm{L}$ (i.e. $-\mathrm{g} / \mathrm{m}^{3}$ ), in which case CONVB will be 1.0. (F10.0)

Records 3-4 are input as a unit $N O B C(K)$ times:

Record 3--Boundary Location (2I5)

$\mathrm{IBC}(\mathrm{K}) \quad=\quad$ boundary segment number. (I5) 
WSRC-TR-98-00234

June 1998

$\operatorname{NOBRK}(\mathrm{K})=$ number of values and times used to describe the broken line approximation. The number of breaks must be equal for all boundary conditions within a system. (I5)

\section{Record 4--Boundary Concentrations (4(2F10.0))}

$\mathrm{BCT}(\mathrm{K})=$ value of the boundary concentration at time $\mathrm{T}(\mathrm{K})$ in $\mathrm{mg} / \mathrm{L} .(\mathrm{F} 10.0)$

$\mathrm{T}(\mathrm{K})=$ time in days. If the length of the simulation exceeds $\mathrm{T}(\mathrm{NOBRK})$, the broken line approximation is repeated, starting at $\mathrm{T}(1)$, i.e., the approximation is assumed to be periodic, with period equation to $\mathrm{T}$ (NOBRK). All break times must agree for all segments, i.e., $\mathrm{T}(1)$ must be the same for all boundaries, $T(2)$ must be the same for all boundaries, etc. (F10.0)

Record 4 is repeated $\operatorname{NOBRK}(K) / 4$ times.

Records 1 and 2 are entered once. Records 3 and 4 are a set and are repeated NOBC times. Within each NOBC set, Record 3 is entered once and Record 4 is repeated until NOBRK entries are input. Four entries (four BCT(K)-T(K) pairs) will fit on each 80-space line. The whole group (Records $1-4$ ) is repeated NOSYS times, once for each model system. For STREAM2, NOSYS is 2. 


\section{DATA GROUP F: WASTE LOADS}

The pollutant loading for STREAM2 is defined by the user at the pre-processor module and the loading is passed to WASP5 from sub-routine TRACE

\subsection{RECORD FORMATS}

Data Block F1 (records 1 ) is repeated in its entirety NOSYS times:

Record 1--Number of Point Sources (I5)

IWK = segment number that has point source loading BWK. (I5)

Record 1 is repeated NOSYS times, once for each system. For STREAM2, NOSYS is 2.

Data Block F2, record 2, is input once:

Record 2-Instantaneous Release (I10)

NPSFIL $=$ To conform with the WASP5 logic, NPSFIL is an external file used by WASP 5 to input instantaneous release. This file name should include the directory name in which the NPSFIL resides. This file and its contents are described below. (A12)

\subsection{THE EXTERNAL NONPOINT SOURCE FILE}

This file contains information on which WASP5 systems and segments receive instantaneous releases.

Six records comprise the instantaneous release file.

Record 1--Data Options (A15, 3I5) 
WSRC-TR-98-00234

June 1998
NPSMOD $=$ Name or description of loading source model or method of generation; this is echoed to the output file for the record. (A15)
NUMSEG $=$ Number of segments receiving loads. (I5)
INTOPT = Interpolation option; $1=$ step function (only one in code now). (I5)
NUMSYS $=$ Number of WASP systems receiving loads. (I5)

Record 2--Loading Segments (I5)

LSEG(I) = segment number receiving loads. (I5)

Record 2 is repeated NUMSEG times.

Record 3--Loading Systems (2015)

LSYS(I) = WASP system numbers receiving loads. (I5)

Record 4--System Descriptors (A15)

NAMESY(I) $=\quad$ Name or description of WASP systems receiving loads. (A15)

Record 4 is repeated NUMSYS times.

Records 5 and 6 are repeated as a unit for the number of days that nonzero loads occur:

Record 5--Loading Days (F10.0)

LDAY $=$ Time in days for the following nonzero load. (F10.0)

Record 6--Nonpoint Source Loads (A15, 20F10.0)

NAMESY $(\mathrm{I})=$ System name or description (not read in by WASP). (A15)

$\operatorname{NPSWK}(\mathrm{I}, \mathrm{J})^{*} \quad=\quad 0.0$; this is the loading that will be assigned by user at the preprocessor module and passed to WASP 5 by subroutine TRACE (20F10.0)

Record 6 is repeated NUMSYS times. 
Record 1 is input once. Record 2 is repeated NUMSEG times. Record 3 is then input once. Record 4 is repeated NUMSYS times. Records 5 and 6 are a set and are repeated (as a set) NUMSYS times. Within each set, Record 5 is entered once and Record 6 is repeated NUMSYS times.

\section{DATA GROUP G: PARAMETERS}

Parameters are not used by STREAM2.

\subsection{RECORD FORMATS}

Record 1--Number of Parameters (I10, 70X)

NOPAM* $=0 \quad \begin{aligned} & \text { number of parameters required by the model. If no parameters are } \\ & \text { to be input, set NOPAM to zero and go to Data Group H. (I10) }\end{aligned}$
TITLE $\quad=\quad$ name of data group. $(70 \mathrm{X})$




\section{DATA GROUP H: CONSTANTS}

STREAM2 does not use this data group.

\subsection{RECORD FORMATS}

$\underline{\text { Record 1--Header (80X) }}$

TITLE = name of data group. $(80 \mathrm{X})$

Records 2-4 are input as a group NOSYS+1 times:

$\underline{\text { Record 2--Data Fields in Group ISYS }(A 10, I 10)}$

CHNAME(ISYS) = a ten-character descriptive name for System (ISYS). (A10)

NFLD* $^{*} \quad=0$ number of fields of constants for this group; $0=$ no constants for this group; the user may subdivide the constants into any number of arbitrary fields. (I10)

Record 1 is entered once in Data Group H. Record 2 is entered as NOSYS + 1 groups. For STREAM2, NOSYS is 2. 


\section{DATA GROUP I: KINETIC TIME FUNCTIONS}

Note: STREAM2 does not use kinetic time functions.

\subsection{RECORD FORMATS}

Record 1--Number of Time Functions $(\mathrm{I10}, 70 \mathrm{X})$

NFUNC $\quad=0$ number of time functions required by the model. If no time functions are to be input, set NFUNC equal to zero and go to Data Group J. (I10)

TITLE = name of data group. (70X) 


\section{DATA GROUP J: INITIAL CONDITIONS}

\subsection{RECORD FORMATS}

The initial conditions are the segment concentrations and densities for the state variables at time zero (the start of the simulation).

Records 1-2 are input as a group NOSYS times:

Record 1--System Information (A40, I5, F5.0, F10.0, 20X)

$\begin{array}{ll}\text { CHEML } & =\quad \begin{array}{l}\text { chemical or system name }(\mathrm{A} 40) . \\ \text { IFIELD }\end{array} \quad \begin{array}{l}\text { solids field }(3,4, \text { or } 5) \text { that transports this system in its pure } \\ \text { or sorbed form (I5). }\end{array} \\ \text { DSED } & =\quad \begin{array}{l}\text { density of system; } 0.0 \text { for chemical, } 0.5-2.5 \text { for solids, } \\ \mathrm{kg} / \mathrm{L} .(\mathrm{F} 5.0) .\end{array} \\ \text { CMAX } & =\quad \text { maximum concentration allowed, mg/L. (F10.0) } \\ \text { TITLE } \quad=\quad \text { name of data group. (20X) }\end{array}$

Record 2--Initial Conditions (3(A5, 2F10.0))
$\operatorname{ANAME}(\mathrm{K})=$ an optional one to five alphanumeric character descriptive name or number identifying segment $K$. (A5)
$\mathrm{C}(\mathrm{ISYS}, \mathrm{K})=$ initial concentration in segment $\mathrm{K}$ of system ISYS in the appropriate units, mg/L. (F10.0)
DISSF $=$ dissolved fraction of chemical in segment K. (F10.0)

\section{Record 2 is repeated NOSEG/3 times.}

Records 1 and 2 are a set and will be repeated NOSYS times. Within each NOSYS set, Record 2 will use as many 80 -space lines as needed to input NOSEG entries. Three entries (ANAME-C-DISSF) will fit on one line. After NOSEG entries have been entered in a NOSYS set, begin the next NOSYS set on the following line. For STREAM2, NOSYS is 2. 
(Blank Page) 
Appendix 2 Input File for Release from H-Outfall to Fourmile Branch (HH.inp)

Release From H-outfall to $4 \mathrm{MB}$

USING ACE MILES AND FLOW AT AUGUSTA (SOLID), detailed $4 \mathrm{~m}$ flw, $4 \mathrm{mb}$ seg=150m NSEG NSYS ICRD DMPF JMAS NSLN INTY ADFC DD HFMM TRAN A:MODEL OPTIONS

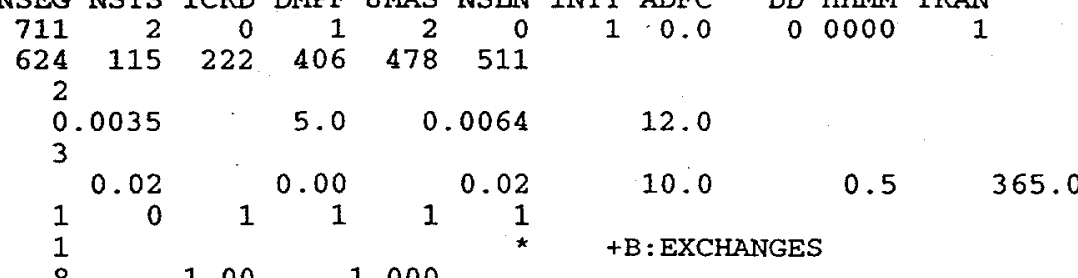

551

277.966

277.966

277.966

277.966

277.966

277.966

277.966

277.966

277.966

277.966

277.966

277.966

277.966

277.966

277.966

277.966

277.966

277.966

277.966

277.966

277.966

277.966

277.966

277.966

277.966

277.966

277.966

277.966

277.966

277.966

277.966

277.966

277.966

277.966

277.966

277.966

277.966

277.966

277.966

277.966

277.966

277.966

277.966

277.966

277.966

277.966

277.966

277.966

277.966

277.966

277.966

277.966

277.966

277.966

277.966

277.966

277.966

277.966

277.966

277.966

277.966

277.966

277.966

$\begin{array}{rrr}250.0 & 0 & 1 \\ 500.0 & 1 & 2 \\ 500.0 & 2 & 3 \\ 500.0 & 3 & 4 \\ 500.0 & 4 & 5 \\ 500.0 & 5 & 6 \\ 500.0 & 6 & 7 \\ 500.0 & 7 & 8 \\ 500.0 & 8 & 9 \\ 500.0 & 9 & 10 \\ 500.0 & 10 & 11 \\ 500.0 & 11 & 12 \\ 500.0 & 12 & 13 \\ 500.0 & 13 & 14 \\ 500.0 & 14 & 15 \\ 500.0 & 15 & 16 \\ 500.0 & 16 & 17 \\ 500.0 & 17 & 18 \\ 500.0 & 18 & 19 \\ 500.0 & 19 & 20 \\ 500.0 & 20 & 21 \\ 500.0 & 21 & 22 \\ 500.0 & 22 & 23 \\ 500.0 & 23 & 24 \\ 500.0 & 24 & 25 \\ 500.0 & 25 & 26 \\ 500.0 & 26 & 27 \\ 500.0 & 27 & 28 \\ 500.0 & 28 & 29 \\ 500.0 & 29 & 30 \\ 500.0 & 30 & 31 \\ 500.0 & 31 & 32 \\ 500.0 & 32 & 33 \\ 500.0 & 33 & 34 \\ 500.0 & 34 & 35 \\ 500.0 & 35 & 36 \\ 500.0 & 36 & 37 \\ 500.0 & 37 & 38 \\ 500.0 & 38 & 39 \\ 500.0 & 39 & 40 \\ 500.0 & 40 & 41 \\ 500.0 & 41 & 42 \\ 500.0 & 42 & 43 \\ 500.0 & 43 & 44 \\ 500.0 & 44 & 45 \\ 500.0 & 45 & 46 \\ 500.0 & 46 & 47 \\ 500.0 & 47 & 48 \\ 500.0 & 48 & 49 \\ 500.0 & 49 & 50 \\ 500.0 & 50 & 51 \\ 500.0 & 51 & 52 \\ 500.0 & 52 & 53 \\ 500.0 & 53 & 54 \\ 500.0 & 54 & 55 \\ 500.0 & 55 & 56 \\ 500.0 & 56 & 57 \\ 500.0 & 57 & 58 \\ 500.0 & 58 & 59 \\ 500.0 & 59 & 60 \\ 500.0 & 60 & 61 \\ 500.0 & 61 & 62 \\ 500.0 & 62 & 63\end{array}$




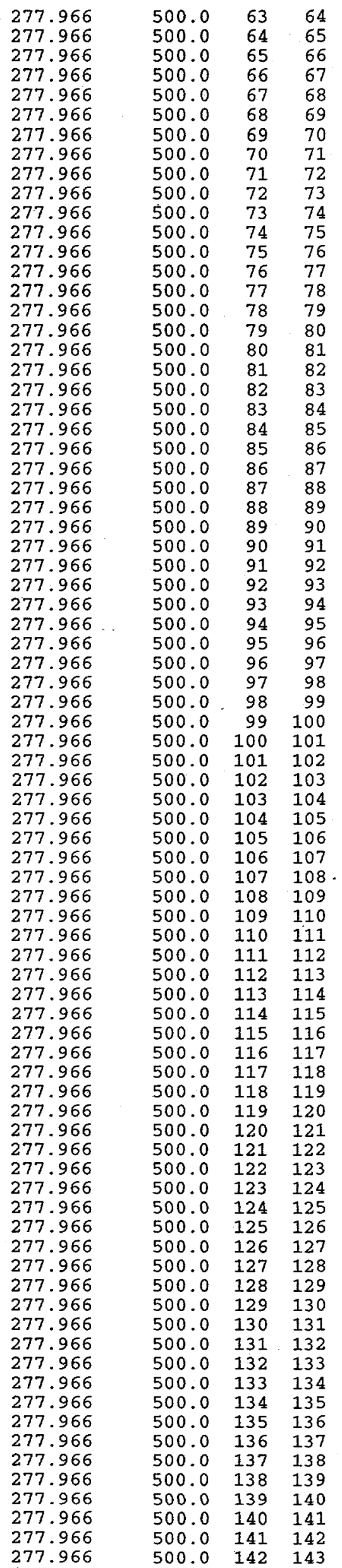




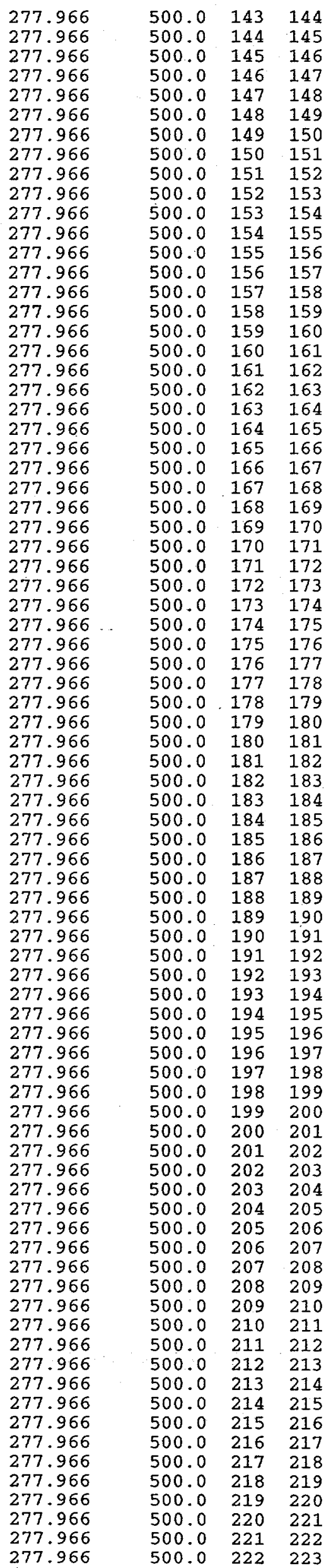




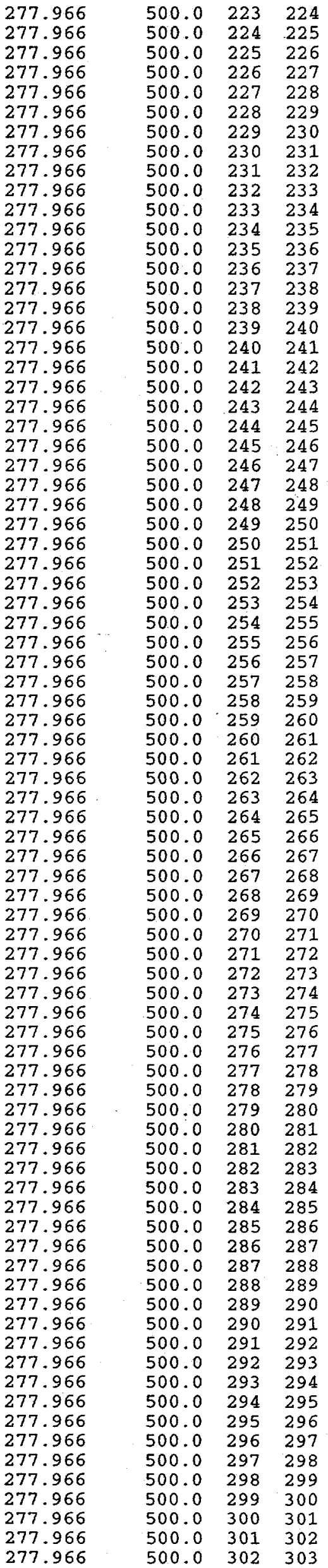




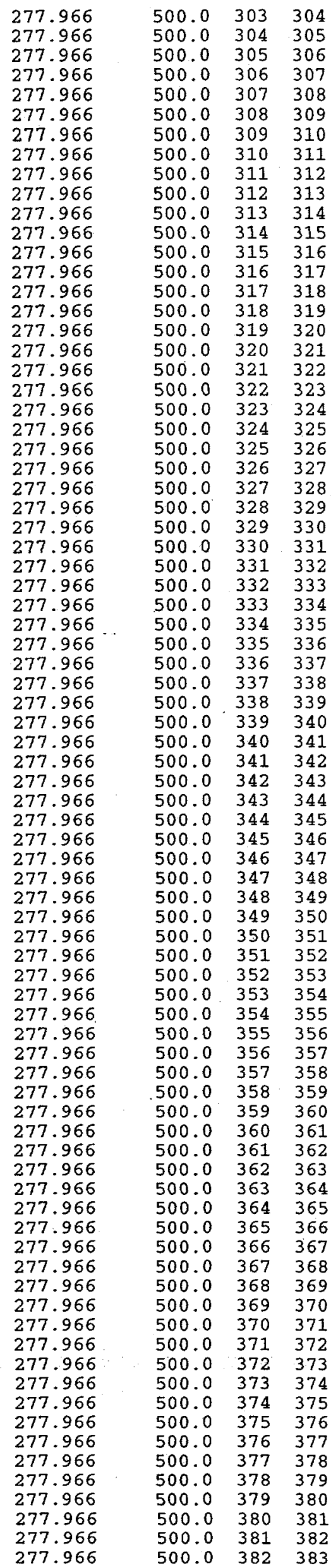


WSRC-TR-98-00234

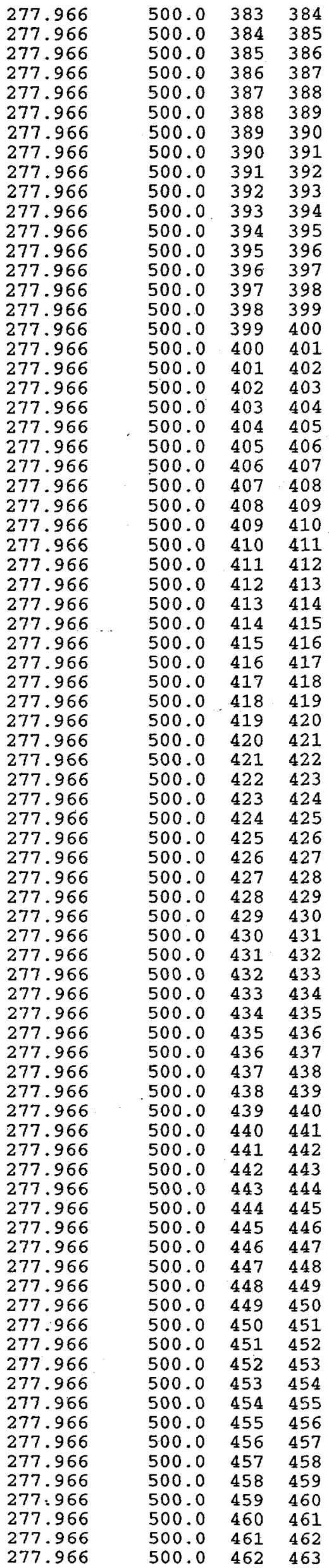


277.966

277.966

277.966

277.966

277.966

277.966

277.966

277.966

277.966

277.966

277.966

277.966

277.966

277.966

277.966

277.966

277.966

277.966

277.966

277.966

277.966

277.966

277.966

277.966

277.966

277.966

277.966

277.966

277.966

277.966

277.966

277.966

277.966

277.966

277.966

277.966

277.966

277.966

277.966

277.966

277.966

277.966

277.966

277.966

277.966

277.966

277.966

277.966

277.966

277.966

277.966

277.966

277.966

277.966

277.966

277.966

277.966

277.966

277.966

277.966

277.966

277.966

277.966

277.966

277.966

277.966

277.966

277.966

277.966

277.966

277.966

277.966

277.966

277.966

277.966

277.966

277.966

277.966

277.966

$500.0 \quad 463 \quad 464$

$500.0 \quad 464 \quad 465$

$500.0 \quad 465 \quad 466$

$500.0 \quad 466 \quad 467$

$500.0 \quad 467 \quad 468$

$500.0 \quad 468 \quad 469$

$500.0 \quad 469 \quad 470$

$500.0 \quad 470 \quad 471$

$500.0 \quad 471 \quad 472$

$500.0 \quad 472 \quad 473$

$500.0 \quad 473 \quad 474$

$500.0 \quad 474 \quad 475$

$500.0 \quad 475 \quad 476$

$500.0 \quad 476 \quad 477$

$500.0 \quad 477 \quad 478$

$500.0 \quad 478 \quad 479$

$500.0 \quad 479 \quad 480$

$500.0 \quad 480 \quad 481$

$\begin{array}{llll}500.0 & 481 & 482\end{array}$

$500.0 \quad 482 \quad 483$

$500.0 \quad 483 \quad 484$

$500.0 \quad 484 \quad 485$

$500.0 \quad 485 \quad 486$

$500.0 \quad 486 \quad 487$

$500.0 \quad 487 \quad 488$

$500.0 \quad 488 \quad 489$

$500.0 \quad 489 \quad 490$

$500.0 \quad 490 \quad 491$

$500.0 \quad 491 \quad 492$

$500.0 \quad 492 \quad 493$

$500.0 \quad 493 \quad 494$

$500.0 \quad 494 \quad 495$

$500.0 \quad 495 \quad 496$

$500.0 \quad 496 \quad 497$

$500.0 \quad 497 \quad 498$

$500.0 \quad 498 \quad 499$

$500.0 \quad 499 \quad 500$

$500.0 \quad 500 \quad 501$

$500.0 \quad 501 \quad 502$

$500.0 \quad 502 \quad 503$

$500.0 \quad 503 \quad 504$

$500.0 \quad 504 \quad 505$

$500.0 \quad 505 \quad 506$

$500.0 \quad 506 \quad 507$

$500.0 \quad 507 \quad 508$

$500.0 \quad 508 \quad 509$

$500.0 \quad 509 \quad 510$

$500.0 \quad 510 \quad 511$

$500.0 \quad 511 \quad 512$

$500.0 \quad 512 \quad 513$

$500.0 \quad 513 \quad 514$

$500.0 \quad 514 \quad 515$

$500.0 \quad 515 \quad 516$

$500.0 \quad 516 \quad 517$

$500.0 \quad 517 \quad 518$

$500.0 \quad 518 \quad 519$

$500.0 \quad 519 \quad 520$

$500.0 \quad 520 \quad 521$

$500.0 \quad 521 \quad 522$

$500.0 \quad 522 \quad 523$

$500.0 \quad 523 \quad 524$

$500.0 \quad 524 \quad 525$

$500.0 \quad 525 \quad 526$

$500.0 \quad 526 \quad 527$

$500.0 \quad 527 \quad 528$

$\begin{array}{lll}500.0 & 528 & 529\end{array}$

$500.0 \quad 529 \quad 530$

$500.0 \quad 530 \quad 531$

$500.0 \quad 531 \quad 532$

$500.0 \quad 532 \quad 533$

$500.0 \quad 533 \quad 534$

$500.0 \quad 534 \quad 535$

$500.0 \quad 535 \quad 536$

$500.0 \quad 536 \quad 537$

$500.0 \quad 537 \quad 538$

$500.0 \quad 538 \quad 539$

$500.0 \quad 539 \quad 540$

$500.0 \quad 540 \quad 541$

$500.0 \quad 541 \quad 542$

$500.0 \quad 542 \quad 543$ 
277.966

277.966

277.966

277.966

277.966

277.966

277.966

277.966

2

11

15.0

4.50000

4.50000

4.50000

4.50000

4.50000

4.50000

4.50000

4.50000

4.50000

4.50000

4.50000

$$
2
$$

19

$$
0.0
$$

4.50000

4.50000

4.50000

4.50000

4. 50000

4.50000

4.50000

4.50000

4.50000

4.50000

4.50000

4.50000

4.50000

4. 50000

4.50000

4.50000

4.50000

4.50000

4.50000

2

$$
0.0
$$

14

4.50000

4.50000

4.50000

4.50000

4. 50000

4.50000

4.50000

4.50000

4. 50000

4.50000

4.50000

4.50000

4. 50000

4.50000$$
0.0
$$

20

4. 50000

4.50000

4.50000

4.50000

4.50000

4.50000

4.50000

4.50000

4.50000

4.50000

4.50000

4.50000

4.50000

4.50000

4.50000

4.50000
$500.0 \quad 543 \quad 544$

$500.0 \quad 544 \quad 545$

$500.0 \quad 545 \quad 546$

$500.0 \quad 546 \quad 547$

$\begin{array}{lll}500.0 & 547 \quad 548\end{array}$

$500.0 \quad 548 \quad 549$

$500.0 \quad 549 \quad 550$

$250.0 \quad 550$. 0

0. $\quad 15.0$

365.0

$75.0 \quad 0 \quad 551$

$150.0 \quad 551 \quad 552$

$150.0 \quad 552 \quad 553$

$150.0 \quad 553 \quad 554$

$150.0 \quad 554 \quad 555$

$150.0 \quad 555 \quad 556$

$150.0 \quad 556 \quad 557$

$150.0 \quad 557 \quad 558$

$150.0 \quad 558 \quad 559$

$150.0 \quad 559 \quad 560$

$150.0 \quad 560 \quad 561$

0.0

365.0

$150.0 \quad 561 \quad 562$

$150.0 \quad 562 \quad 563$

$150.0 \quad 563 \quad 564$

$150.0 \quad 564 \quad 565$

$150.0 \quad 565 \quad 566$

$150.0 \quad 566 \quad 567$

$150.0 \quad 567 \quad 568$

$150.0 \quad 568 \quad 569$

$150.0 \quad 569 \quad 570$

$150.0 \quad 570 \quad 571$

$150.0 \quad 571 \quad 572$

$150.0 \quad 572 \quad 573$

$150.0 \quad 573 \quad 574$

$150.0 \quad 574 \quad 575$

$150.0 \quad 575 \quad 576$

$150.0 \quad 576 \quad 577$

$\begin{array}{lll}150.0 & 577 & 578\end{array}$

$\begin{array}{lll}150.0 & 578 & 579\end{array}$

$150.0 \quad 579 \quad 580$

\section{0 .}

0.0

365.0

$150.0 \quad 580 \quad 581$

$\begin{array}{lll}150.0 & 581 & 582\end{array}$

$150.0 \quad 582 \quad 583$

$150.0 \quad 583 \quad 584$

$150.0 \quad 584 \quad 585$

$150.0 \quad 585 \quad 586$

$150.0 \quad 586 \quad 587$

$150.0 \quad 587 \quad 588$

$150.0 \quad 588 \quad 589$

$150.0 \quad 589 \quad 590$

$150.0 \quad 590 \quad 591$

$150.0 \quad 591 \quad 592$

$150.0 \quad 592 \quad 593$

$150.0 \quad 593 \quad 594$

0. $\quad 0.0$

365.0

$150.0 \quad 594 \quad 595$

$150.0 \quad 595 \quad 596$

$150.0 \quad 596 \quad 597$

$\begin{array}{lll}150.0 & 597 & 598\end{array}$

$150.0 \quad 598 \quad 599$

$150.0 \quad 599600$

$150.0 \quad 600 \quad 601$

$150.0 \quad 601 \quad 602$

$150.0 \quad 602 \quad 603$

$150.0 \quad 603 \quad 604$

$150.0 \quad 604 \quad 605$

150.0605606

$150.0 \quad 606 \quad 607$

$\begin{array}{lll}150.0 & 607 & 608\end{array}$

$150.0 \quad 608 \quad 609$

$150.0 \quad 609 \quad 610$ 


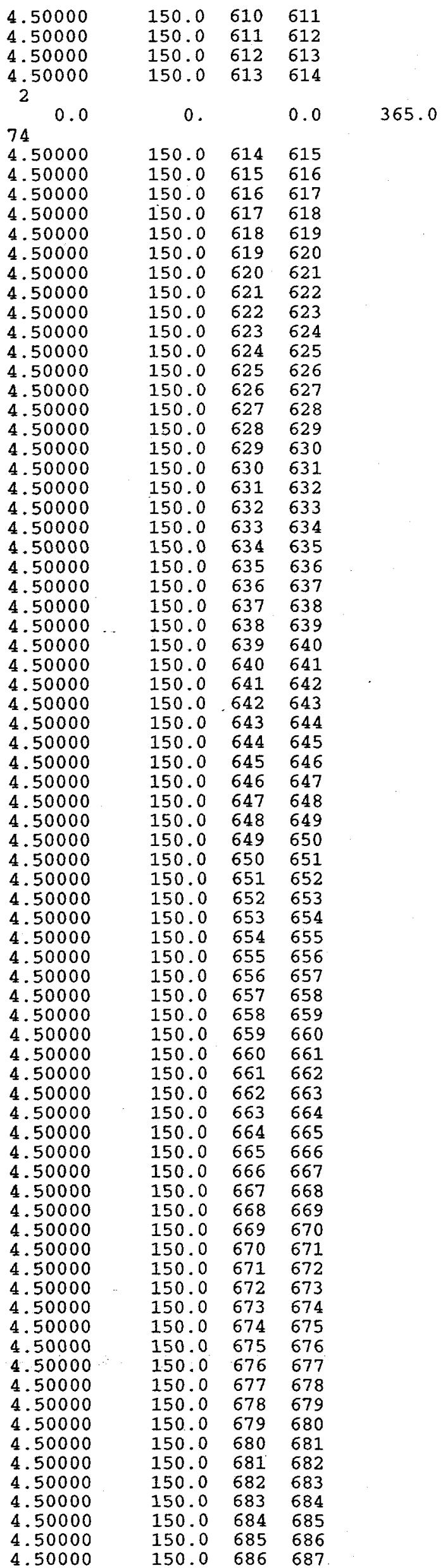




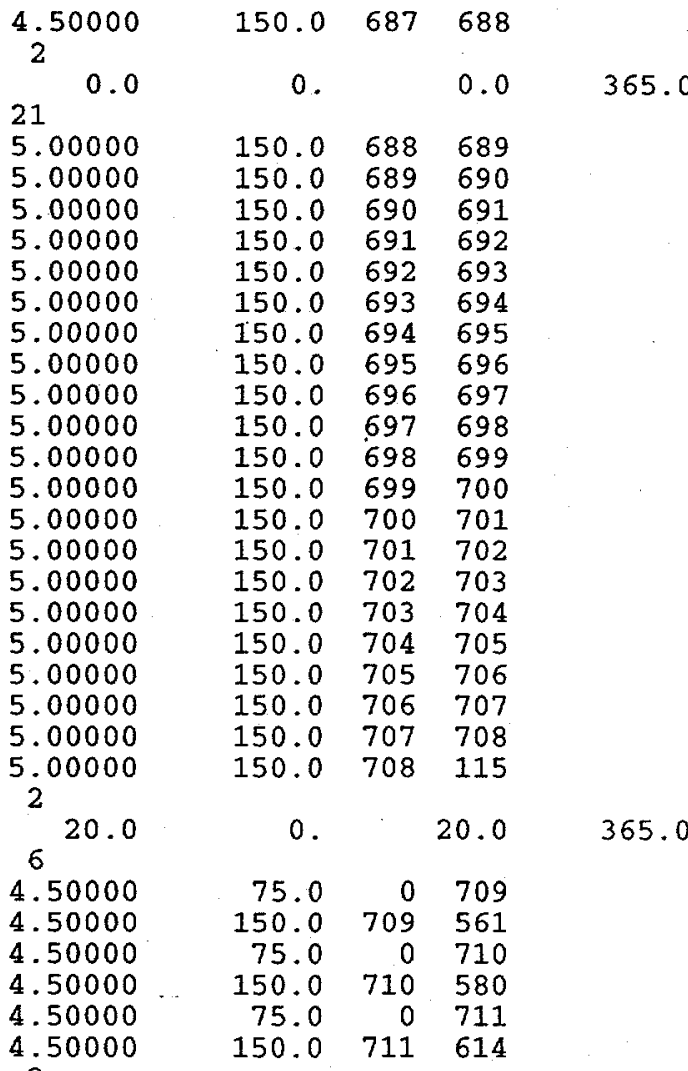

10

1.000

$\frac{1}{2}$

3
0 .

1.20
1.00

$\begin{array}{lll}0 & 1 & 138983.00\end{array}$

1138983.00

1138983.00

1138983.00

1138983.00

1138983.00

1138983.00

1138983.00

1138983.00

1138983.00

1138983.00

1138983.00

1138983.00

1138983.00

1138983.00

1138983.00

1138983.00

1138983.00

1138983.00

1.138983 .00

1138983.00

1138983.00

1138983.00

1138983.00

1138983.00

1138983.00

1138983.00

1138983.00

1138983.00

1138983.00

1138983.00

1138983.00

1138983.00

1138983.00

1138983.00

1138983.00

1138983.00

1138983.00

1138983.00

1138983.00

1138983.00

$\begin{array}{ll}0.054 & 0.43 \\ 0.054 & 0.43 \\ 0.054 & 0.43 \\ 0.054 & 0.43 \\ 0.054 & 0.43 \\ 0.054 & 0.43 \\ 0.054 & 0.43 \\ 0.054 & 0.43 \\ 0.054 & 0.43 \\ 0.054 & 0.43 \\ 0.054 & 0.43 \\ 0.054 & 0.43 \\ 0.054 & 0.43 \\ 0.054 & 0.43 \\ 0.054 & 0.43 \\ 0.054 & 0.43 \\ 0.054 & 0.43 \\ 0.054 & 0.43 \\ 0.054 & 0.43 \\ 0.054 & 0.43 \\ 0.054 & 0.43 \\ 0.054 & 0.43 \\ 0.054 & 0.43 \\ 0.054 & 0.43 \\ 0.054 & 0.43 \\ 0.054 & 0.43 \\ 0.054 & 0.43 \\ 0.054 & 0.43 \\ 0.054 & 0.43 \\ 0.054 & 0.43 \\ 0.054 & 0.43 \\ 0.054 & 0.43 \\ 0.054 & 0.43 \\ 0.054 & 0.43 \\ 0.054 & 0.43 \\ 0.054 & 0.43 \\ 0.054 & 0.43 \\ 0.054 & 0.43 \\ 0.054 & 0.43 \\ 0.054 & 0.43 \\ 0.054 & 0.43\end{array}$

C:VOLUMES

0.4497

0.4497

0.4497

0.4497

0.4497

0.4497

0.4497

0.4497

0.4497

0.4497

0.4497

0.4497

0.4497

0.4497

0.4497

0.4497

0.4497

0.4497

0.4497

0.4497

0.4497

0.4497

0.4497

0.4497

0.4497

0.4497

0.4497

0.4497

0.4497

0.4497

0.4497

0.4497

0.4497

0.4497

0.4497

0.4497

0.4497

0.4497

0.4497

0.4497

0.4497
0.45

0.45

0.45

0.45

0.45

0.45

0.45

0.45

0.45

0.45

0.45

0.45

0.45

0.45

0.45

0.45

0.45

0.45

0.45

0.45

0.45

0.45

0.45

0.45

0.45

0.45

0.45

0.45

0.45

0.45

0.45

0.45

0.45

0.45

0.45

0.45

0.45

0.45

0.45

0.45

0.45 


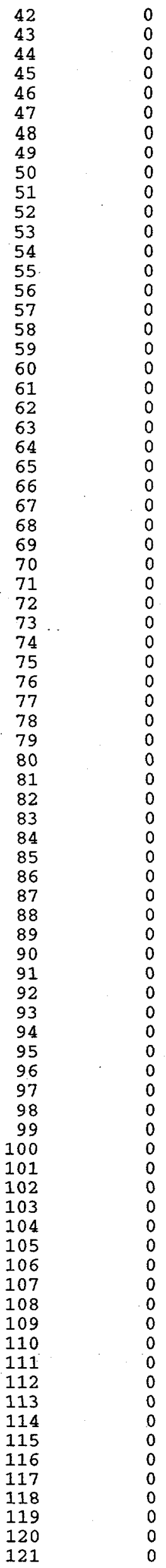

1138983.00

1138983.00

1138983.00

1138983.00

1138983.00

1138983.00

1138983.00

1138983.00

1138983.00

1138983.00

1138983.00

1138983.00

1138983.00

1138983.00

1138983.00

1138983.00

1138983.00

1138983.00

1138983.00

1138983.00

1138983.00

1138983.00

1138983.00

1138983.00

1138983.00

1138983.00

1138983.00

1138983.00

1138983.00

1138983.00

1138983.00

1138983.00

1138983.00

1138983.00

1138983.00

1138983.00

1138983.00

1138983.00

1138983.00

1138983.00

1138983.00

1138983.00

1138983.00

1138983.00

1138983.00

1138983.00

1138983.00

1138983.00

1138983.00

1138983.00

1138983.00

1138983.00

1138983.00

1138983.00

1138983.00

1138983.00

1138983.00

1138983.00

1138983.00

1138983.00

1138983.00

1138983.00

1138983.00

1138983.00

1138983.00

I 138983.00

1138983.00

1138983.00

1138983.00

1138983.00

1138983.00

1138983.00

1138983.00

1138983.00

1138983.00

1138983.00

1138983.00

1138983.00

1138983.00

1138983.00

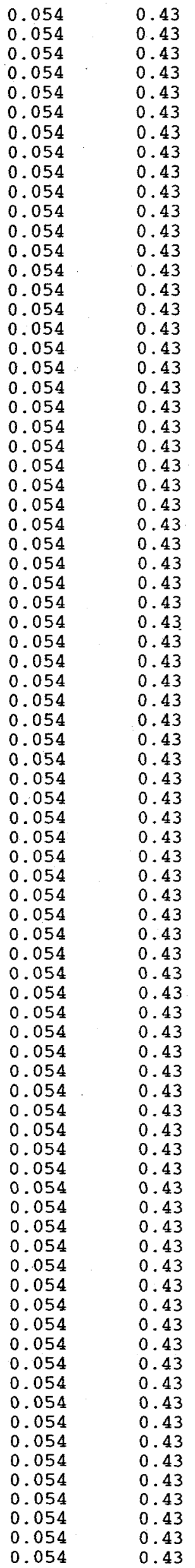

0.4497

0.4497

0.4497

0.4497

0.4497

0.4497

0.4497

0.4497

0.4497

0.4497

0.4497

0.4497

0.4497

0.4497

0.4497

0.4497

0.4497

0.4497

0.4497

0.4497

0.4497

0.4497

0.4497

0.4497

0.4497

0.4497

0.4497

0.4497

0.4497

0.4497

0.4497

0.4497

0.4497

0.4497

0.4497

0.4497

0.4497

0.4497

0.4497

0.4497

0.4497

0.4497

0.4497

0.4497

0.4497

0.4497

0.4497

0.4497

0.4497

0.4497

0.4497

0.4497

0.4497

0.4497

0.4497

0.4497

0.4497

0.4497

0.4497

0.4497

0.4497

0.4497

0.4497

0.4497

0.4497

0.4497

0.4497

0.4497

0.4497

0.4497

0.4497

0.4497

0.4497

0.4497

0.4497

0.4497

0.4497

0.4497

0.4497

0.4497
0.45

0.45 .

0.45

0.45

0.45

0.45

0.45

0.45

0.45

0.45

0.45

0.45

0.45

0.45

0.45

0.45

0.45

0.45

0.45

0.45

0.45

0.45

0.45

0.45

0.45

0.45

0.45

0.45

0.45

0.45

0.45

0.45

0.45

0.45

0.45

0.45

0.45

0.45

0.45

0.45

0.45

0.45

0.45

0.45

0.45

0.45

0.45

0.45

0.45

0.45

0.45

0.45

0.45

0.45

0.45

0.45

0.45

0.45

0.45

0.45

0.45

0.45

0.45

0.45

0.45

0.45

0.45

0.45

0.45

0.45

0.45

0.45

0.45

0.45

0.45

0.45

0.45

0.45

0.45

0.45 


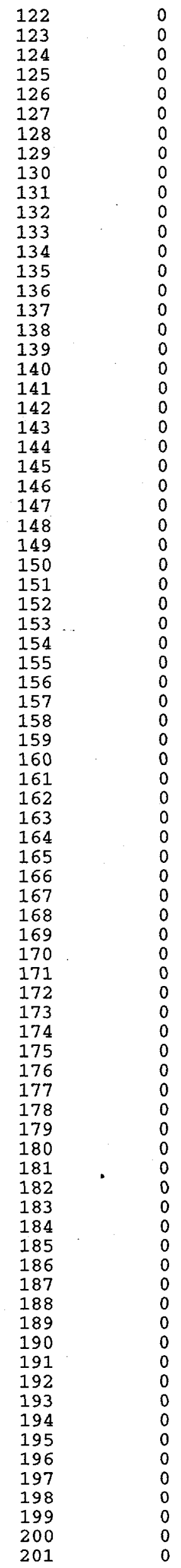

1138983.00

1138983.00

1138983.00

1138983.00

1138983.00

1138983.00

1138983.00

1138983.00

1138983.00

1138983.00

1138983.00

1138983.00

1138983.00

1138983.00

1138983.00

1138983.00

1138983.00

1138983.00

1138983.00

1138983.00

1138983.00

1138983.00

1.138983 .00

1138983.00

1138983.00

1138983.00

1138983.00

1138983.00

1138983.00

1138983.00

1138983.00

1138983.00

1138983.00

1138983.00

I 138983.00

I 138983.00

1138983.00

1138983.00

1138983.00

1138983.00

1138983.00

1138983.00

1138983.00

1138983.00

1138983.00

1138983.00

1138983.00

1138983.00

1138983.00

1138983.00

1138983.00

1138983.00

1138983.00

1138983.00

1138983.00

1138983.00

1138983.00

1138983.00

1138983.00

1138983.00

1138983.00

1138983.00

1138983.00

1138983.00

1138983.00

1138983.00

1138983.00

1138983.00

1138983.00

1138983.00

1138983.00

1138983.00

1138983.00

1138983.00

1138983.00

1138983.00

1138983.00

1138983.00

1138983.00

1138983.00
0.054

0.054

0.054

0.054

0.054

0.054

0.054

0.054

0.054

0.054

0.054

0.054

0.054

0.054

0.054

0.054

0.054

0.054

0.054

0.054

0.054

0.054

0.054

0.054

0.054

0.054

0.054

0.054

0.054

0.054

0.054

0.054

0.054

0.054

0.054

0.054

0.054

0.054

0.054

0.054

0.054

0.054

0.054

* 0.054

0.054

0.054

0.054

0.054

0.054

0.054

0.054

0.054

0.054

0.054

0.054

0.054

0.054

0.054

0.054

0.054

0.054

0.054

0.054

0.054

0.054

0.054

0.054

0.054

0.054

0.054

0.054

0.054

0.054

0.054

0.054

0.054

0.054

0.054

0.054

0.054
0.43

0.43

0.43

0.43

0.43

0.43

0.43

0.43

0.43

0.43

0.43

0.43

0.43

0.43

0.43

0.43

0.43

0.43

0.43

0.43

0.43

0.43

0.43

0.43

0.43

0.43

0.43

0.43

0.43

0.43

0.43

0.43

0.43

0.43

0.43

0.43

0.43

0.43

0.43

0.43

0.43

0.43

0.43

0.43

0.43

0.43

0.43

0.43

0.43

0.43

0.43

0.43

0.43

0.43

0.43

0.43

0.43

0.43

0.43

0.43

0.43

0.43

0.43

0.43

0.43

0.43

0.43

0.43

0.43

0.43

0.43

$0.4: 3$

0.43

0.43

0.43

0.43

0.43

0.43

0.43

0.43

0.4497

0.4497

0.4497

0.4497

0.4497

0.4497

0.4497

0.4497

0.4497

0.4497

0.4497

0.4497

0.4497

0.4497

0.4497

0.4497

0.4497

0.4497

0.4497

0.4497

0.4497

0.4497

0.4497

0.4497

0.4497

0.4497

0.4497

0.4497

0.4497

0.4497

0.4497

0.4497

0.4497

0.4497

0.4497

0.4497

0.4497

0.4497

0.4497

0.4497

0.4497

0.4497

0.4497

0.4497

0.4497

0.4497

0.4497

0.4497

0.4497 


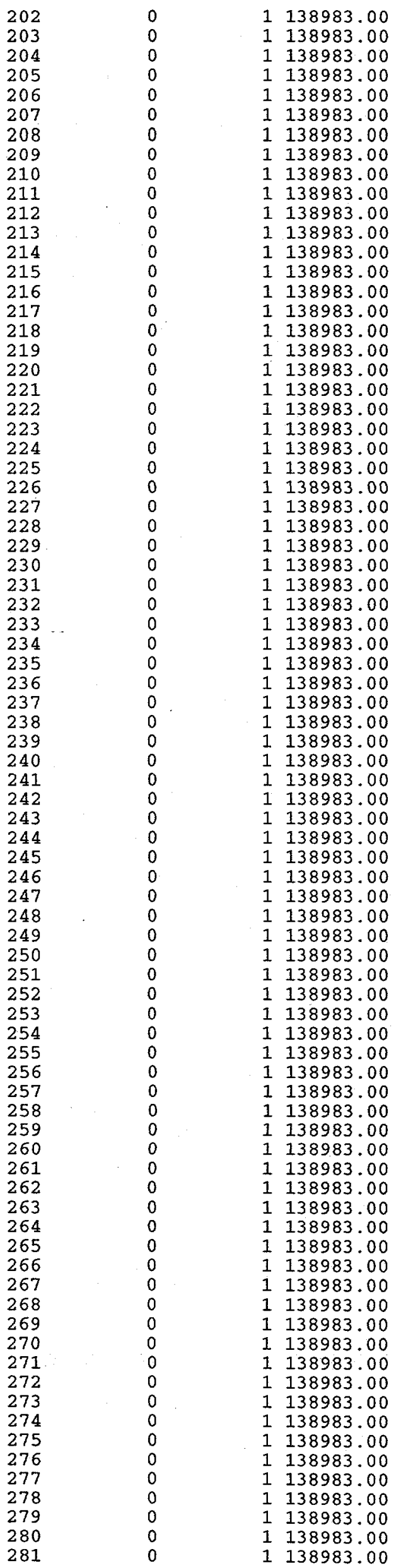

\begin{tabular}{|c|c|}
\hline 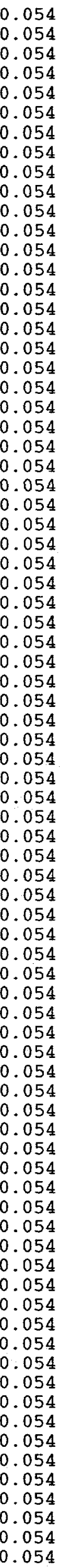 & 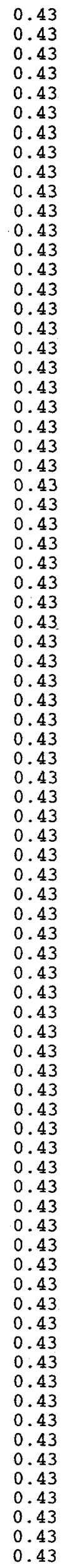 \\
\hline
\end{tabular}

0.4497

0.4497

0.4497

0.4497

0.4497

0.4497

0.4497

0.4497

0.4497

0.4497

0.4497

0.4497

0.4497

0.4497

0.4497

0.4497

0.4497

0.4497

0.4497

0.4497

0.4497

0.4497

0.4497

0.4497

0.4497

0.4497

0.4497

0.4497

0.4497

0.4497

0.4497

0.4497

0.4497

0.4497

0.4497

0.4497

0.4497

0.4497

0.4497

0.4497

0.4497

0.4497

0.4497

0.4497

0.4497

0.4497

0.4497

0.4497

0.4497

0.4497

0.4497

0.4497

0.4497

0.4497

0.4497

0.4497

0.4497

0.4497

0.4497

0.4497

0.4497

0.4497

0.4497

0.4497

0.4497

0.4497

0.4497

0.4497

0.4497

0.4497

0.4497

0.4497

0.4497

0.4497

0.4497

0.4497

0.4497

0.4497

0.4497

0.4497
0.45

0.45

0.45

0.45

0.45

0.45

0.45

0.45

0.45

0.45

0.45

0.45

0.45

0.45

0.45

0.45

0.45

0.45

0.45

0.45

0.45

0.45

0.45

0.45

0.45

0.45

0.45

0.45

0.45

0.45

0.45

0.45

0.45

0.45

0.45

0.45

0.45

0.45

0.45

0.45

0.45

0.45

0.45

0.45

0.45

0.45

0.45

0.45

0.45

0.45

0.45

0.45

0.45

0.45

0.45

0.45

0.45

0.45 .

0.45

0.45

0.45

0.45

0.45

0.45

0.45

0.45

0.45

0.45

0.45

0.45

0.45

0.45

0.45

0.45

0.45

0.45

0.45

0.45

0.45

0.45 


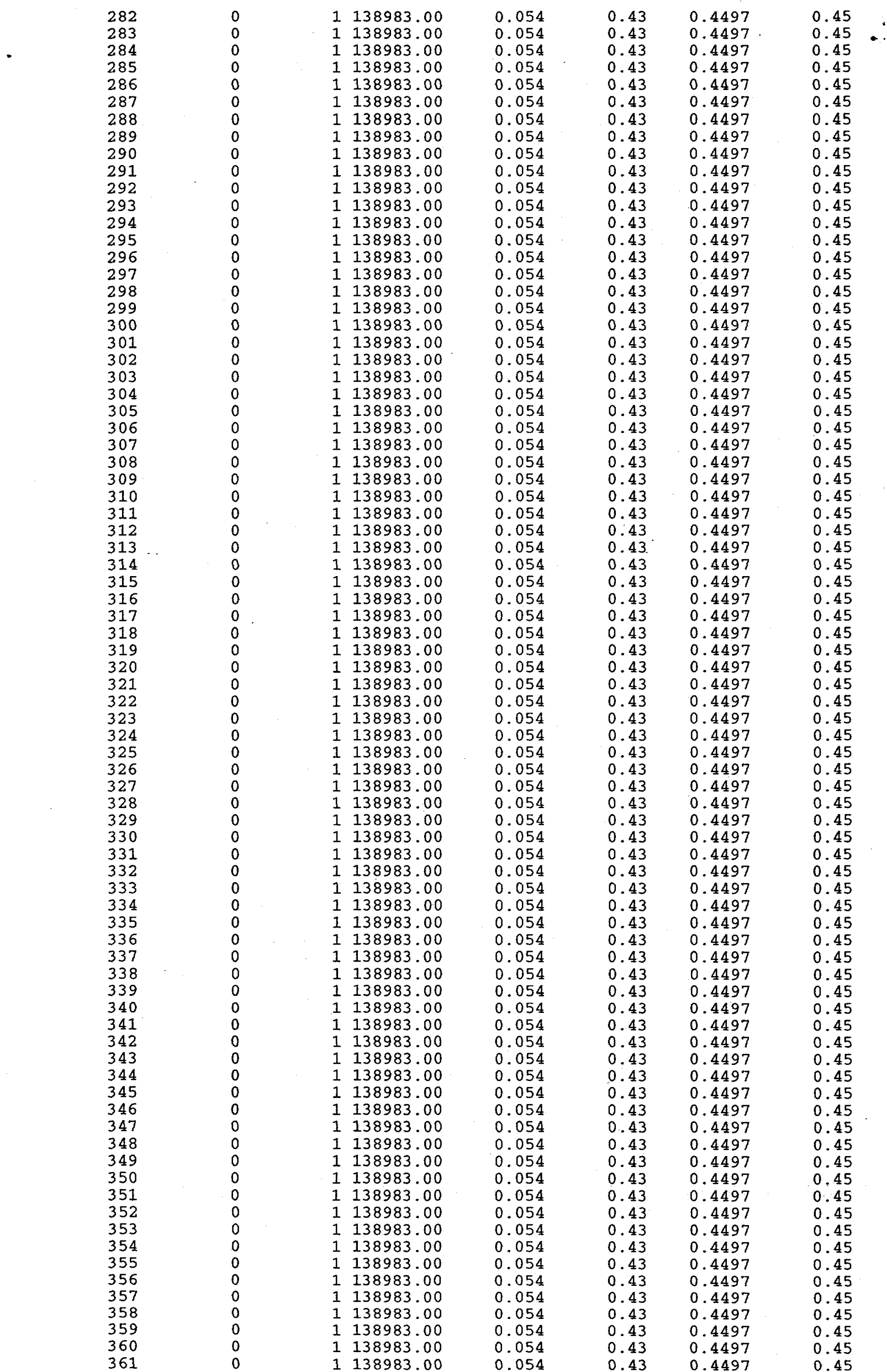




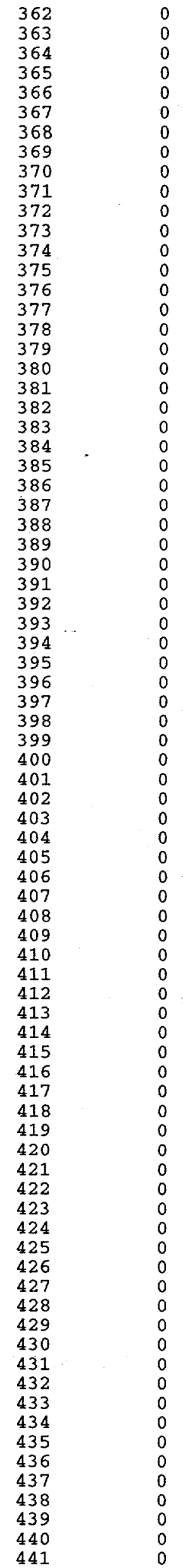

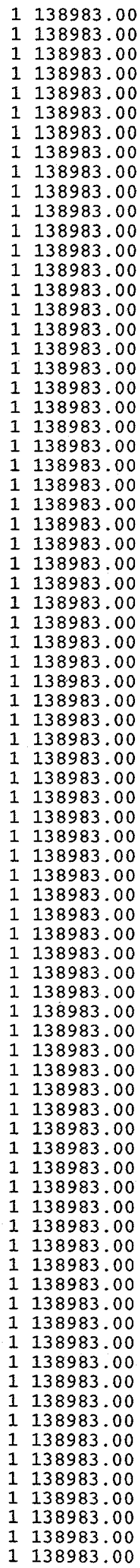

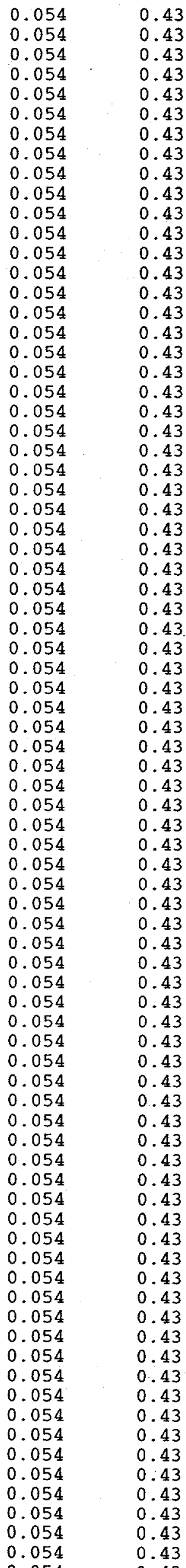

0.4497

0.4497

0.4497

0.4497

0.4497

0.4497

0.4497

0.4497

0.4497

0.4497

0.4497

0.4497

0.4497

0.4497

0.4497

0.4497

0.4497

0.4497

0.4497

0.4497

0.4497

0.4497

0.4497

0.4497

0.4497

0.4497

0.4497

0.4497

0.4497

0.4497

0.4497

0.4497

0.4497

0.4497

0.4497

0.4497

0.4497

0.4497

0.4497

0.4497

0.4497

0.4497

0.4497

0.4497

0.4497

0.4497

0.4497

0.4497

0.4497

0.4497

0.4497

0.4497

0.4497

0.4497

0.4497

0.4497

0.4497

0.4497

0.4497

0.4497

0.4497

0.4497

0.4497

0.4497

0.4497

0.4497

0.4497

0.4497

0.4497

0.4497

0.4497

0.4497

0.4497

0.4497

0.4497

0.4497

0.4497

0.4497

0.4497

0.4497
0.45

0.45

0.45

0.45

0.45

0.45

0.45

0.45

0.45

0.45

0.45

0.45

0.45

0.45

0.45

0.45

0.45

0.45

0.45

0.45

0.45

0.45

.0 .45

0.45

0.45

0.45

0.45

0.45

0.45

0.45

0.45

0.45

0.45

0.45

0.45

0.45

0.45

0.45

0.45

0.45

0.45

0.45

0.45

0.45

0.45

0.45

0.45

0.45

0.45

0.45

0.45

0.45

0.45

0.45

0.45

0.45

0.45

0.45

0.45

0.45

0.45

0.45

0.45

0.45

0.45

0.45

0.45

0.45

0.45

0.45

0.45

0.45

0.45

0.45

0.45

0.45

0.45

0.45

0.45

0.45 


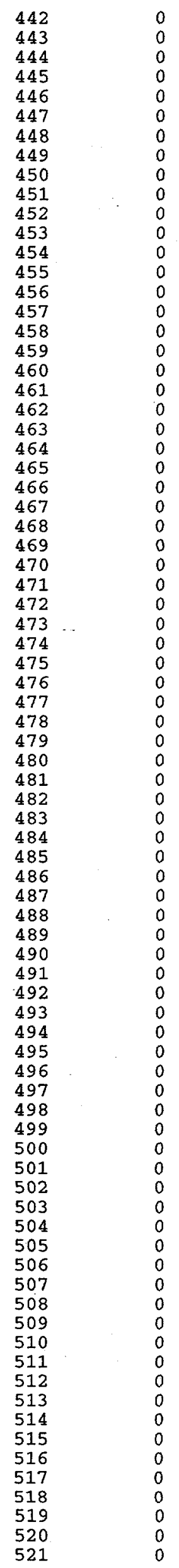

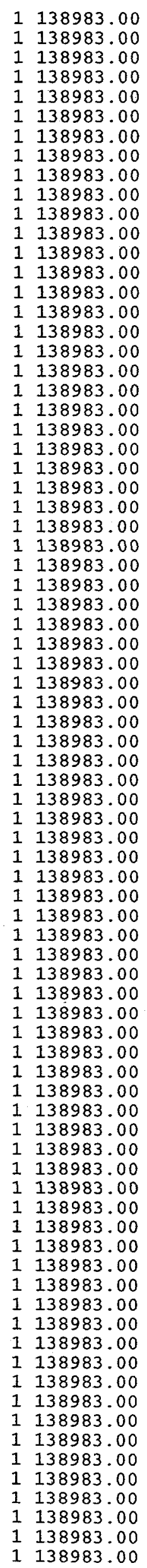

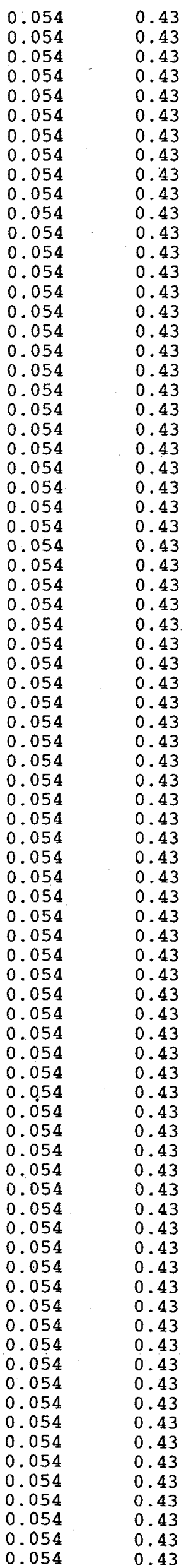

0.4497

0.4497
0.4497

0.4497

0.4497

0.4497

0.4497

0.4497

0.4497

0.4497

0.4497

0.4497

0.4497

0.4497

0.4497

0.4497

0.4497

0.4497

0.4497

0.4497

0.4497

0.4497

0.4497

0.4497

0.4497

0.4497

0.4497

0.4497

0.4497

0.4497

0.4497

0.4497

0.4497

0.4497

0.4497

0.4497

0.4497

0.4497

0.4497

0.4497

0.4497

0.4497

0.4497

0.4497

0.4497

0.4497

0.4497

0.4497

0.4497

0.4497

0.4497

0.4497

0.4497

0.4497

0.4497

0.4497

0.4497

0.4497

0.4497

0.4497

0.4497

0.4497

0.4497

0.4497

0.4497

0.4497

0.4497

0.4497

0.4497

0.4497

0.4497

0.4497

0.4497

0.4497

0.4497

0.4497

0.4497

0.4497

0.4497

0.4497
0.45

0.45

0.45

0.45

0.45

0.45

0.45

0.45

0.45

0.45

0.45

0.45

0.45

0.45

0.45

0.45

0.45

0.45

0.45

0.45

0.45

0.45

0.45

0.45

0.45

0.45

0.45

0.45

0.45

0.45

0.45

0.45

0.45

0.45

0.45

0.45

0.45

0.45

0.45

0.45

0.45

0.45

0.45

0.45

0.45

0.45

0.45

0.45

0.45

0.45

0.45

0.45

0.45

0.45

0.45

0.45

0.45

0.45

0.45

0.45

0.45

0.45

0.45

0.45

0.45

0.45

0.45

0.45

0.45

0.45

0.45

0.45

0.45

0.45

0.45

0.45

0.45

0.45

0.45 


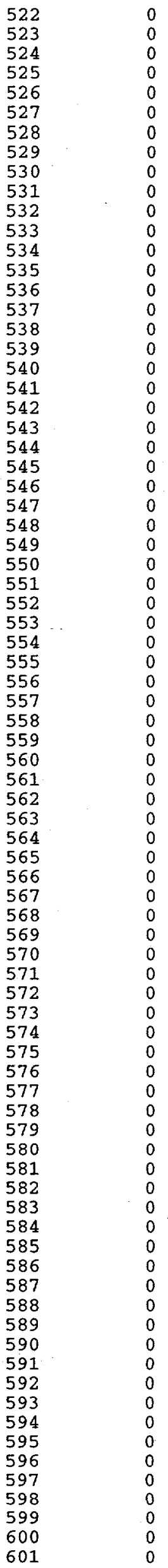

1138983.00

1138983.00

1138983.00

1138983.00

1138983.00

1138983.00

1138983.00

1138983.00

1138983.00

1138983.00

1138983.00

1138983.00

1138983.00

1138983.00

1138983.00

1138983.00

1138983.00

1138983.00

1138983.00

1138983.00

1138983.00

1138983.00

1138983.00

1138983.00

1138983.00

1138983.00

1138983.00

1138983.00

1138983.00

1675.00000

1675.00000

1675.00000

1675.00000

1675.00000

1675.00000

1675.00000

1675.00000

1675.00000

1675.00000

1675.00000

1675.00000

1675.00000

1675.00000

1675.00000

1675.00000

1675.00000

1675.00000

1675.00000

1675.00000

1675.00000

1675.00000

1675.00000

1675.00000

1675.00000

1675.00000

1675.00000

1675.00000

1675.00000

1675.00000

1675.00000

1675.00000

1675.00000

1675.00000

1675.00000

1675.00000

1675.00000

1675.00000

1675.00000

1675.00000

1675.00000

1675.00000

1675.00000

1675.00000

1675.00000

1675.00000

1675.00000

1675.00000

1675.00000

1675.00000

1675.00000

\begin{tabular}{|c|c|}
\hline 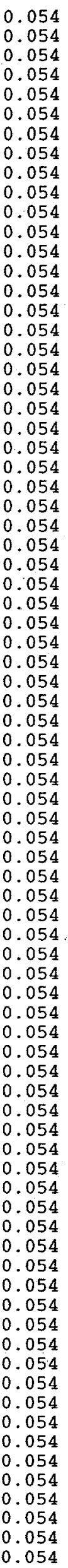 & 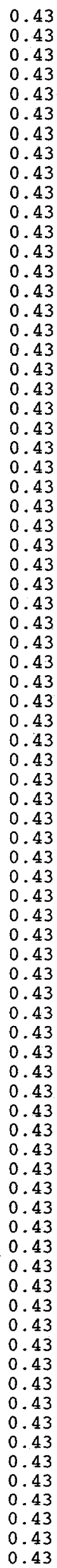 \\
\hline
\end{tabular}

0.4497

0.4497

0.4497

0.4497

0.4497

0.4497

0.4497

0.4497

0.4497

0.4497

0.4497

0.4497

0.4497

0.4497

0.4497

0.4497

0.4497

0.4497

0.4497

0.4497

0.4497

0.4497

0.4497

0.4497

0.4497

0.4497

0.4497

0.4497

0.4497

0.4497

0.4497

0.4497

0.4497

0.4497

0.4497

0.4497

0.4497

0.4497

0.4497

0.4497

0.4497

0.4497

0.4497

0.4497

0.4497

0.4497

0.4497

0.4497

0.4497

0.4497

0.4497

0.4497

0.4497

0.4497

0.4497

0.4497

0.4497

0.4497

0.4497

0.4497

0.4497

0.4497

0.4497

0.4497

0.4497

0.4497

0.4497

0.4497

0.4497

0.4497

0.4497

0.4497

0.4497

0.4497

0.4497

0.4497

0.4497

0.4497

0.4497
0.45

0.45 .

0.45

0.45

0.45

0.45

0.45

0.45

0.45

0.45

0.45

0.45

0.45

0.45

0.45

0.45

0.45

0.45

0.45

0.45

0.45

0.45

0.45

0.45

0.45

0.45

0.45

0.45

0.45

0.45

0.45

0.45

0.45

0.45

0.45

0.45

0.45

0.45

0.45

0.45

0.45

0.45

0.45

0.45

0.45

0.45

0.45

0.45

0.45

0.45

0.45

0.45

0.45

0.45

0.45

0.45

0.45

0.45

0.45

0.45

0.45

0.45

0.45

0.45

0.45

0.45

0.45

0.45

0.45

0.45

0.45

0.45

0.45

0.45

0.45

0.45

0.45

0.45

0.45

0.45 


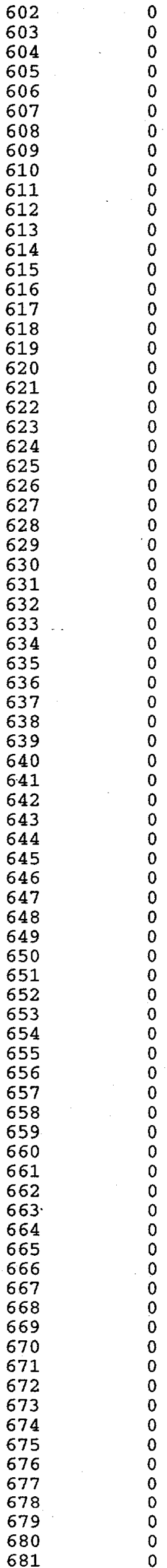

1675.00000

1675.00000

1675.00000

1675.00000

1675.00000

1675.00000

1675.00000

1675.00000

1675.00000

1675.00000

1675.00000

1675.00000

1675.00000

1675.00000

1675.00000

1675.00000

1675.00000

1675.00000

1675.00000

1675.00000

1675.00000

1675.00000

1675.00000

1675.00000

1675.00000

1675.00000

1675.00000

1675.00000

1675.00000

1675.00000

1675.00000

1675.00000

1675.00000

1675.00000

1675.00000

1675.00000

1675.00000

1675.00000

1675.00000

1675.00000

1675.00000

1675.00000

1675.00000

1675.00000

1675.00000

1675.00000

1675.00000

1675.00000

1675.00000

1675.00000

1675.00000

1675.00000

1675.00000

1675.00000

1675.00000

1675.00000

1675.00000

1675.00000

1675.00000

1675.00000

1675.00000

1675.00000

1675.00000

1675.00000

1675.00000

1675.00000

1675.00000

1675.00000

1675.00000

1675.00000

1675.00000

1675.00000

1675.00000

1675.00000

1675.00000

1675.00000

1675.00000

1675.00000

1675.00000

1675.00000

\subsection{4}

0.054

0.054

0.054

0.054

0.054

0.054

0.054

0.054

0.054

0.054

0.054

0.054

0.054

0.054

0.054

0.054

0.054

0.054

0.054

0.054

0.054

0.054

0.054

0.054

0.054

0.054

0.054

0.054

0.054

0.054

0.054

0.054

0.054

0.054

0.054

0.054

0.054

0.054

0.054

0.054

0.054

0.054

0.054

0.054

0.054

0.054

0.054

0.054

0.054

0.054

0.054

0.054

0.054

0.054

0.054

0.054

0.054

0.054

0.054

0.054

0.054

0.054

0.054

0.054

0.054

0.054

0.054

0.054

0.054

0.054

0.054

0.054

0.054

0.054

0.054

0.054

0.054

0.054

0.054

0.43

0.43

0.43

0.43

0.43

0.43

0.43

0.43

0.43

0.43

0.43

0.43

0.43

0.43

0.43

0.43

0.43

0.43

0.43

0.43

0.43

0.43

0.43

0.43

0.43

0.43

0.43

0.43

0.43

0.43

0.43

0.43

0.43

0.43

0.43

0.43

0.43

0.43

0.43

0.43

0.43

0.43

0.43

0.43

0.43

0.43

0.43

0.43

0.43

0.43

0.43

0.43

0.43

0.43

0.43

0.43

0.43

0.43

0.43

0.43

0.43

0.43

0.43

0.43

0.43

0.43

0.43

0.43

0.43

0.43

0.43

0.43

0.43

0.43

0.43

0.43

0.43

0.43

0.4497

0.4497

0.4497

0.4497
0.4497

0.4497

0.4497

0.4497

0.4497

0.4497

0.4497

0.4497

0.4497

0.4497

0.4497

0.4497

0.4497

0.4497

0.4497

0.4497

0.4497

0.4497

0.4497

0.4497

0.4497

0.4497

0.4497

0.4497

0.4497

0.4497

0.4497

0.4497

0.4497

0.4497

0.4497

0.4497

0.4497

0.4497

0.4497

0.4497

0.4497

0.4497

0.4497

0.4497

0.4497

0.4497

0.4497

0.4497

0.4497

0.4497

0.4497

0.4497

0.4497 


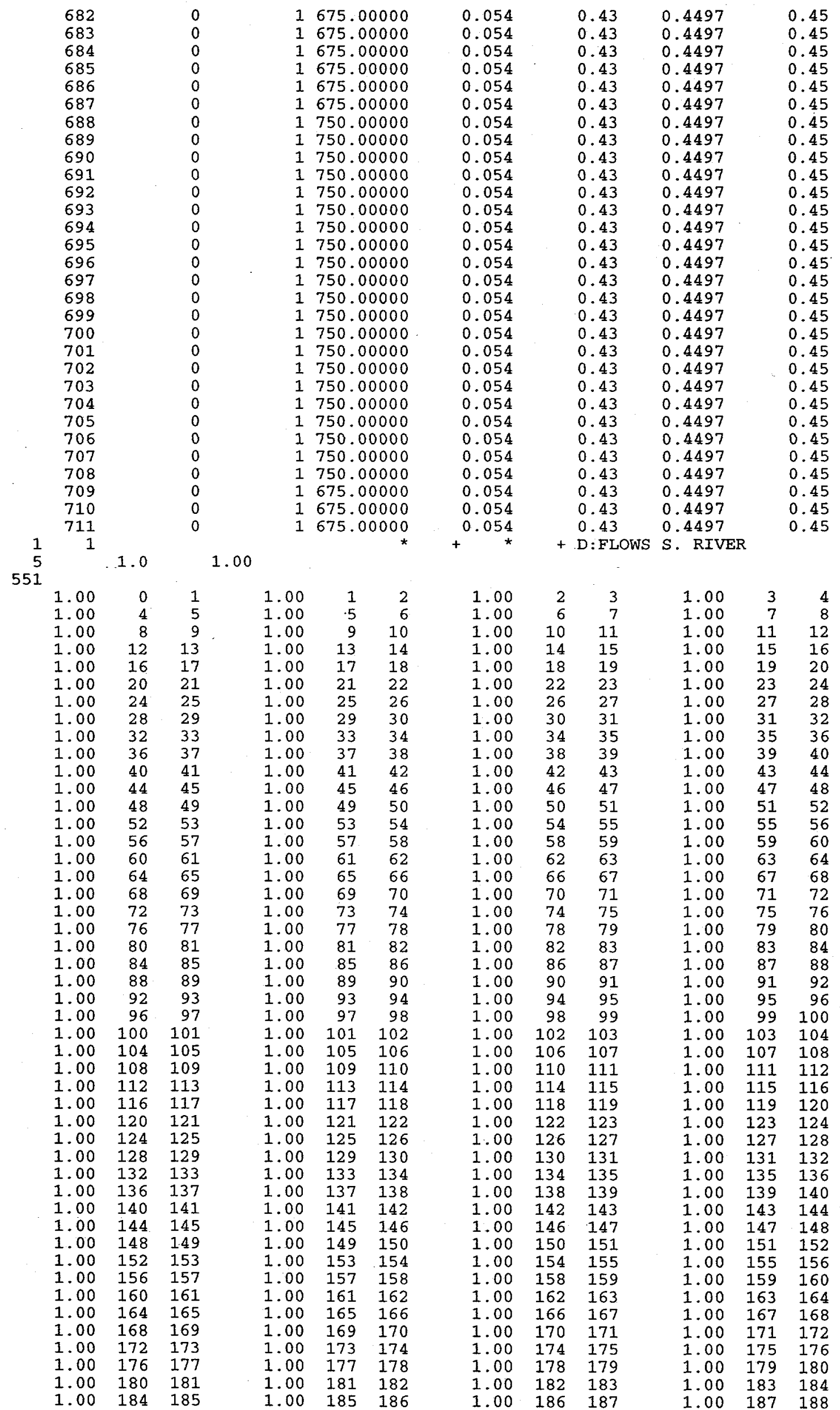




\begin{tabular}{|c|c|c|c|c|c|c|c|c|c|c|c|}
\hline 1.00 & 188 & 189 & 1.00 & 189 & 190 & 1.00 & 190 & 191 & 1.00 & 191 & 192 \\
\hline 1.00 & 192 & 193 & 1.00 & 193 & 194 & 1.00 & 194 & 195 & 1.00 & 195 & 196 \\
\hline 1.00 & 196 & 197 & 1.00 & 197 & 198 & 1.00 & 198 & 199 & 1.00 & 199 & 200 \\
\hline 1.00 & 200 & 201 & 1.00 & 201 & 202 & 1.00 & 202 & 203 & 1.00 & 203 & 204 \\
\hline 1.00 & 204 & 205 & 1.00 & 205 & 206 & 1.00 & 206 & 207 & 1.00 & 207 & 208 \\
\hline 1.00 & 208 & 209 & 1.00 & 209 & 210 & 1.00 & 210 & 211 & 1.00 & 211 & 212 \\
\hline 1.00 & 212 & 213 & 1.00 & 213 & 214 & 1.00 & 214 & 215 & 1.00 & 215 & 216 \\
\hline 1.00 & 216 & 217 & 1.00 & 217 & 218 & 1.00 & 218 & 219 & 1.00 & 219 & 220 \\
\hline 1.00 & 220 & 221 & 1.00 & 221 & 222 & 1.00 & 222 & 223 & 1.00 & 223 & 224 \\
\hline 1.00 & 224 & 225 & 1.00 & 225 & 226 & 1.00 & 226 & 227 & 1.00 & 227 & 228 \\
\hline 1.00 & 228 & 229 & 1.00 & 229 & 230 & 1.00 & 230 & 231 & 1.00 & 231 & 232 \\
\hline 1.00 & 232 & 233 & 1.00 & 233 & 234 & 1.00 & 234 & 235 & 1.00 & 235 & 236 \\
\hline 1.00 & 236 & 237 & 1.00 & 237 & 238 & 1.00 & 238 & 239 & 1.00 & 239 & 240 \\
\hline 1.00 & 240 & 241 & 1.00 & 241 & 242 & 1.00 & 242 & 243 & 1.00 & 243 & 244 \\
\hline 1.00 & 244 & 245 & 1.00 & 245 & 246 & 1.00 & 246 & 247 & 1.00 & 247 & 248 \\
\hline 1.00 & 248 & 249 & 1.00 & 249 & 250 & 1.00 & 250 & 251 & 1.00 & 251 & 252 \\
\hline 1.00 & 252 & 253 & 1.00 & 253 & 254 & 1.00 & 254 & 255 & 1.00 & 255 & 256 \\
\hline 1.00 & 256 & 257 & 1.00 & 257 & 258 & 1.00 & 258 & 259 & 1.00 & 259 & 260 \\
\hline 1.00 & 260 & 261 & 1.00 & 261 & 262 & 1.00 & 262 & 263 & 1.00 & 263 & 264 \\
\hline 1.00 & 264 & 265 & 1.00 & 265 & 266 & 1.00 & 266 & 267 & 1.00 & 267 & 268 \\
\hline 1.00 & 268 & 269 & 1.00 & 269 & 270 & 1.00 & 270 & 271 & 1.00 & 271 & 272 \\
\hline 1.00 & 272 & 273 & 1.00 & 273 & 274 & 1.00 & 274 & 275 & 1.00 & 275 & 276 \\
\hline 1.00 & 276 & 277 & 1.00 & 277 & 278 & 1.00 & 278 & 279 & 1.00 & 279 & 280 \\
\hline 1.00 & 280 & 281 & 1.00 & 281 & 282 & 1.00 & 282 & 283 & 1.00 & 283 & 284 \\
\hline 1.00 & 284 & 285 & 1.00 & 285 & 286 & 1.00 & 286 & 287 & 1.00 & 287 & 288 \\
\hline 1.00 & 288 & 289 & 1.00 & 289 & 290 & 1.00 & 290 & 291 & 1.00 & 291 & 292 \\
\hline 1.00 & 292 & 293 & 1.00 & 293 & 294 & 1.00 & 294 & 295 & 1.00 & 295 & 296 \\
\hline 1.00 & 296 & 297 & 1.00 & 297 & 298 & 1.00 & 298 & 299 & 1.00 & 299 & 300 \\
\hline 1.00 & 300 & 301 & 1.00 & 301 & 302 & 1.00 & 302 & 303 & 1.00 & 303 & 304 \\
\hline 1.00 & 304 & 305 & 1.00 & 305 & 306 & 1.00 & 306 & 307 & 1.00 & 307 & 308 \\
\hline 1.00 & 308 & 309 & 1.00 & 309 & 310 & 1.00 & 310 & 311 & 1.00 & 311 & 312 \\
\hline 1.00 & 312 & 313 & 1.00 & 313 & 314 & 1.00 & 314 & 315 . & 1.00 & 315 & 316 \\
\hline 1.00 & 316 & 317 & 1.00 & 317 & 318 & 1.00 & 318 & 319 & 1.00 & 319 & 320 \\
\hline 1.00 & 320 & 321 & 1.00 & 321 & 322 & 1.00 & 322 & 323 & 1.00 & 323 & 324 \\
\hline 1.00 & 324 & 325 & 1.00 & 325 & 326 & 1.00 & 326 & 327 & 1.00 & 327 & 328 \\
\hline 1.00 & 328 & 329 & 1.00 & 329 & 330 & 1.00 & 330 & 331 & 1.00 & 331 & 332 \\
\hline 1.00 & 332 & 333 & 1.00 & 333 & 334 & 1.00 & 334 & 335 & 1.00 & 335 & 336 \\
\hline 1.00 & 336 & 337 & 1.00 & 337 & 338 & 1.00 & 338 & 339 & 1.00 & 339 & 340 \\
\hline 1.00 & 340 & 341 & 1.00 & 341 & 342 & 1.00 & 342 & 343 & 1.00 & 343 & 344 \\
\hline 1.00 & 344 & 345 & 1.00 & 345 & 346 & 1.00 & 346 & 347 & 1.00 & 347 & 348 \\
\hline 1.00 & 348 & 349 & 1.00 & 349 & 350 & 1.00 & 350 & 351 & 1.00 & 351 & 352 \\
\hline 1.00 & 352 & 353 & 1.00 & 353 & 354 & 1.00 & 354 & 355 & 1.00 & 355 & 356 \\
\hline 1.00 & 356 & 357 & 1.00 & 357 & 358 & 1.00 & 358 & 359 & 1.00 & 359 & 360 \\
\hline 1.00 & 360 & 361 & 1.00 & 361 & 362 & 1.00 & 362 & 363 & 1.00 & 363 & 364 \\
\hline 1.00 & 364 & 365 & 1.00 & 365 & 366 & 1.00 & 366 & 367 & 1.00 & 367 & 368 \\
\hline 1.00 & 368 & 369 & 1.00 & 369 & 370 & 1.00 & 370 & 371 & 1.00 & 371 & 372 \\
\hline 1.00 & 372 & 373 & 1.00 & 373 & 374 & 1.00 & 374 & 375 & 1.00 & 375 & 376 \\
\hline 1.00 & 376 & 377 & 1.00 & 377 & 378 & 1.00 & 378 & 379 & 1.00 & 379 & 380 \\
\hline 1.00 & 380 & 381 & 1.00 & 381 & 382 & 1.00 & 382 & 383 & 1.00 & 383 & 384 \\
\hline 1.00 & 384 & 385 & 1.00 & 385 & 386 & 1.00 & 386 & 387 & 1.00 & 387 & 388 \\
\hline 1.00 & 388 & 389 & 1.00 & 389 & 390 & 1.00 & 390 & 391 & 1.00 & 391 & 392 \\
\hline 1.00 & 392 & 393 & 1.00 & 393 & 394 & 1.00 & 394 & 395 & 1.00 & 395 & 396 \\
\hline 1.00 & 396 & 397 & 1.00 & 397 & 398 & 1.00 & 398 & 399 & 1.00 & 399 & 400 \\
\hline 1.00 & 400 & 401 & 1.00 & 401 & 402 & 1.00 & 402 & 403 & 1.00 & 403 & 404 \\
\hline 1.00 & 404 & 405 & 1.00 & 405 & 406 & 1.00 & 406 & 407 & 1.00 & 407 & 408 \\
\hline 1.00 & 408 & 409 & 1.00 & 409 & 410 & 1.00 & 410 & 411 & 1.00 & 411 & 412 \\
\hline 1.00 & 412 & 413 & 1.00 & 413 & 414 & 1.00 & 414 & 415 & 1.00 & 415 & 416 \\
\hline 1.00 & 416 & 417 & 1.00 & 417 & 418 & 1.00 & 418 & 419 & 1.00 & 419 & 420 \\
\hline 1.00 & 420 & 421 & 1.00 & 421 & 422 & 1.00 & 422 & 423 & 1.00 & 423 & 424 \\
\hline 1.00 & 424 & 425 & 1.00 & 425 & 426 & 1.00 & 426 & 427 & 1.00 & 427 & 428 \\
\hline 1.00 & 428 & 429 & 1.00 & 429 & 430 & 1.00 & 430 & 431 & 1.00 & 431 & 432 \\
\hline 1.00 & 432 & 433 & 1.00 & 433 & 434 & 1.00 & 434 & 435 & 1.00 & 435 & 436 \\
\hline 1.00 & 436 & 437 & 1.00 & 437 & 438 & 1.00 & 438 & 439 & 1.00 & 439 & 440 \\
\hline 1.00 & 440 & 441 & 1.00 & 441 & 442 & 1.00 & 442 & 443 & 1.00 & 443 & 444 \\
\hline 1.00 & 444 & 445 & 1.00 & 445 & 446 & $1: 00$ & 446 & 447 & 1.00 & 447 & 448 \\
\hline 1.00 & 448 & 449 & 1.00 & 449 & 450 & 1.00 & 450 & 451 & 1.00 & 451 & 452 \\
\hline 1.00 & 452 & 453 & 1.00 & 453 & 454 & 1.00 & 454 & 455 & 1.00 & 455 & 456 \\
\hline 1.00 & 456 & 457 & 1.00 & 457 & 458 & 1.00 & 458 & 459 & 1.00 & 459 & 460 \\
\hline 1.00 & 460 & 461 & 1.00 & 461 & 462 & 1.00 & 462 & 463 & 1.00 & 463 & 464 \\
\hline 1.00 & 464 & 465 & 1.00 & 465 & 466 & 1.00 & 466 & 467 & 1.00 & 467 & 468 \\
\hline 1.00 & 468 & 469 & 1.00 & 469 & 470 & 1.00 & 470 & 471 & 1.00 & 471 & 472 \\
\hline 1.00 & 472 & 473 & 1.00 & 473 & 474 & 1.00 & 474 & 475 & 1.00 & 475 & 476 \\
\hline 1.00 & 476 & 477 & 1.00 & 477 & 478 & 1.00 & 478 & 479 & 1.00 & 479 & 480 \\
\hline 1.00 & 480 & 481 & 1.00 & 481 & 482 & 1.00 & 482 & 483 & 1.00 & 483 & 484 \\
\hline 1.00 & 484 & 485 & 1.00 & 485 & 486 & 1.00 & 486 & 487 & 1.00 & 487 & 488 \\
\hline 1.00 & 488 & 489 & 1.00 & 489 & 490 & 1.00 & 490 & 491 & 1.00 & 491 & 492 \\
\hline 1.00 & 492 & 493 & 1.00 & 493 & 494 & 1.00 & 494 & 495 & 1.00 & 495 & 496 \\
\hline 1.00 & 496 & 497 & 1.00 & 497 & 498 & 1.00 & 498 & 499 & 1.00 & 499 & 500 \\
\hline 1.00 & 500 & 501 & 1.00 & 501 & 502 & 1.00 & 502 & 503 & 1.00 & 503 & 504 \\
\hline 1.00 & 504 & 505 & 1.00 & 505 & 506 & 1.00 & 506 & 507 & 1.00 & 507 & 508 \\
\hline
\end{tabular}




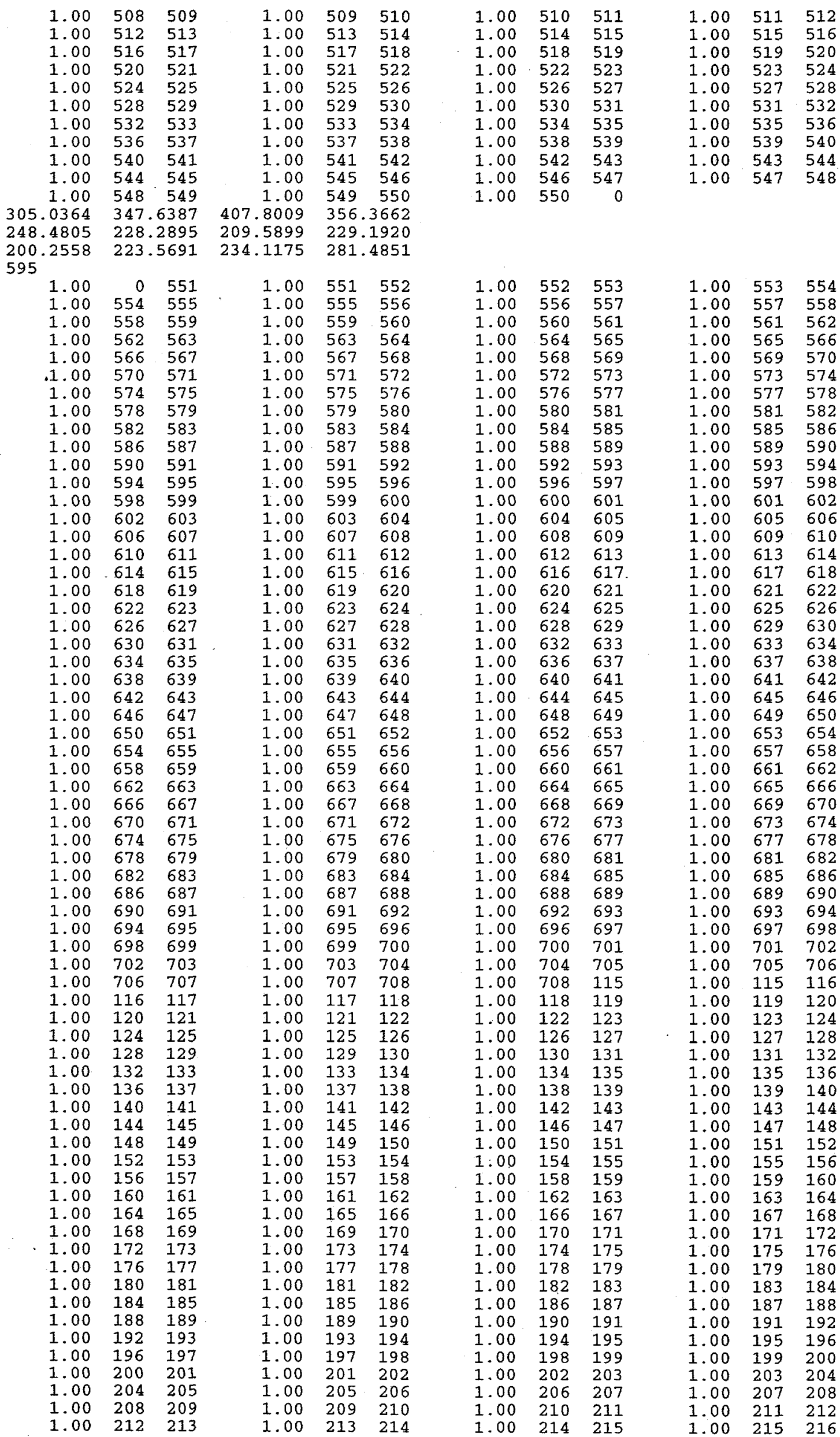




\begin{tabular}{|c|c|c|}
\hline 1.00 & 216 & 217 \\
\hline 1.00 & 220 & 221 \\
\hline 1.00 & 224 & 225 \\
\hline 1.00 & 228 & 229 \\
\hline 1.00 & 232 & 233 \\
\hline 1.00 & 236 & 237 \\
\hline 1.00 & 240 & 241 \\
\hline 1.00 & 244 & 245 \\
\hline 1.00 & 248 & 249 \\
\hline 1.00 & 252 & 253 \\
\hline 1.00 & 256 & 257 \\
\hline 1.00 & 260 & 261 \\
\hline 1.00 & 264 & 265 \\
\hline 1.00 & 268 & 269 \\
\hline 1.00 & 272 & 273 \\
\hline 1.00 & 276 & 277 \\
\hline 1.00 & 280 & 281 \\
\hline 1.00 & 284 & 285 \\
\hline 1.00 & 288 & 289 \\
\hline 1.00 & 292 & 293 \\
\hline 1.00 & 296 & 297 \\
\hline 1.00 & 300 & 301 \\
\hline 1.00 & 304 & 305 \\
\hline 1.00 & 308 & 309 \\
\hline 1.00 & 312 & 313 \\
\hline 1.00 & 316 & 317 \\
\hline 1.00 & 320 & 321 \\
\hline 1.00 & 324 & 325 \\
\hline 1.00 & 328 & 329 \\
\hline 1.00 & 332 & 333 \\
\hline 1.00 & 336 & 337 \\
\hline 1.00 & .340 & 341 \\
\hline 1.00 & 344 & 345 \\
\hline 1.00 & 348 & 349 \\
\hline 1.00 & 352 & 353 \\
\hline 1.00 & 356 & 357 \\
\hline 1.00 & 360 & 361 \\
\hline 1.00 & 364 & 365 \\
\hline 1.00 & 368 & 369 \\
\hline 1.00 & 372 & 373 \\
\hline 1.00 & 376 & 377 \\
\hline 1.00 & 380 & 381 \\
\hline 1.00 & 3 & 385 \\
\hline 1.00 & 388 & 389 \\
\hline 1.00 & 392 & 393 \\
\hline 1.00 & 396 & 397 \\
\hline 1.00 & 400 & 401 \\
\hline 1.00 & 404 & 405 \\
\hline 1.00 & 408 & 409 \\
\hline 1.00 & 412 & 413 \\
\hline 1.00 & 416 & 417 \\
\hline 1.00 & 420 & 421 \\
\hline 1.00 & 424 & 425 \\
\hline 1.00 & 428 & 429 \\
\hline 1.00 & 432 & 433 \\
\hline 1.00 & 436 & 437 \\
\hline 1.00 & 440 & 441 \\
\hline 1.00 & 444 & 445 \\
\hline 1.00 & 448 & 449 \\
\hline 1.00 & 452 & 453 \\
\hline 1.00 & 456 & 457 \\
\hline 1.00 & 460 & 461 \\
\hline 1.00 & 464 & 465 \\
\hline 1.00 & 468 & 469 \\
\hline 1.00 & 472 & 473 \\
\hline 1.00 & 476 & 477 \\
\hline 1.00 & & 481 \\
\hline 1.00 & 484 & 485 \\
\hline 1.00 & 488 & 489 \\
\hline 1.00 & 492 & 493 \\
\hline 1.00 & 496 & 497 \\
\hline 1.00 & 500 & 501 \\
\hline 1.00 & 504 & 505 \\
\hline 1.00 & 508 & 509 \\
\hline 1.00 & 512 & 513 \\
\hline 1.00 & 516 & 517 \\
\hline 1.00 & 520 & 521 \\
\hline 1.00 & 524 & 525 \\
\hline 1.00 & 52 & 529 \\
\hline & 53 & 533 \\
\hline
\end{tabular}

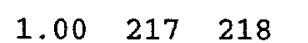

$1.00 \quad 221 \quad 222$

$1.00 \quad 225 \quad 226$

$\begin{array}{lll}1.00 & 229 & 230\end{array}$

$\begin{array}{lll}1.00 & 233 & 234\end{array}$

$\begin{array}{lll}1.00 & 237 & 238\end{array}$

$1.00 \quad 241 \quad 242$

$1.00 \quad 245 \quad 246$

$\begin{array}{lll}1.00 & 249 & 250\end{array}$

$\begin{array}{lll}1.00 & 253 & 254\end{array}$

$\begin{array}{lll}1.00 & 257 & 258\end{array}$

$\begin{array}{lll}1.00 & 261 & 262\end{array}$

$\begin{array}{lll}1.00 & 265 & 266\end{array}$

$1.00 \quad 269 \quad 270$

$1.00 \quad 273 \quad 274$

$\begin{array}{lll}1.00 & 277 & 278\end{array}$

$\begin{array}{lll}1.00 & 281 & 282\end{array}$

$1.00 \quad 285 \quad 286$

$1.00 \quad 289 \quad 290$

$\begin{array}{lll}1.00 & 293 & 294\end{array}$

$\begin{array}{lll}1.00 & 297 & 298\end{array}$

$\begin{array}{lll}1.00 & 301 & 302\end{array}$

$1.00 \quad 305 \quad 306$

$1.00 \quad 309 \cdot 310$

$1.00 \quad 313 \quad 314$

$1.00 \quad 317 \quad 318$

$\begin{array}{lll}1.00 & 321 & 322\end{array}$

$1.00 \quad 325 \quad 326$

$1.00 \quad 329 \quad 330$

$1.00 \quad 333 \quad 334$

$\begin{array}{lll}1.00 & 337 & 338\end{array}$

$1.00 \quad 341 \quad 342$

$1.00 \quad 345 \quad 346$

$1.00 \quad 349 \quad 350$

$1.00 \quad 353 \quad 354$

$\begin{array}{lll}1.00 & 357 \quad 358\end{array}$

$\begin{array}{lll}1.00 & 361 & 362\end{array}$

$1.00 \quad 365 \quad 366$

$\begin{array}{lll}1.00 & 369 & 370\end{array}$

$\begin{array}{lll}1.00 & 373 & 374\end{array}$

$\begin{array}{lll}1.00 & 377 & 378\end{array}$

$\begin{array}{lll}1.00 & 381 \quad 382\end{array}$

$1.00 \quad 385 \quad 386$

$\begin{array}{lll}1.00 & 389 & 390\end{array}$

$1.00 \quad 393 \quad 394$

$\begin{array}{lll}1.00 & 397 & 398\end{array}$

$\begin{array}{lll}1.00 & 401 \quad 402\end{array}$

$1.00 \quad 405 \quad 406$

$1.00 \quad 409 \quad 410$

$1.00 \quad 413 \quad 414$

$1.00 \quad 417 \quad 418$

$\begin{array}{lll}1.00 & 421 & 422\end{array}$

$1.00 \quad 425 \quad 426$

$1.00 \quad 429 \quad 430$

1. $00 \quad 433 \quad 434$

$1.00 \quad 437 \quad 438$

$\begin{array}{lll}1.00 & 441 & 442\end{array}$

$1.00 \quad 445 \quad 446$

$1.00 \cdot 449 \quad 450$

$1.00 \quad 453 \quad 454$

$\begin{array}{lll}1.00 & 457 & 458\end{array}$

$1.00 \quad 461 \quad 462$

$1.00 \quad 465 \quad 466$

$1.00 \quad 469 \quad 470$

$1.00 \quad 473 \quad 474$

$1.00 \quad 477 \quad 478$

$1.00 \quad 481 \quad 482$

1.00 $485 \quad 486$

$1.00 \quad 489 \quad 490$

$1.00 \quad 493 \quad 494$

$\begin{array}{lll}1.00 & 497 & 498\end{array}$

$1.00 \quad 501 \quad 502$

$1.00 \quad 505 \quad 506$

$1.00 \quad 509 \quad 510$

$\begin{array}{lll}1.00 & 513 & 514\end{array}$

$1.00 \quad 517 \quad 518$

$1.00 \quad 521 \quad 522$

$1.00 \quad 525 \quad 526$

$1.00 \quad 529 \quad 530$

$1.00 \quad 533 \quad 534$ $\begin{array}{lll}1.00 & 218 & 219\end{array}$

$1.00 \quad 222 \quad 223$

$1.00 \quad 226 \quad 227$

$1.00 \quad 230 \quad 231$

$1.00 \quad 234 \quad 235$

$1.00 \quad 238 \quad 239$

$1.00 \quad 242 \quad 243$

$1.00 \quad 246 \quad 247$

$\begin{array}{lll}1.00 & 250 & 251\end{array}$

$1.00 .254 \quad 255$

$1.00 \quad 258 \quad 259$

$1.00 \quad 262 \quad 263$

$\begin{array}{lll}1.00 & 266 & 267\end{array}$

$\begin{array}{lll}1.00 & 270 & 271\end{array}$

$\begin{array}{lll}1.00 & 274 & 275\end{array}$

$\begin{array}{lll}1.00 & 278 & 279\end{array}$

$1.00 \quad 282 \quad 283$

$\begin{array}{lll}1.00 & 286 & 287\end{array}$

$\begin{array}{lll}1.00 & 290 & 291\end{array}$

$\begin{array}{lll}1.00 & 294 & 295\end{array}$

$\begin{array}{lll}1.00 & 298 & 299\end{array}$

$1.00 \quad 302 \quad 303$

$1.00 \quad 306 \quad 307$

$1.00 .310 \quad 311$

$\begin{array}{lll}1.00 & 314 & 315\end{array}$

$1.00 \quad 318 \quad 319$

$1.00 \quad 322 \quad 323$

$\begin{array}{lll}1.00 & 326 & 327\end{array}$

$1.00 \quad 330 \quad 331$

$1.00 \quad 334 \quad 335$

$1.00 \quad 338 \quad 339$

$1.00 \quad 342 \quad 343$

$\begin{array}{lll}1.00 & 346 & 347\end{array}$

$\begin{array}{lll}1.00 & 350 & 351\end{array}$

$1.00 \quad 354 \quad 355$

$1.00 \quad 358: 359$

$\begin{array}{lll}1.00 & 362 & 363\end{array}$

$\begin{array}{lll}1.00 & 366 & 367\end{array}$

$\begin{array}{lll}1.00 & 370 & 371\end{array}$

$1.00 \quad 374 \quad 375$

$\begin{array}{lll}1.00 & 378 \quad 379\end{array}$

$\begin{array}{lll}1.00 & 382 & 383\end{array}$

$\begin{array}{lll}1.00 & 386 & 387\end{array}$

$\begin{array}{lll}1.00 & 390 & 391\end{array}$

$1.00 \quad 394 \quad 395$

$1.00 \quad 398 \quad 399$

$1.00 \quad 402 \quad 403$

$1.00 \quad 406 \quad 407$

$1.00 \quad 410 \quad 411$

$1.00 \quad 414 \quad 415$

$1.00 \quad 418 \quad 419$

$1.00 \quad 422 \quad 423$

$1.00 \quad 426 \quad 427$

$1.00 \quad 430.431$

$1.00 \quad 434 \quad 435$

$1.00 \quad 438 \quad 439$

$1.00 \quad 442 \quad 443$

$1.00 \quad 446 \quad 447$

$1.00 \quad 450 \quad 451$

$1.00 \quad 454 \quad 455$

$\begin{array}{lll}1.00 & 458 & 459\end{array}$

$\begin{array}{lll}1.00 & 462 & 463\end{array}$

$1.00 \quad 466 \quad 467$

$1.00 \quad 470 \quad 471$

$1.00 \quad 474 \quad 475$

$1.00 \quad 478.479$

$\begin{array}{lll}1.00 & 482 & 483\end{array}$

$1.00 \quad 486 \quad 487$

$1.00 \quad 490 \quad 491$

$1.00 \quad 494 \quad 495$

$1.00 \quad 498 \quad 499$

$1.00 \quad 502 \quad 503$

$\begin{array}{lll}1.00 & 506 & 507\end{array}$

$1.00 \quad 510 \quad 511$

$1.00 \quad 514 \quad 515$

$1.00 \quad 518 \quad 519$

$1.00 \quad 522 \quad 523$

$1.00 \quad 526 \quad 527$.

$\begin{array}{lll}1.00 & 530 & 531 \\ 1.00 & 534 & 535\end{array}$
$1.00 \quad 219 \quad 220$

$\begin{array}{llll}1.00 & 223 & 224 \\ 1.00 & 227 & 228\end{array}$

$\begin{array}{lll}1.00 & 231 & 232\end{array}$

$1.00 \quad 235 \quad 236$

$1.00 \quad 239 \quad 240$

$1.00 \quad 243 \quad 244$

$\begin{array}{lll}1.00 & 247 & 248\end{array}$

$1.00 \quad 251 \quad 252$

$\begin{array}{lll}1.00 & 255 & 256\end{array}$

$1.00 \quad 259 \quad 260$

$\begin{array}{lll}1.00 & 263 & 264\end{array}$

$1.00 \quad 267 \quad 268$

$\begin{array}{lll}1.00 & 271 & 272\end{array}$

$1.00 \quad 275 \quad 276$

$1.00 \quad 279 \quad 280$

$1.00 \quad 283 \quad 284$

$1.00 \quad 287 \quad 288$

$\begin{array}{lll}1.00 & 291 & 292\end{array}$

$1.00 \quad 295 \quad 296$

$1.00 \quad 299 \quad 300$

$1.00 \quad 303 \quad 304$

$\begin{array}{lll}1.00 & 307 & 308\end{array}$

$\begin{array}{lll}1.00 & 311 & 312\end{array}$

$1.00 \quad 315 \quad 316$

$\begin{array}{lll}1.00 & 319 & 320\end{array}$

$\begin{array}{lll}1.00 & 323 & 324\end{array}$

$\begin{array}{lll}1.00 & 327 & 328\end{array}$

$\begin{array}{lll}1.00 & 331 & 332\end{array}$

$1.00 \quad 335 \quad 336$

$1.00 \quad 339 \quad 340$

$1.00 \quad 343 \quad 344$

$\begin{array}{lll}1.00 & 347 & 348\end{array}$

$1.00 \quad 351 \quad 352$

$1.00 \quad 355 \quad 356$

$1.00 \quad 359 \quad 360$

$\begin{array}{lll}1.00 & 363 & 364\end{array}$

$\begin{array}{lll}1.00 & 367 & 368\end{array}$

$1.00 \quad 371 \quad 372$

$1.00 \quad 375 \quad 376$

$1.00 \quad 379 \quad 380$

$1.00 \quad 383 \quad 384$

$1.00 \quad 387 \quad 388$

$\begin{array}{lll}1.00 & 391 & 392\end{array}$

$1.00 \quad 395 \quad 396$

$1.00 \quad 399 \quad 400$

$1.00 \quad 403 \quad 404$

$1.00 \quad 407 \quad 408$

$\begin{array}{lll}1.00 & 411 & 412\end{array}$

$1.00 \quad 415 \quad 416$

$1.00 \quad 419 \quad 420$

$1.00 \quad 423 \quad 424$

$\begin{array}{lll}1.00 & 427 & 428\end{array}$

$\begin{array}{lll}1.00 & 431 & 432\end{array}$

$1.00 \quad 435 \quad 436$

$1.00 \quad 439 \quad 440$

$1.00 \quad 443 \quad 444$

$1.00 \quad 447 \quad 448$

$1.00 \quad 451 \quad 452$

$1.00 \quad 455 \quad 456$

$1.00 \quad 459 \quad 460$

$1.00 \quad 463 \quad 464$

$\begin{array}{lll}1.00 & 467 & 468\end{array}$

$1.00 \quad 471 \quad 472$

$1.00 \quad 475 \quad 476$

$1.00 \quad 479 \quad 480$

$1.00 \quad 483 \quad 484$

$1.00 \quad 487 \quad 488$

$\begin{array}{lll}1.00 & 491 \quad 492\end{array}$

$1.00 \quad 495 \quad 496$

$1.00 \quad 499 \quad 500$

$1.00 \quad 503 \quad 504$

$1.00 \quad 507 \quad 508$

$1.00 \quad 511 \quad 512$

$1.00 \quad 515 \quad 516$

$1.00 \quad 519 \quad 520$

$1.00 \quad 523 \quad 524$

$1.00 \quad 527 \quad 528$

$1.00 \quad 531 \quad 532$

$1.00 \quad 535 \quad 536$ 


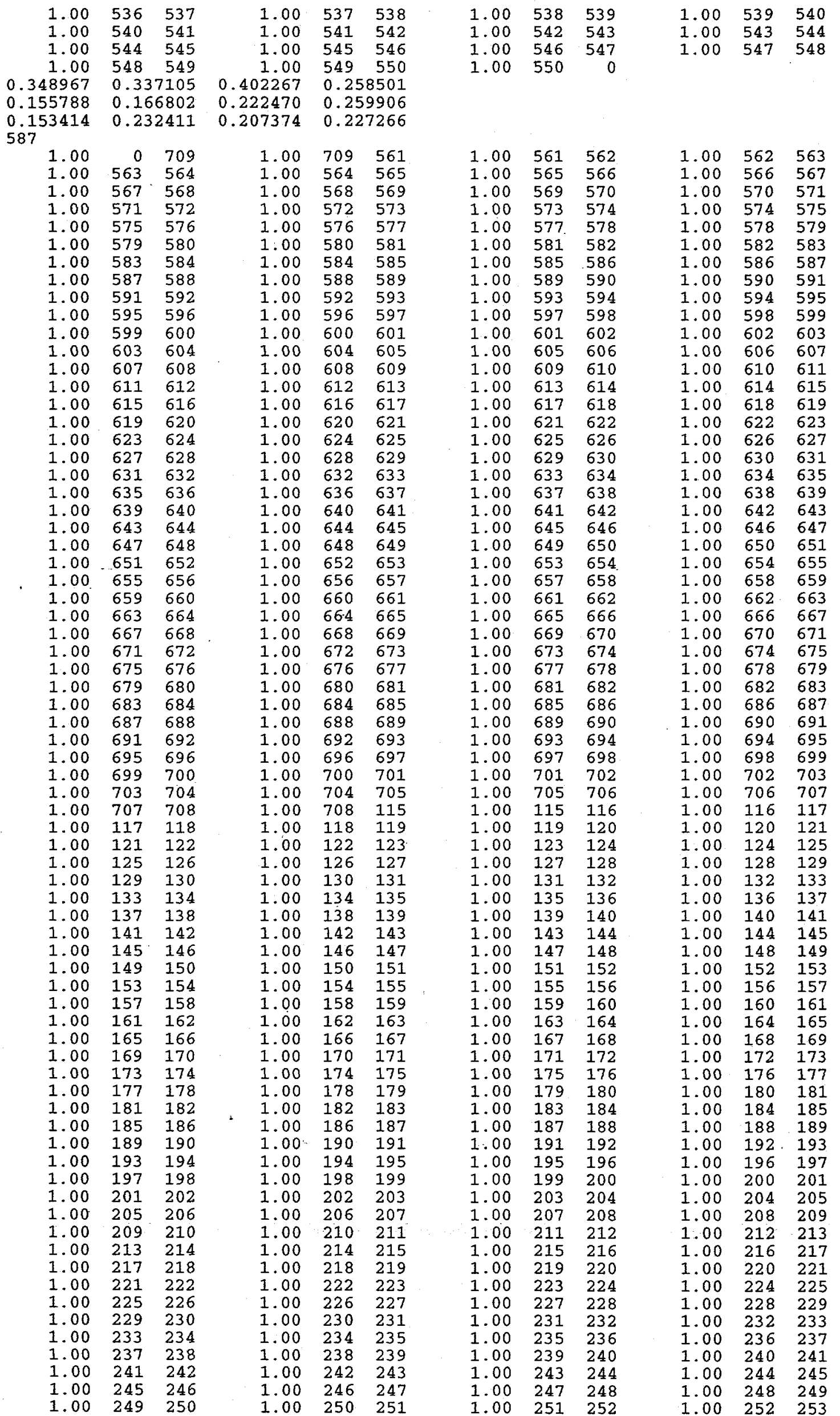




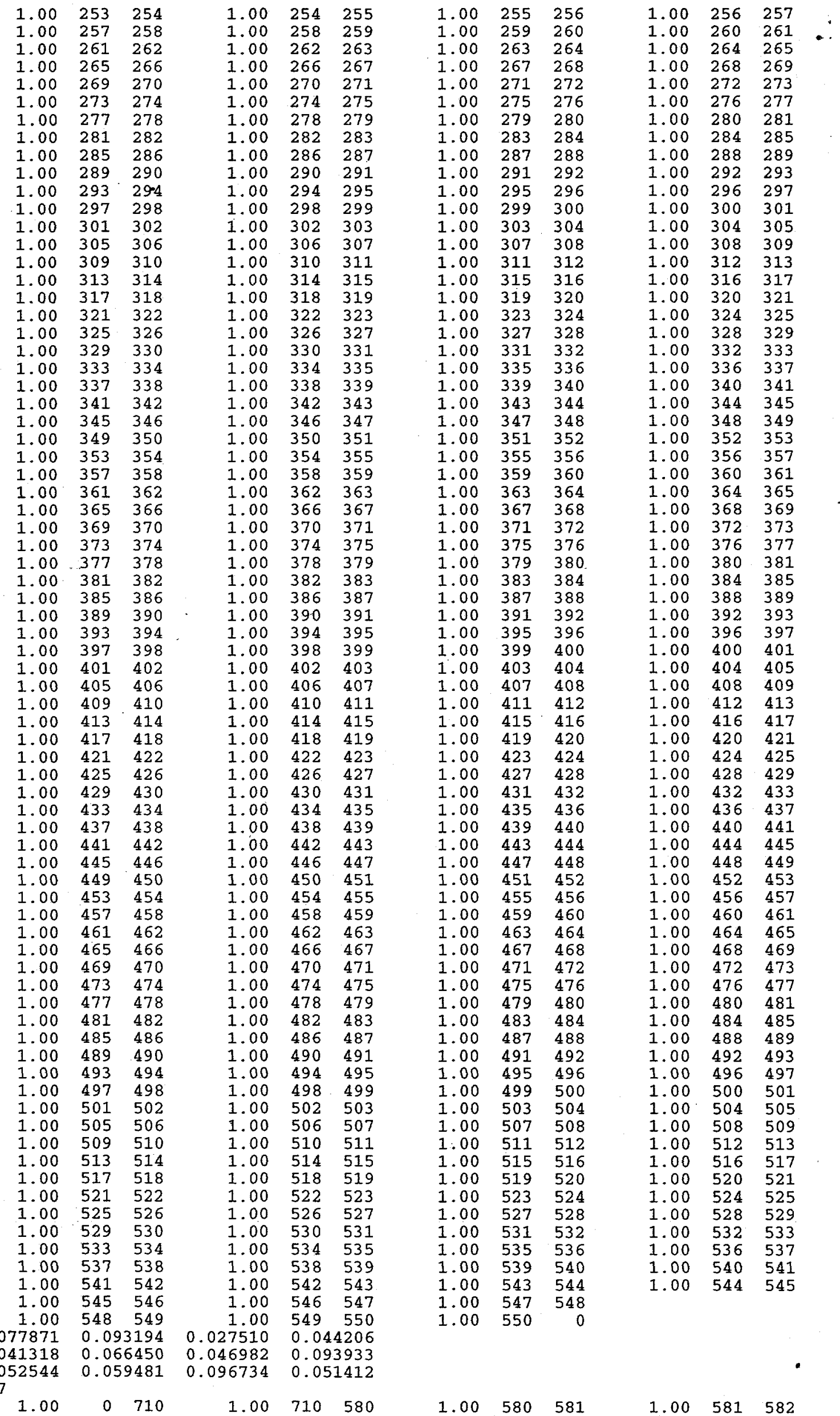




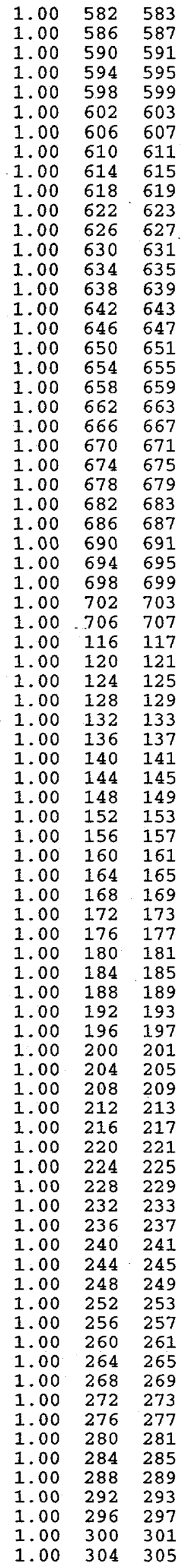

\begin{tabular}{|c|c|c|}
\hline & & \\
\hline $\begin{array}{l}1.00 \\
1.00\end{array}$ & $\begin{array}{l}583 \\
587\end{array}$ & $\begin{array}{l}584 \\
588\end{array}$ \\
\hline 1.00 & 591 & 592 \\
\hline 1.00 & 595 & 596 \\
\hline 1.00 & 599 & 600 \\
\hline 1.00 & 6 & 604 \\
\hline 1.00 & 607 & 608 \\
\hline 1.00 & 611 & 612 \\
\hline 1.00 & 615 & 616 \\
\hline 1.00 & 619 & 620 \\
\hline 1.00 & 623 & 624 \\
\hline 1.00 & 627 & 628 \\
\hline 1.00 & 631 & 632 \\
\hline 1.00 & 635 & 636 \\
\hline 1.00 & 639 & 640 \\
\hline 1.00 & 64 & 644 \\
\hline 1.00 & 647 & 648 \\
\hline 1.00 & 651 & 652 \\
\hline 1.00 & 655 & 656 \\
\hline 1.00 & 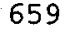 & 660 \\
\hline 1.00 & & 64 \\
\hline 1.00 & 667 & 668 \\
\hline 1.00 & 671. & 672 \\
\hline 1.00 & 675 & 676 \\
\hline 1.00 & 679 & 680 \\
\hline 1.00 & 683 & 684 \\
\hline 1.00 & 687 & 688 \\
\hline 1.00 & 691 & 692 \\
\hline 1.00 & 6 & 696 \\
\hline 1.00 & 699 & 700 \\
\hline 1.00 & & 704 \\
\hline 1.00 & 70 & 708 \\
\hline 1.00 & 117 & 118 \\
\hline 1.00 & 121 & 122 \\
\hline 1.00 & 125 & 126 \\
\hline 1.00 & 129 & 130 \\
\hline 1.00 & 13 & 134 \\
\hline 1.00 & 137 & 138 \\
\hline 1.00 & 141 & 142 \\
\hline 1.00 & 14 & 146 \\
\hline 1.00 & 14 & 150 \\
\hline 1.00 & 15 & 154 \\
\hline 1.00 & 157 & 158 \\
\hline 1.00 & 161 & 162 \\
\hline 1.00 & 165 & 166 \\
\hline 1.00 & 16 & 170 \\
\hline 1.00 & 173 & 174 \\
\hline 1.00 & 177 & 178 \\
\hline 1.00 & 181 & 182 \\
\hline 1.00 & 185 & 186 \\
\hline 1.00 & 18 & 190 \\
\hline 1.00 & 193 & 194 \\
\hline 1.00 & 19 & 198 \\
\hline 1.00 & 20 & 202 \\
\hline 1.00 & 20 & 206 \\
\hline 1.00 & 20 & 210 \\
\hline 1.00 & 213 & 214 \\
\hline 1.00 & 217 & 218 \\
\hline 1.00 & 221 & 222 \\
\hline 1.00 & 225 & 226 \\
\hline 1.00 & 229 & 230 \\
\hline 1.00 & 23 & 234 \\
\hline 1.00 & 237 & 238 \\
\hline 1.00 & 241 & 242 \\
\hline 1.00 & 245 & 246 \\
\hline 1.00 & 24 & 250 \\
\hline 1.00 & & 254 \\
\hline 1.00 & 25 & 258 \\
\hline 1.00 & 26 & 262 \\
\hline 1.00 & 26 & 266 \\
\hline 1.00 & 26 & 270 \\
\hline 1.00 & 273 & 274 \\
\hline 1.00 & 277 & 278 \\
\hline 1.00 & 281 & 282 \\
\hline 1.00 & 28 & 286 \\
\hline 1.00 & 28 & 290 \\
\hline 1.00 & 29 & 294 \\
\hline 1.00 & 29 & 298 \\
\hline 1.00 & 30 & 302 \\
\hline 1.00 & 30 & 306 \\
\hline
\end{tabular}

$1.00 \quad 584 \quad 585$

$1.00 \quad 588 \quad 589$

$1.00 \quad 592 \quad 593$

$1.00 \quad 596 \quad 597$

$1.00 \quad 600 \quad 601$

$1.00 \quad 604 \quad 605$

$1.00 \quad 608 \quad 609$

$1.00 \quad 612 \quad 613$

$\begin{array}{lll}1.00 & 616 & 617\end{array}$

$1.00 \quad 620 \quad 621$

$\begin{array}{lll}1.00 & 624 & 625\end{array}$

$\begin{array}{lll}1.00 & 628 & 629\end{array}$

$1.00 \quad 632 \quad 633$

$1.00 \quad 636 \quad 637$

$1.00 \quad 640 \quad 641$

$1.00 \quad 644 \quad 645$

$\begin{array}{lll}1.00 & 648 & 649\end{array}$

$1.00 \quad 652 \quad 653$

$1.00 \quad 656 \quad 657$

$1.00 \quad 660 \quad 661$

$1.00 \quad 664 \quad 665$

$1.00 \quad 668 \quad 669$

$1.00 \quad 672 \quad 673$

$\begin{array}{lll}1.00 & 676 & 677\end{array}$

$1.00 \quad 680 \quad 681$

$1.00 \quad 684 \quad 685$

$1.00 \quad 688 \quad 689$

$1.00 \quad 692693$

$1.00 \quad 696 \quad 697$

$\begin{array}{lll}1.00 & 700 & 701 \\ 1.00 & 704 . & 705\end{array}$

$1.00708 \quad 115$

$\begin{array}{lll}1.00 & 118 & 119\end{array}$

$\begin{array}{lll}1.00 & 122 & 123\end{array}$

$\begin{array}{lll}1.00 & 126 & 127\end{array}$

$\begin{array}{lll}1.00 & 130 & 131\end{array}$

$1.00 \quad 134 \quad 135$

$1.00 \quad 138 \quad 139$

$\begin{array}{lll}1.00 & 142 & 143\end{array}$

$\begin{array}{lll}1.00 & 146 & 147\end{array}$

$\begin{array}{lll}1.00 & 150 & 151\end{array}$

$1.00 \quad 154 \quad 155$

$\begin{array}{lll}1.00 & 158 & 159\end{array}$

$1.00 \quad 162 \quad 163$

$1.00 \quad 166 \quad 167$

$\begin{array}{lll}1.00 & 170 & 171\end{array}$

$1.00 \quad 174 \quad 175$

$1.00 \quad 178 \quad 179$

$1.00 \quad 182 \quad 183$

$\begin{array}{lll}1.00 & 186 & 187\end{array}$

$\begin{array}{lll}1.00 & 190 & 191\end{array}$

$\begin{array}{lll}1.00 & 194 & 195\end{array}$

$\begin{array}{lll}1.00 & 198 & 199\end{array}$

$\begin{array}{lll}1.00 & 202 \quad 203\end{array}$

$1.00 \cdot 206 \quad 207$

$1.00 \quad 210: 211$

$1.00 \quad 214 \quad 215$

$\begin{array}{lll}1.00 & 218 & 219\end{array}$

$\begin{array}{lll}1.00 & 222 & 223\end{array}$

$\begin{array}{lll}1.00 & 226 & 227\end{array}$

$1.00 \quad 230 \quad 231$

$\begin{array}{lll}1.00 & 234 & 235\end{array}$

$\begin{array}{lll}1.00 & 238 & 239\end{array}$

$\begin{array}{lll}1.00 & 242 & 243\end{array}$

$1.00 \quad 246 \quad 247$

$1.00 \quad 250 \quad 251$

$\begin{array}{lll}1.00 & 254 & 255\end{array}$

$\begin{array}{lll}1.00 & 258 & 259\end{array}$

$\begin{array}{lll}1.00 & 262 & 263\end{array}$

$\begin{array}{lll}1.00 & 266 & 267\end{array}$

$\begin{array}{lll}1.00 & 270 & 271\end{array}$

$1.00 \quad 274 \quad 275$

$\begin{array}{lll}1.00 & 278 & 279\end{array}$

$\begin{array}{lll}1.00 & 282 & 283\end{array}$

$\begin{array}{lll}1.00 & 286 & 287\end{array}$

$\begin{array}{lll}1.00 & 290 & 291\end{array}$

$1.00 \quad 294 \quad 295$

$\begin{array}{lll}1.00 & 298 & 299\end{array}$

$\begin{array}{lll}1.00 & 302 & 303 \\ 1.00 & 306 & 307\end{array}$ $\begin{array}{llll}1.00 & 585 & 586 & \\ 1.00 & 589 & 590 \\ 1.00 & 593 & 594 & \ldots \\ 1.00 & 597 & 598 \\ 1.00 & 601 & 602 \\ 1.00 & 605 & 606 & \end{array}$

$1.00 \quad 609 \quad 610$

$1.00 \quad 613 \quad 614$

$\begin{array}{lll}1.00 & 617 & 618\end{array}$

$1.00 \quad 621 \quad 622$

$1.00 \quad 625 \quad 626$

$1.00 \quad 629 \quad 630$

$1.00 \quad 633 \quad 634$

$1.00 \quad 637 \quad 638$

$\begin{array}{lll}1.00 & 641 & 642\end{array}$

$1.00 \quad 645 \quad 646$

$1.00 \quad 649650$

$1.00 \quad 653 \quad 654$

$1.00 \quad 657 \quad 658$

$1.00 \quad 661 \quad 662$

$1.00 \quad 665 \quad 666$

$1.00 \quad 669 \quad 670$

$1.00 \quad 673 \quad 674$

$1.00 \quad 677 \quad 678$

$1.00 \quad 681 \quad 682$

$1.00 \quad 685 \quad 686$

$1.00 \quad 689 \quad 690$

$1.00 \quad 693 \quad 694$

$\begin{array}{lll}1.00 & 697 & 698\end{array}$

$\begin{array}{lll}1.00 & 701 & 702\end{array}$

$1.00 \quad 705 \quad 706$

$1.00 \quad 115 \quad 116$

$\begin{array}{lll}1.00 & 119 & 120\end{array}$

$\begin{array}{lll}1.00 & 123 & 124\end{array}$

$\begin{array}{lll}1.00 & 127 & 128\end{array}$

$\begin{array}{lll}1.00 & 131 & 132\end{array}$

$\begin{array}{lll}1.00 & 135 & 136\end{array}$

$\begin{array}{lll}1.00 & 139 & 140\end{array}$

$\begin{array}{lll}1.00 & 143 & 144\end{array}$

$\begin{array}{lll}1.00 & 147 & 148\end{array}$

$\begin{array}{lll}1.00 & 151 & 152\end{array}$

$1.00 \quad 155 \quad 156$

$\begin{array}{lll}1.00 & 159 & 160\end{array}$

$\begin{array}{lll}1.00 & 163 & 164\end{array}$

$1.00 \quad 167 \quad 168$

$\begin{array}{lll}1.00 & 171 & 172\end{array}$

$1.00 \quad 175 \quad 176$

$1.00 \quad 179 \quad 180$

$1.00 \quad 183 \quad 184$

$\begin{array}{lll}1.00 & 187 & 188\end{array}$

$\begin{array}{lll}1.00 & 191 & 192\end{array}$

$\begin{array}{lll}1.00 & 195 & 196\end{array}$

$\begin{array}{lll}1.00 & 199 & 200\end{array}$

$\begin{array}{lll}1.00 & 203 & 204\end{array}$

$\begin{array}{lll}1.00 & 207 & 208\end{array}$

$\begin{array}{lll}1.00 & 211 & 212\end{array}$

$1.00 \quad 215 \quad 216$

$1.00 \quad 219 \quad 220$

$1.00 \quad 223 \quad 224$

$\begin{array}{lll}1.00 & 227 & 228\end{array}$

$\begin{array}{lll}1.00 & 231 & 232\end{array}$

$\begin{array}{lll}1.00 & 235 & 236\end{array}$

$1.00 \quad 239 \quad 240$

$1.00 \quad 243 \quad 244$

$\begin{array}{lll}1.00 & 247 & 248\end{array}$

$\begin{array}{lll}1.00 & 251 & 252\end{array}$

$1.00 \quad 255 \quad 256$

$\begin{array}{lll}1.00 & 259 & 260\end{array}$

$1.00 \quad 263 \quad 264$

$\begin{array}{lll}1.00 & 267 & 268\end{array}$

$\begin{array}{lll}1.00 & 271 & 272\end{array}$

$1.00 \quad 275 \quad 276$

$\begin{array}{lll}1.00 & 279 & 280\end{array}$

$\begin{array}{lll}1.00 & 283 & 284\end{array}$

$\begin{array}{lll}1.00 & 287 & 288\end{array}$

$\begin{array}{lll}1.00 & 291 & 292\end{array}$

$\begin{array}{lll}1.00 & 295 & 296\end{array}$

$1.00 \quad 299 \quad 300$

$\begin{array}{lll}1.00 & 303 & 304 \\ 1.00 & 307 & 308\end{array}$ 


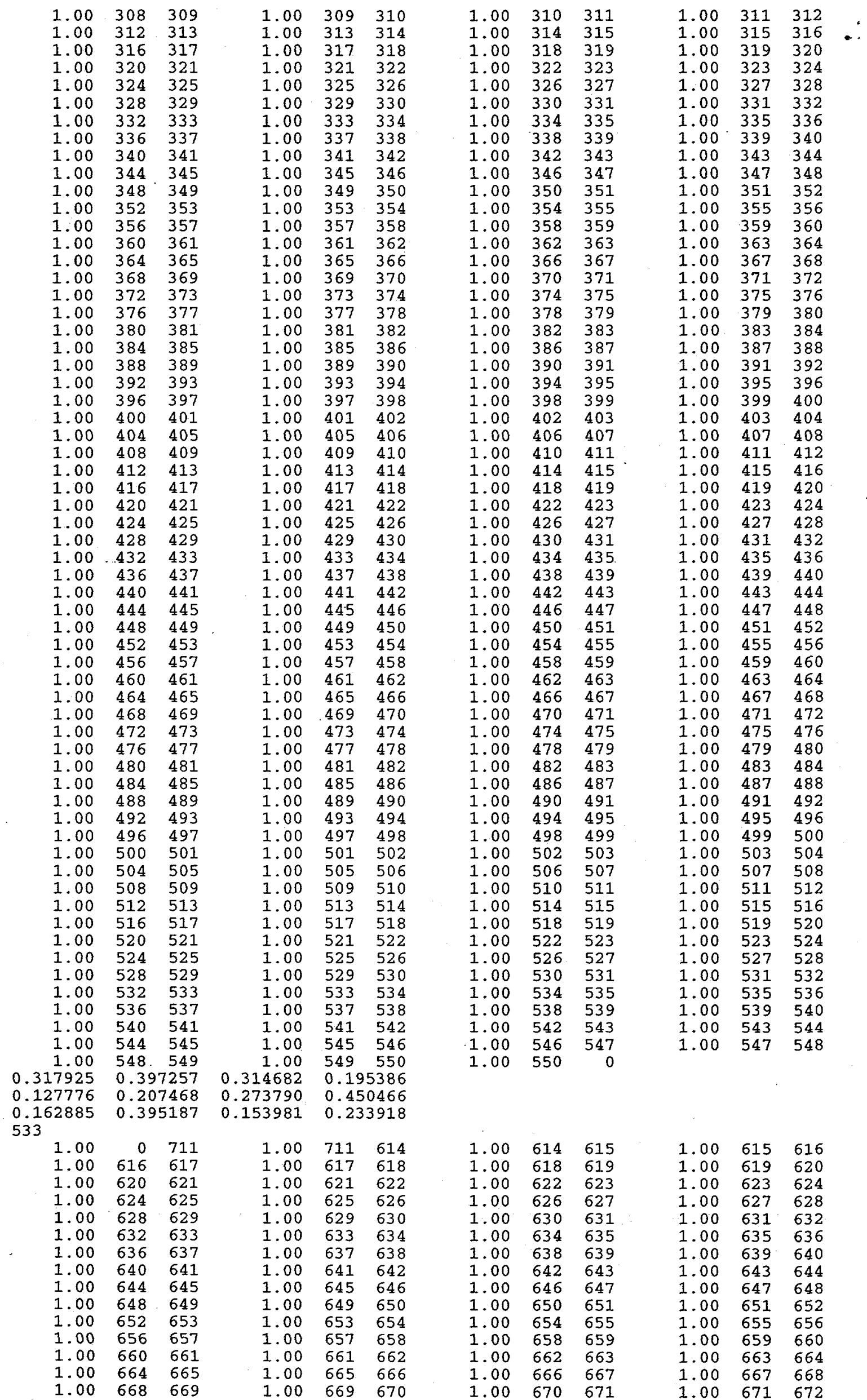




\begin{tabular}{|c|c|c|c|c|c|c|c|c|c|c|c|}
\hline 1.00 & 672 & 673 & 1.00 & 673 & 674 & 1.00 & 674 & 675 & 1.00 & 675 & 676 \\
\hline 1.00 & 676 & 677 & 1.00 & 677 & 678 & 1.00 & 678 & 679 & 1.00 & 679 & 680 \\
\hline 1.00 & 680 & 681 & 1.00 & 681 & 682 & 1.00 & 682 & 683 & 1.00 & 683 & 684 \\
\hline 1.00 & 684 & 685 & 1.00 & 685 & 686 & 1.00 & 686 & 687 & 1.00 & 687 & 688 \\
\hline 1.00 & 688 & 689 & 1.00 & 689 & 690 & 1.00 & 690 & 691 & 1.00 & 691 & 692 \\
\hline 1.00 & 692 & 693 & 1.00 & 693 & 694 & 1.00 & 694 & 695 & 1.00 & 695 & 696 \\
\hline 1.00 & 696 & 697 & 1.00 & 697 & 698 & 1.00 & 698 & 699 & 1.00 & 699 & 700 \\
\hline 1.00 & 700 & 701 & 1.00 & 701 & 702 & 1.00 & 702 & 703 & 1.00 & 703 & 704 \\
\hline 1.00 & 704 & 705 & 1.00 & 705 & 706 & 1.00 & 706 & 707 & 1.00 & 707 & 708 \\
\hline 1.00 & 708 & 115 & 1.00 & 115 & 116 & 1.00 & 116 & 117 & 1.00 & 117 & 118 \\
\hline 1.00 & 118 & 119 & 1.00 & 119 & 120 & 1.00 & 120 & 121 & 1.00 & 121 & 122 \\
\hline 1.00 & 122 & 123 & 1.00 & 123 & 124 & 1.00 & 124 & 125 & 1.00 & 125 & 126 \\
\hline 1.00 & 126 & 127 & 1.00 & 127 & 128 & 1.00 & 128 & 129 & 1.00 & 129 & 130 \\
\hline 1.00 & 130 & 131 & 1.00 & 131 & 132 & 1.00 & 132 & 133 & 1.00 & 133 & 134 \\
\hline 1.00 & 134 & 135 & 1.00 & 135 & 136 & 1.00 & 136 & 137 & 1.00 & 137 & 138 \\
\hline 1.00 & 138 & 139 & 1.00 & 139 & 140 & 1.00 & 140 & 141 & 1.00 & 141 & 142 \\
\hline 1.00 & 142 & 143 & 1.00 & 143 & 144 & 1.00 & 144 & 145 & 1.00 & 145 & 146 \\
\hline 1.00 & 146 & 147 & $1: 00$ & 147 & 148 & 1.00 & 148 & 149 & 1.00 & 149 & 150 \\
\hline 1.00 & 150 & 151 & 1.00 & 151 & 152 & 1.00 & 152 & 153 & 1.00 & 153 & 154 \\
\hline 1.00 & 154 & 155 & 1.00 & 155 & 156 & 1.00 & 156 & 157 & 1.00 & 157 & 158 \\
\hline 1.00 & 158 & 159 & 1.00 & 159 & 160 & 1.00 & 160 & 161 & 1.00 & 161 & 162 \\
\hline 1.00 & 162 & 163 & 1.00 & 163 & 164 & 1.00 & 164 & 165 & 1.00 & 165 & 166 \\
\hline 1.00 & 166 & 167 & 1.00 & 167 & 168 & 1.00 & 168 & 169 & 1.00 & 169 & 170 \\
\hline 1.00 & 170 & 171 & 1.00 & 171 & 172 & 1.00 & 172 & 173 & 1.00 & 173 & 174 \\
\hline 1.00 & 174 & 175 & 1.00 & 175 & 176 & 1.00 & 176 & 177 & 1.00 & 177 & 178 \\
\hline 1.00 & 178 & 179 & 1.00 & 179 & 180 & 1.00 & 180 & 181 & 1.00 & 181 & 182 \\
\hline 1.00 & 182 & 183 & 1.00 & 183 & 184 & 1.00 & 184 & 185 & 1.00 & 185 & 186 \\
\hline 1.00 & 186 & 187 & 1.00 & 187 & 188 & 1.00 & 188 & 189 & 1.00 & 189 & 190 \\
\hline 1.00 & 190 & 191 & 1.00 & 191 & 192 & 1.00 & 192 & 193 & 1.00 & 193 & 194 \\
\hline 1.00 & 194 & 195 & 1.00 & 195 & 196 & 1.00 & 196 & 197 & 1.00 & 197 & 198 \\
\hline 1.00 & 198 & 199 & 1.00 & 199 & 200 & 1.00 & 200 & 201 & 1.00 & 201 & 202 \\
\hline 1.00 & 202 & 203 & 1.00 & 203 & 204 & 1.00 & 204 & 205 & 1.00 & 205 & 206 \\
\hline 1.00 & 206 & 207 & 1.00 & 207 & 208 & 1.00 & 208 & 209 & 1.00 & 209 & 210 \\
\hline 1.00 & 210 & 211 & 1.00 & 211 & 212 & 1.00 & 212 & 213 & 1.00 & 213 & 214 \\
\hline 1.00 & 214 & 215 & 1.00 & 215 & 216 & 1.00 & 216 & 217 & 1.00 & 217 & 218 \\
\hline 1.00 & 218 & 219 & 1.00 & 219 & 220 & 1.00 & 220 & 221 & 1.00 & 221 & 222 \\
\hline 1.00 & 222 & 223 & 1.00 & 223 & 224 & 1.00 & 224 & 225 & 1.00 & 225 & 226 \\
\hline 1.00 & 226 & 227 & 1.00 & 227 & 228 & 1.00 & 228 & 229 & 1.00 & 229 & 230 \\
\hline 1.00 & 230 & 231 & 1.00 & 231 & 232 & 1.00 & 232 & 233 & 1.00 & 233 & 234 \\
\hline 1.00 & 234 & 235 & 1.00 & 235 & 236 & 1.00 & 236 & 237 & 1.00 & 237 & 238 \\
\hline 1.00 & 238 & 239 & 1.00 & 239 & 240 & 1.00 & 240 & 241 & 1.00 & 241 & 242 \\
\hline 1.00 & 242 & 243 & 1.00 & 243 & 244 & 1.00 & 244 & 245 & 1.00 & 245 & 246 \\
\hline 1.00 & 246 & 247 & 1.00 & 247 & 248 & 1.00 & 248 & 249 & 1.00 & 249 & 250 \\
\hline 1.00 & 250 & 251 & 1.00 & 251 & 252 & 1.00 & 252 & 253 & 1.00 & 253 & 254 \\
\hline 1.00 & 254 & 255 & 1.00 & 255 & 256 & 1.00 & 256 & 257 & 1.00 & 257 & 258 \\
\hline 1.00 & 258 & 259 & 1.00 & 259 & 260 & 1.00 & 260 & 261 & 1.00 & 261 & 262 \\
\hline 1.00 & 262 & 263 & 1.00 & 263 & 264 & 1.00 & 264 & 265 & 1.00 & 265 & 266 \\
\hline 1.00 & 266 & 267 & 1.00 & 267 & 268 & 1.00 & 268 & 269 & 1.00 & 269 & 270 \\
\hline 1.00 & 270 & 271 & 1.00 & 271 & 272 & 1.00 & 272 & 273 & 1.00 & 273 & 274 \\
\hline 1.00 & 274 & 275 & 1.00 & 275 & $276^{\circ}$ & 1.00 & 276 & 277 & 1.00 & 277 & 278 \\
\hline 1.00 & 278 & 279 & 1.00 & 279 & 280 & 1.00 & 280 & 281 & 1.00 & 281 & 282 \\
\hline 1.00 & 282 & 283 & 1.00 & 283 & 284 & 1.00 & 284 & 285 & 1.00 & 285 & 286 \\
\hline 1.00 & 286 & 287 & 1.00 & 287 & 288 & 1.00 & 288 & 289 & 1.00 & 289 & 290 \\
\hline 1.00 & 290 & 291 & 1.00 & 291 & 292 & 1.00 & 292 & 293 & 1.00 & 293 & 294 \\
\hline 1.00 & 294 & 295 & 1.00 & 295 & 296 & 1.00 & 296 & 297 & 1.00 & 297 & 298 \\
\hline 1.00 & 298 & 299 & 1.00 & 299 & 300 & 1.00 & 300 & 301 & 1.00 & 301 & 302 \\
\hline 1.00 & 302 & 303 & 1.00 & 303 & 304 & 1.00 & 304 & 305 & 1.00 & 305 & 306 \\
\hline 1.00 & 306 & 307 & 1.00 & 307 & 308 & 1.00 & 308 & 309 & 1.00 & 309 & 310 \\
\hline 1.00 & 310 & 311 & 1.00 & 311 & 312 & 1.00 & 312 & 313 & 1.00 & 313 & 314 \\
\hline 1.00 & 314 & 315 & 1.00 & 315 & 316 & 1.00 & 316 & 317 & 1.00 & 317 & 318 \\
\hline 1.00 & 318 & 319 & 1.00 & 319 & 320 & 1.00 & 320 & 321 & 1.00 & 321 & 322 \\
\hline 1.00 & 322 & 323 & 1.00 & 323 & 324 & 1.00 & 324 & 325 & 1.00 & 325 & 326 \\
\hline 1.00 & 326 & 327 & 1.00 & 327 & 328 & 1.00 & 328 & 329 & 1.00 & 329 & 330 \\
\hline 1.00 & 330 & 331 & 1.00 & 331 & 332 & 1.00 & 332 & 333 & 1.00 & 333 & 334 \\
\hline 1.00 & 334 & 335 & 1.00 & 335 & 336 & 1.00 & 336 & 337 & 1.00 & 337 & 338 \\
\hline 1.00 & 338 & 339 & 1.00 & 339 & 340 & 1.00 & 340 & 341 & 1.00 & 341 & 342 \\
\hline 1.00 & 342 & 343 & 1.00 & 343 & 344 & 1.00 & 344 & 345 & 1.00 & 345 & 346 \\
\hline 1.00 & 346 & 347 & 1.00 & 347 & 348 & 1.00 & 348 & 349 & 1.00 & 349 & 350 \\
\hline 1.00 & 350 & 351 & 1.00 & 351 & 352 & 1.00 & 352 & 353 & 1.00 & 353 & 354 \\
\hline 1.00 & 354 & 355 & 1.00 & 355 & 356 & 1.00 & 356 & 357 & 1.00 & 357 & 358 \\
\hline 1.00 & 358 & 359 & 1.00 & 359 & 360 & 1.00 & 360 & 361 & 1.00 & 361 & 362 \\
\hline 1.00 & 362 & 363 & 1.00 & 363 & 364 & 1.00 & 364 & 365 & 1.00 & 365 & 366 \\
\hline 1.00 & 366 & 367 & 1.00 & 367 & 368 & 1.00 & 368 & 369 & 1.00 & 369 & 370 \\
\hline 1.00 & 370 & 371 & 1.00 & 371 & 372 & 1.00 & 372 & 373 & 1.00 & 373 & 374 \\
\hline 1.00 & 374 & 375 & 1.00 & 375 & 376 & 1.00 & 376 & 377 & 1.00 & 377 & 378 \\
\hline 1.00 & 378 & 379 & 1.00 & 379 & 380 & 1.00 & 380 & 381 & 1.00 & 381 & 382 \\
\hline 1.00 & 382 & 383 & 1.00 & 383 & 384 & 1.00 & 384 & 385 & 1.00 & 385 & 386 \\
\hline 1.00 & 386 & 387 & 1.00 & 387 & 388 & 1.00 & 388 & 389 & 1.00 & 389 & 390 \\
\hline 1.00 & 390 & 391 & 1.00 & 391 & 392 & 1.00 & 392 & 393 & 1.00 & 393 & 394 \\
\hline 1.00 & 394 & 395 & 1.00 & 395 & 396 & 1.00 & 396 & 397 & 1.00 & 397 & 398 \\
\hline
\end{tabular}




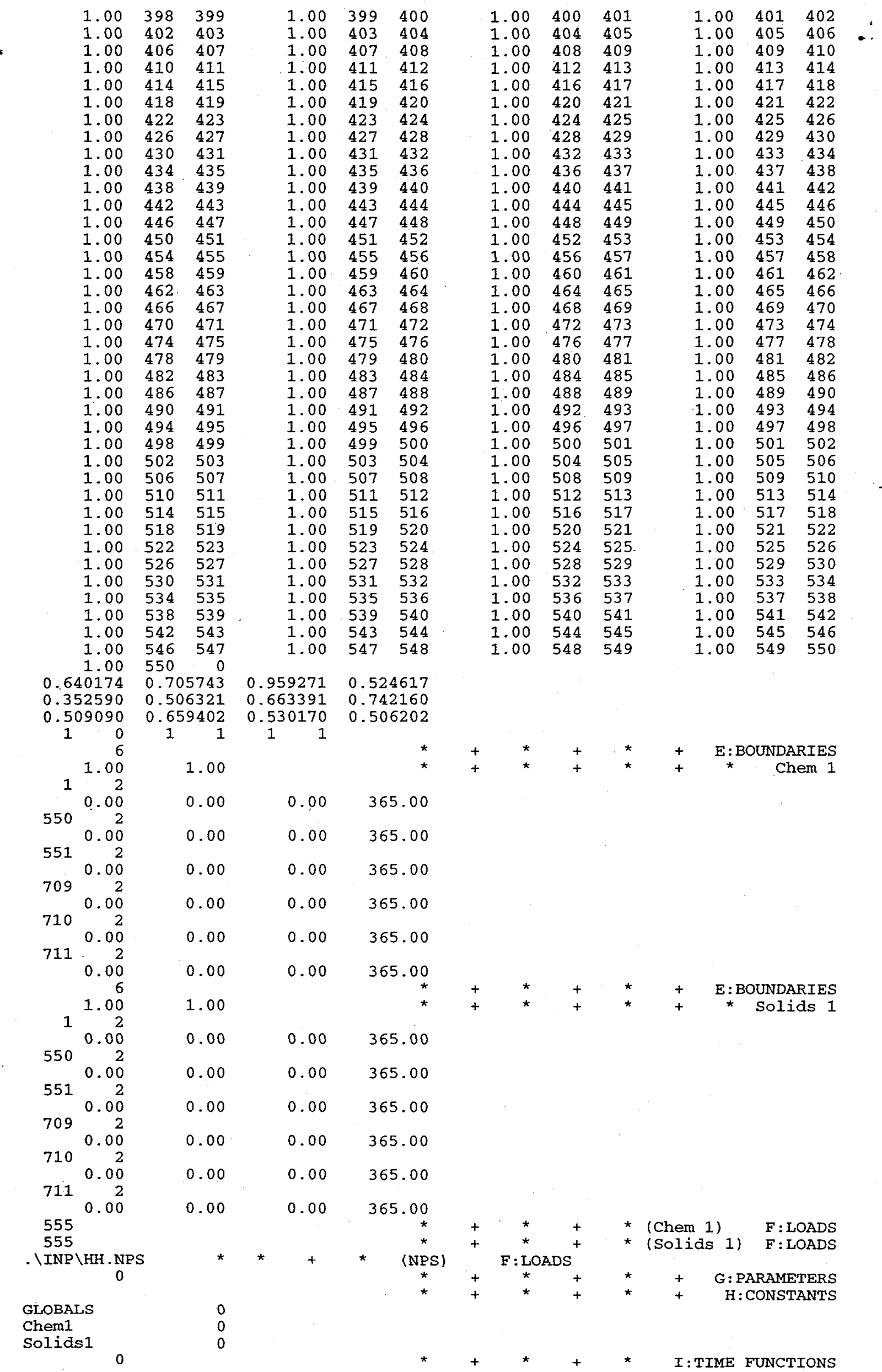


0000000000000000000000000000000000000000000000000000000000000000000000000000000 :

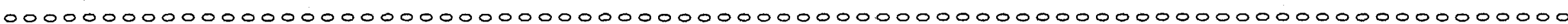

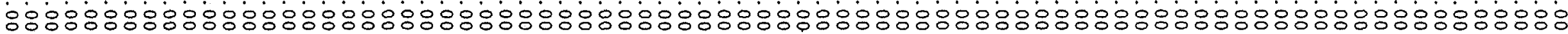

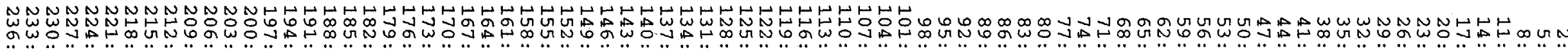

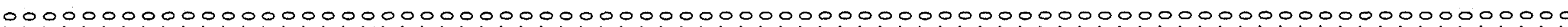

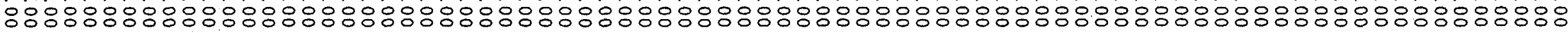

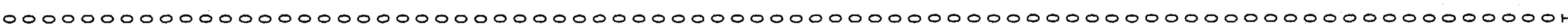

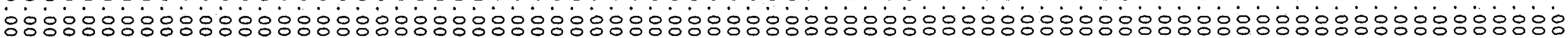

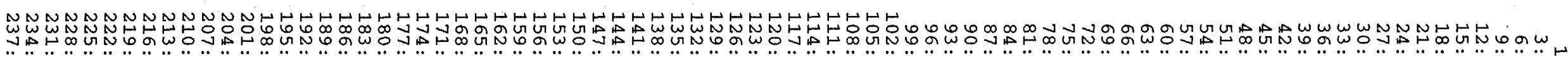

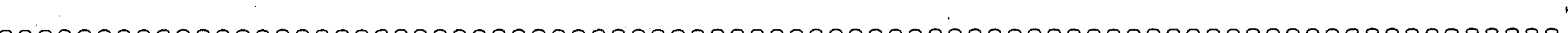
¿8:

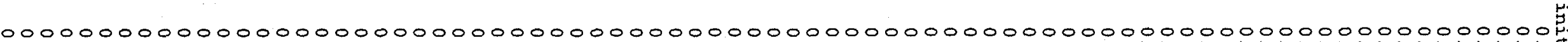

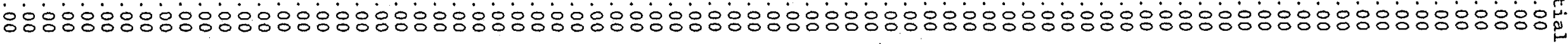




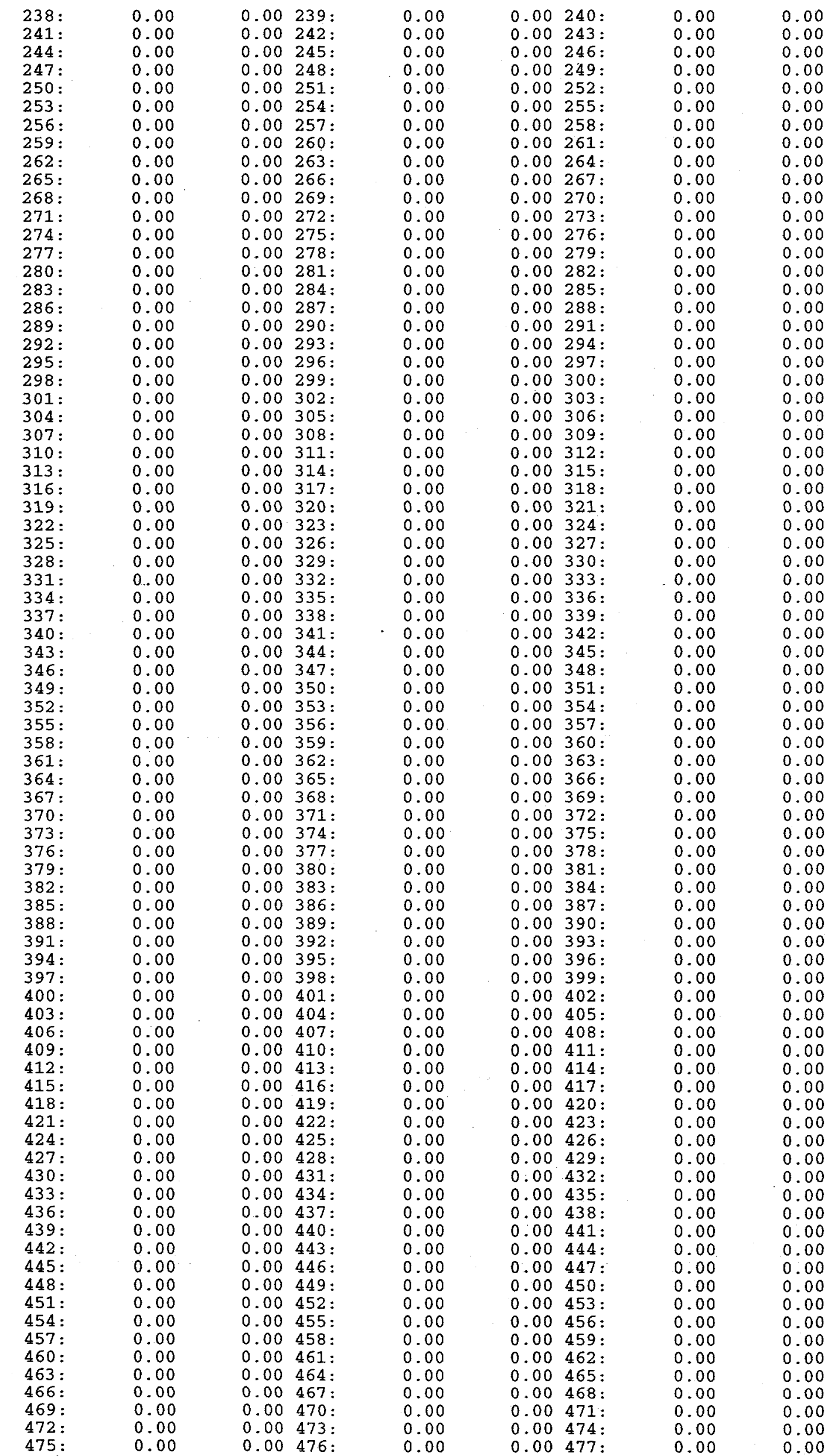




\begin{tabular}{|c|c|c|c|c|c|c|c|c|}
\hline $478:$ & 0.00 & 0.00 & $479:$ & 0.00 & 0.00 & $480:$ & 0.00 & 0.00 \\
\hline 481: & 0.00 & 0.00 & $482:$ & 0.00 & 0.00 & $483:$ & 0.00 & 0.00 \\
\hline $484:$ & 0.00 & 0.00 & $485:$ & 0.00 & 0.00 & $486:$ & 0.00 & 0.00 \\
\hline $487:$ & 0.00 & 0.00 & $488:$ & 0.00 & 0.00 & 489 : & 0.00 & 0.00 \\
\hline $490:$ & 0.00 & 0.00 & 491: & 0.00 & 0.00 & $492:$ & 0.00 & 0.00 \\
\hline 493 : & 0.00 & 0.00 & $494:$ & 0.00 & 0.00 & $495:$ & 0.00 & 0.00 \\
\hline $496:$ & 0.00 & 0.00 & 497: & 0.00 & 0.00 & 498: & 0.00 & 0.00 \\
\hline 499 : & 0.00 & 0.00 & $500:$ & 0.00 & 0.00 & 501: & 0.00 & 0.00 \\
\hline $502:$ & 0.00 & 0.00 & $503:$ & 0.00 & 0.00 & $504:$ & 0.00 & 0.00 \\
\hline 505: & 0.00 & 0.00 & $506:$ & 0.00 & 0.00 & 507: & 0.00 & 0.00 \\
\hline $508:$ & 0.00 & 0.00 & 509: & 0.00 & 0.00 & $510:$ & 0.00 & 0.00 \\
\hline 511: & 0.00 & 0.00 & $512:$ & 0.00 & 0.00 & $513:$ & 0.00 & 0.00 \\
\hline 514: & 0.00 & 0.00 & 515: & 0.00 & 0.00 & 516: & 0.00 & 0.00 \\
\hline 517: & 0.00 & 0.00 & $518:$ & 0.00 & 0.00 & 519: & 0.00 & 0.00 \\
\hline $520:$ & 0.00 & 0.00 & $521:$ & 0.00 & 0.00 & $522:$ & 0.00 & 0.00 \\
\hline $523:$ & 0.00 & 0.00 & $524:$ & 0.00 & 0.00 & $525:$ & 0.00 & 0.00 \\
\hline $526=$ & 0.00 & 0.00 & $527:$ & 0.00 & 0.00 & $528:$ & 0.00 & 0.00 \\
\hline $529:$ & 0.00 & 0.00 & $530:$ & 0.00 & 0.00 & 531: & 0.00 & 0.00 \\
\hline $532:$ & 0.00 & 0.00 & $533:$ & 0.00 & 0.00 & $534:$ & 0.00 & 0.00 \\
\hline 535 : & 0.00 & 0.00 & 536 : & 0.00 & 0.00 & $537:$ & 0.00 & 0.00 \\
\hline 538: & 0.00 & 0.00 & $539:$ & 0.00 & 0.00 & $540:$ & 0.00 & 0.00 \\
\hline $541:$ & 0.00 & 0.00 & $542:$ & 0.00 & 0.00 & $543:$ & 0.00 & 0.00 \\
\hline $544:$ & 0.00 & 0.00 & $545:$ & 0.00 & 0.00 & $546:$ & 0.00 & 0.00 \\
\hline $547:$ & 0.00 & 0.00 & $548:$ & 0.00 & 0.00 & $549:$ & 0.00 & 0.00 \\
\hline $550:$ & 0.00 & 0.00 & 551: & 0.00 & 0.00 & $552:$ & 0.00 & 0.00 \\
\hline 553 : & 0.00 & 0.00 & $554:$ & 0.00 & 0.00 & $555:$ & 0.00 & 0.00 \\
\hline 556 : & 0.00 & 0.00 & $557:$ & 0.00 & 0.00 & 558: & 0.00 & 0.00 \\
\hline 559: & 0.00 & 0.00 & $560:$ & 0.00 & 0.00 & 561: & 0.00 & 0.00 \\
\hline $562:$ & 0.00 & 0.00 & $563:$ & 0.00 & 0.00 & $564:$ & 0.00 & 0.00 \\
\hline $565:$ & 0.00 & 0.00 & $566:$ & 0.00 & 0.00 & $567:$ & 0.00 & 0.00 \\
\hline $568:$ & 0.00 & 0.00 & 569 : & 0.00 & 0.00 & $570:$ & 0.00 & 0.00 \\
\hline 571: & 0.00 & 0.00 & $572:$ & 0.00 & 0.00 & $573:$ & 0.00 & 0.00 \\
\hline $574:$ & 0.00 & 0.00 & $575:$ & 0.00 & 0.00 & $576:$ & 0.00 & 0.00 \\
\hline 577: & 0.00 & 0.00 & $578:$ & 0.00 & 0.00 & $579:$ & 0.00 & 0.00 \\
\hline $580:$ & 0.00 & 0.00 & 581: & 0.00 & 0.00 & $582:$ & 0.00 & 0.00 \\
\hline 583: & 0.00 & 0.00 & 584: & 0.00 & 0.00 & 585: & 0.00 & 0.00 \\
\hline 586: & 0.00 & 0.00 & $587:$ & 0.00 & 0.00 & $588:$ & 0.00 & 0.00 \\
\hline $589:$ & 0.00 & 0.00 & $590:$ & 0.00 & 0.00 & 591: & 0.00 & 0.00 \\
\hline $592:$ & 0.00 & 0.00 & 593 : & 0.00 & 0.00 & $594:$ & 0.00 & 0.00 \\
\hline 595 : & 0.00 & 0.00 & $596:$ & 0.00 & 0.00 & 597 : & 0.00 & 0.00 \\
\hline 598: & 0.00 & 0.00 & $599:$ & 0.00 & 0.00 & $600:$ & 0.00 & 0.00 \\
\hline 601: & 0.00 & 0.00 & $602:$ & 0.00 & 0.00 & $603:$ & 0.00 & 0.00 \\
\hline 604: & 0.00 & 0.00 & $605:$ & 0.00 & 0.00 & $606:$ & 0.00 & 0.00 \\
\hline 607: & 0.00 & 0.00 & 608: & 0.00 & 0.00 & 609: & 0.00 & 0.00 \\
\hline $610:$ & 0.00 & 0.00 & 611: & 0.00 & 0.00 & 612: & 0.00 & 0.00 \\
\hline 613: & 0.00 & 0.00 & 614: & 0.00 & 0.00 & $615:$ & 0.00 & 0.00 \\
\hline $616:$ & 0.00 & 0.00 & $617:$ & 0.00 & 0.00 & 618: & 0.00 & 0.00 \\
\hline 619: & 0.00 & 0.00 & $620:$ & 0.00 & 0.00 & 621: & 0.00 & 0.00 \\
\hline $622:$ & 0.00 & 0.00 & $623:$ & 0.00 & 0.00 & $624:$ & 0.00 & 0.00 \\
\hline $625:$ & 0.00 & 0.00 & $626:$ & 0.00 & 0.00 & $627:$ & 0.00 & 0.00 \\
\hline $628:$ & 0.00 & 0.00 & $629:$ & 0.00 & 0.00 & $630:$ & 0.00 & 0.00 \\
\hline $631:$ & 0.00 & 0.00 & $632:$ & 0.00 & 0.00 & $633:$ & 0.00 & 0.00 \\
\hline $634:$ & 0.00 & 0.00 & 635: & 0.00 & 0.00 & $636:$ & 0.00 & 0.00 \\
\hline 637: & 0.00 & 0.00 & $638:$ & 0.00 & 0.00 & $639:$ & 0.00 & 0.00 \\
\hline $640:$ & 0.00 & 0.00 & 641: & 0.00 & 0.00 & $642:$ & 0.00 & 0.00 \\
\hline 643 : & 0.00 & 0.00 & $644:$ & 0.00 & 0.00 & $645:$ & 0.00 & 0.00 \\
\hline $646:$ & 0.00 & 0.00 & $647:$ & 0.00 & 0.00 & $648:$ & 0.00 & 0.00 \\
\hline $649:$ & 0.00 & 0.00 & $650:$ & 0.00 & 0.00 & 651: & 0.00 & 0.00 \\
\hline $652:$ & 0.00 & 0.00 & $653:$ & 0.00 & 0.00 & $654:$ & 0.00 & 0.00 \\
\hline 655: & 0.00 & 0.00 & $656:$ & 0.00 & 0.00 & 657: & 0.00 & 0.00 \\
\hline 658: & 0.00 & 0.00 & $659:$ & 0.00 & 0.00 & $660:$ & 0.00 & 0.00 \\
\hline 661: & 0.00 & 0.00 & $662:$ & 0.00 & 0.00 & 663: & 0.00 & 0.00 \\
\hline $664:$ & 0.00 & 0.00 & $665:$ & 0.00 & 0.00 & 666: & 0.00 & 0.00 \\
\hline 667: & 0.00 & 0.00 & 668: & 0.00 & 0.00 & $669:$ & 0.00 & .0 .00 \\
\hline $670:$ & 0.00 & 0.00 & 671: & 0.00 & 0.00 & $672:$ & 0.00 & 0.00 \\
\hline $673:$ & 0.00 & 0.00 & 674: & 0.00 & 0.00 & $675:$ & 0.00 & 0.00 \\
\hline $676:$ & 0.00 & 0.00 & $677:$ & 0.00 & 0.00 & $678:$ & 0.00 & 0.00 \\
\hline $679:$ & 0.00 & 0.00 & $680:$ & 0.00 & 0.00 & $681:$ & 0.00 & 0.00 \\
\hline $682:$ & 0.00 & 0.00 & 683: & 0.00 & 0.00 & 684: & 0.00 & 0.00 \\
\hline $685:$ & 0.00 & 0.00 & $686:$ & 0.00 & 0.00 & 687: & 0.00 & 0.00 \\
\hline $688:$ & 0.00 & 0.00 & 689: & 0.00 & 0.00 & $690:$ & 0.00 & 0.00 \\
\hline 691: & 0.00 & 0.00 & 692: & 0.00 & 0.00 & 693: & 0.00 & 0.00 \\
\hline $694:$ & 0.00 & 0.00 & 695 : & 0.00 & 0.00 & 696: & 0.00 & 0.00 \\
\hline 697: & 0.00 & 0.00 & 698: & 0.00 & 0.00 & 699: & 0.00 & 0.00 \\
\hline $700:$ & 0.00 & 0.00 & 701: & 0.00 & 0.00 & $702:$ & 0.00 & 0.00 \\
\hline $703:$ & 0.00 & 0.00 & $704:$ & 0.00 & 0.00 & $705:$ & 0.00 & 0.00 \\
\hline $706:$ & 0.00 & 0.00 & $707:$ & 0.00 & 0.00 & $708:$ & 0.00 & 0.00 \\
\hline $709:$ & 0.00 & 0.00 & $710:$ & 0.00 & 0.00 & $711:$ & 0.00 & 0.00 \\
\hline Solids & 1 & & & & 01.00 & 1. & & \\
\hline 1: & 0.00 & 0.00 & 2: & 0.00 & 0.00 & 3: & 0.00 & 0.00 \\
\hline
\end{tabular}




\begin{tabular}{|c|c|c|c|c|c|c|c|}
\hline 0.00 & 0.00 & 5: & 0.00 & 0.00 & 6: & 0.00 & 0.00 \\
\hline 0.00 & 0.00 & 8: & 0.00 & 0.00 & 9 : & 0.00 & 0.00 \\
\hline 0.00 & 0.00 & 11: & 0.00 & 0.00 & $12:$ & 0.00 & 0.00 \\
\hline 0.00 & 0.00 & $14:$ & 0.00 & 0.00 & 15: & 0.00 & 0.00 \\
\hline 0.00 & 0.00 & 17: & 0.00 & 0.00 & 18: & 0.00 & 0.00 \\
\hline 0.00 & 0.00 & 20: & 0.00 & 0.00 & 21: & 0.00 & 0.00 \\
\hline 0.00 & 0.00 & 23: & 0.00 & 0.00 & $24:$ & 0.00 & 0.00 \\
\hline 0.00 & 0.00 & 26: & 0.00 & 0.00 & 27: & 0.00 & 0.00 \\
\hline 0.00 & 0.00 & $29:$ & 0.00 & 0.00 & $30:$ & 0.00 & 0.00 \\
\hline 0.00 & 0.00 & 32: & 0.00 & 0.00 & $33:$ & 0.00 & 0.00 \\
\hline 0.00 & 0.00 & 35: & 0.00 & 0.00 & 36: & 0.00 & 0.00 \\
\hline 0.00 & 0.00 & 38: & 0.00 & 0.00 & 39: & 0.00 & 0.00 \\
\hline 0.00 & 0.00 & $41:$ & 0.00 & 0.00 & $42:$ & 0.00 & 0.00 \\
\hline 0.00 & 0.00 & $44:$ & 0.00 & 0.00 & 45: & 0.00 & 0.00 \\
\hline 0.00 & 0.00 & $47:$ & 0.00 & 0.00 & 48: & 0.00 & 0.00 \\
\hline 0.00 & 0.00 & $50:$ & 0.00 & 0.00 & 51: & 0.00 & 0.00 \\
\hline 0.00 & 0.00 & 53: & 0.00 & 0.00 & $54:$ & 0.00 & 0.00 \\
\hline 0.00 & 0.00 & 56: & 0.00 & 0.00 & 57: & 0.00 & 0.00 \\
\hline 0.00 & 0.00 & 59: & 0.00 & 0.00 & 60: & 0.00 & 0.00 \\
\hline 0.00 & 0.00 & 62: & 0.00 & 0.00 & 63: & 0.00 & 0.00 \\
\hline 0.00 & 0.00 & 65: & 0.00 & 0.00 & 66: & 0.00 & 0.00 \\
\hline 0.00 & 0.00 & 68: & 0.00 & 0.00 & 69: & 0.00 & 0.00 \\
\hline 0.00 & 0.00 & 71: & 0.00 & 0.00 & $72:$ & 0.00 & 0.00 \\
\hline 0.00 & 0.00 & 74: & 0.00 & 0.00 & $75:$ & 0.00 & 0.00 \\
\hline 0.00 & 0.00 & 77: & 0.00 & 0.00 & 78: & 0.00 & 0.00 \\
\hline 0.00 & 0.00 & 80: & 0.00 & 0.00 & 81: & 0.00 & 0.00 \\
\hline 0.00 & 0.00 & 83: & 0.00 & 0.00 & 84: & 0.00 & 0.00 \\
\hline 0.00 & 0.00 & 86: & 0.00 & 0.00 & 87: & 0.00 & 0.00 \\
\hline 0.00 & 0.00 & 89: & 0.00 & 0.00 & $90:$ & 0.00 & 0.00 \\
\hline 0.00 & 0.00 & 92 : & 0.00 & 0.00 & 93: & 0.00 & 0.00 \\
\hline 0.00 & 0.00 & 95: & 0.00 & 0.00 & $96:$ & 0.00 & 0.00 \\
\hline 0.00 & 0.00 & 98: & 0.00 & 0.00 & 99: & 0.00 & 0.00 \\
\hline 0.00 & 0.00 & 101: & 0.00 & 0.00 & $102:$ & 0.00 & 0.00 \\
\hline 0.00 & 0.00 & $104:$ & 0.00 & 0.00 & 105: & 0.00 & 0.00 \\
\hline 0.00 & 0.00 & 107: & 0.00 & 0.00 & 108: & 0.00 & 0.00 \\
\hline 0.00 & 0.00 & 110: & 0.00 & 0.00 & 111: & 0.00 & 0.00 \\
\hline 0.00 & 0.00 & 113: & 0.00 & 0.00 & 114: & 0.00 & 0.00 \\
\hline 0.00 & 0.00 & 116: & 0.00 & 0.00 & 117: & 0.00 & 0.00 \\
\hline 0.00 & 0.00 & 119: & 0.00 & 0.00 & 120: & 0.00 & 0.00 \\
\hline 0.00 & 0.00 & $122:$ & 0.00 & 0.00 & 123: & 0.00 & 0.00 \\
\hline 0.00 & 0.00 & 125: & 0.00 & 0.00 & 126: & 0.00 & 0.00 \\
\hline 0.00 & 0.00 & 128: & 0.00 & 0.00 & 129: & 0.00 & 0.00 \\
\hline 0.00 & 0.00 & 131: & 0.00 & 0.00 & 132: & 0.00 & 0.00 \\
\hline 0.00 & 0.00 & $134:$ & 0.00 & 0.00 & 135: & 0.00 & 0.00 \\
\hline 0.00 & 0.00 & 137: & 0.00 & 0.00 & 138: & 0.00 & 0.00 \\
\hline 0.00 & 0.00 & $140:$ & 0.00 & 0.00 & 141: & 0.00 & 0.00 \\
\hline 0.00 & 0.00 & $143:$ & 0.00 & 0.00 & $144:$ & 0.00 & 0.00 \\
\hline 0.00 & 0.00 & 146: & 0.00 & 0.00 & $147:$ & 0.00 & 0.00 \\
\hline 0.00 & 0.00 & 149: & 0.00 & 0.00 & 150: & 0.00 & 0.00 \\
\hline 0.00 & 0.00 & 152: & 0.00 & 0.00 & 153: & 0.00 & 0.00 \\
\hline 0.00 & 0.00 & 155: & 0.00 & 0.00 & 156: & 0.00 & 0.00 \\
\hline 0.00 & 0.00 & 158: & 0.00 & 0.00 & 159: & 0.00 & 0.00 \\
\hline 0.00 & 0.00 & 161: & 0.00 & 0.00 & 162: & 0.00 & 0.00 \\
\hline 0.00 & 0.00 & $164:$ & 0.00 & 0.00 & 165: & 0.00 & 0.00 \\
\hline 0.00 & 0.00 & 167: & 0.00 & 0.00 & 168: & 0.00 & 0.00 \\
\hline 0.00 & 0.00 & $170:$ & 0.00 & 0.00 & 171: & 0.00 & 0.00 \\
\hline 0.00 & 0.00 & 173: & 0.00 & 0.00 & 174: & 0.00 & 0.00 \\
\hline 0.00 & 0.00 & $176:$ & 0.00 & 0.00 & 177: & 0.00 & 0.00 \\
\hline 0.00 & 0.00 & 179: & 0.00 & 0.00 & 180: & 0.00 & 0.00 \\
\hline 0.00 & 0.00 & 182: & 0.00 & 0.00 & 183: & 0.00 & 0.00 \\
\hline 0.00 & 0.00 & 185: & 0.00 & 0.00 & 186: & 0.00 & 0.00 \\
\hline 0.00 & 0.00 & 188: & 0.00 & 0.00 & 189: & 0.00 & 0.00 \\
\hline 0.00 & 0.00 & 191: & 0.00 & 0.00 & 192: & 0.00 & 0.00 \\
\hline 0.00 & 0.00 & 194: & 0.00 & 0.00 & 195: & 0.00 & 0.00 \\
\hline 0.00 & 0.00 & 197: & 0.00 & 0.00 & 198: & 0.00 & 0.00 \\
\hline 0.00 & 0.00 & $200:$ & 0.00 & 0.00 & $201:$ & 0.00 & 0.00 \\
\hline 0.00 & 0.00 & 203: & 0.00 & 0.00 & 204: & 0.00 & 0.00 \\
\hline 0.00 & 0.00. & 206: & 0.00 & 0.00 & 207: & 0.00 & 0.00 \\
\hline 0.00 & 0.00 & 209: & 0.00 & 0.00 & 210: & 0.00 & 0.00 \\
\hline 0.00 & 0.00 & 212: & 0.00 & 0.00 & $213:$ & 0.00 & 0.00 \\
\hline 0.00 & 0.00 & 215: & 0.00 & 0.00 & 216: & 0.00 & 0.00 \\
\hline 0.00 & 0.00 & 218: & 0.00 & 0.00 & $219:$ & 0.00 & 0.00 \\
\hline 0.00 & 0.00 & 221: & 0.00 & 0.00 & $222:$ & 0.00 & 0.00 \\
\hline 0.00 & 0.00 & $224:$ & 0.00 & 0.00 & $225:$ & 0.00 & 0.00 \\
\hline 0.00 & 0.00 & $227:$ & 0.00 & 0.00 & $228:$ & 0.00 & 0.00 \\
\hline 0.00 & 0.00 & $230:$ & 0.00 & 0.00 & 231: & 0.00 & 0.00 \\
\hline 0.00 & 0.00 & $233:$ & 0.00 & 0.00 & $234:$ & 0.00 & 0.00 \\
\hline 0.00 & 0.00 & $236:$ & 0.00 & 0.00 & 237: & 0.00 & 0.00 \\
\hline 0.00 & 0.00 & 239: & 0.00 & 0.00 & 240: & 0.00 & 0.00 \\
\hline 0.00 & 0.00 & $242:$ & 0.00 & 0.00 & 243: & 0.00 & 0.00 \\
\hline
\end{tabular}




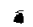

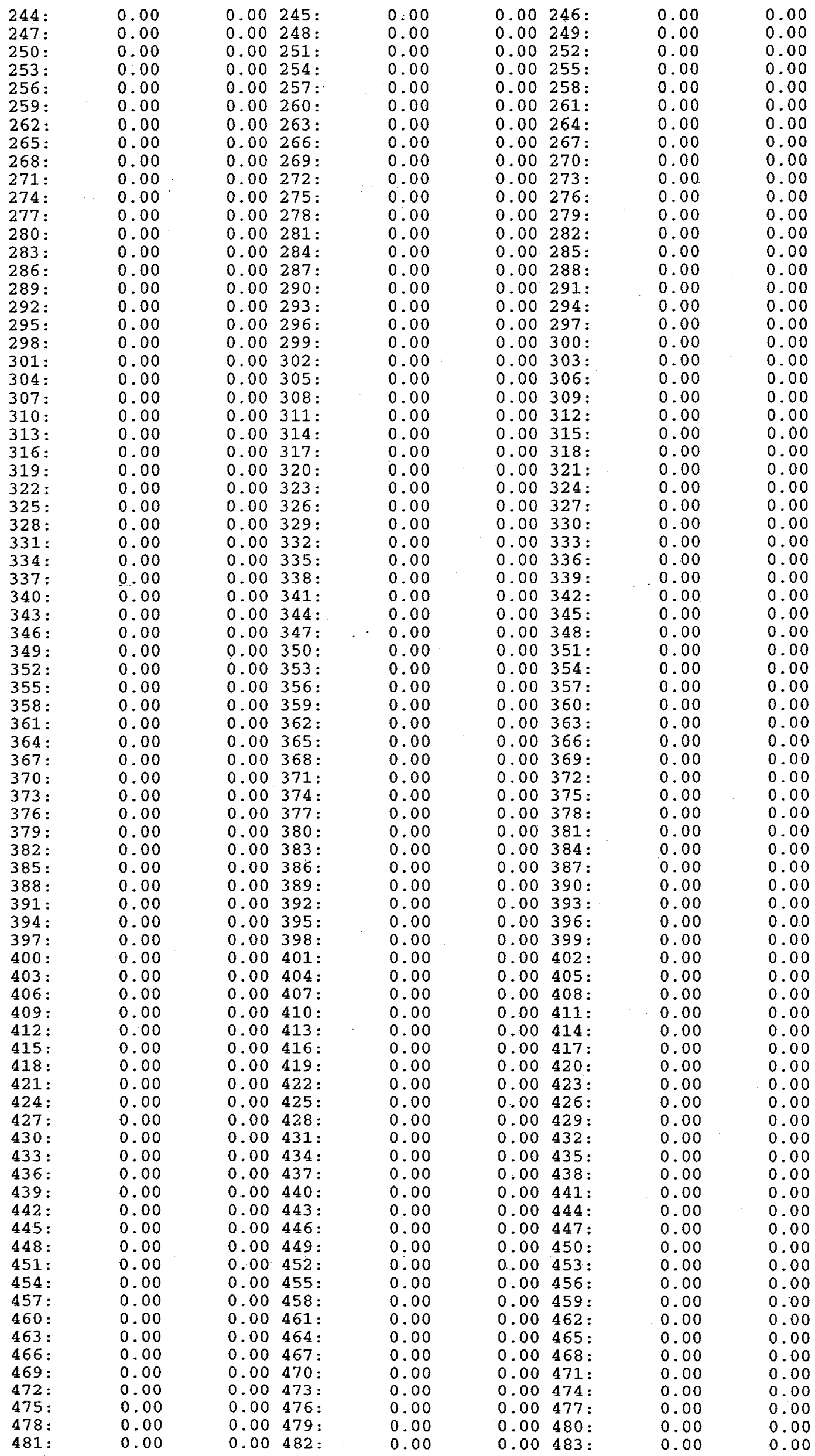







WSRC-TR-98-00234

Input File: HH.NPS

$\underset{555}{\text { Houtfall to }} 4 \mathrm{mb} \quad 1 \quad 11$

SOLID 1

SOLID $1^{1.0}$

0.0000 


\section{WESTINGHOUSE SAVANNAH RIVER CO. \\ Report WSRC-TR-98-00234 \\ DISTRIBUTION}

SAVANNAH RIVER SITE
A. L. Boni, 773-A
R. P. Addis, 773-A
A. J. Garrett, 773-A
W. A. Emel, 735-A
D. W. Hayes, 735-A
D. P. Griggs, 773-A
C. H. Hunter, 773-A
B. L. O'Steen, 773-A
Kuo-Fu Chen, 773-A
SRTC Records (4), 773-52A
NTS Records (5), 773-A 